Check for updates

Cite this: Mater. Adv., 2020, 1. 1399

Received 10th February 2020 Accepted 26th July 2020

DOI: 10.1039/d0ma00019a

rsc.li/materials-advances

\section{Organic acids under pressure: elastic properties, negative mechanical phenomena and pressure induced phase transitions in the lactic, maleic, succinic and citric acids $\dagger$}

\author{
Francisco Colmenero (D)
}

\begin{abstract}
A detailed study of the behavior under pressure of four important organic acids using the first-principles solid-state methodology is presented. These organic acids are the L-(+)-lactic, maleic, succinic and citric acids. The citric acid monohydrate is also investigated. The computed crystal structures and associated $X$-ray diffraction patterns are in very good agreement with their experimental counterparts. The elastic tensors of these materials are determined using the finite deformation method and the mechanical stability of their structures is studied. A set of relevant elastic properties is obtained in terms of the computed elastic tensors. This set includes the bulk, shear and Young moduli, the Poisson's ratio, the ductility, hardness and anisotropy indices and the bulk modulus pressure derivatives. In the solid state, these organic acids are shown to be stable, relatively weak and very anisotropic materials and, with the exception of citric acid monohydrate, all of them exhibit the negative Poisson's ratio (NPR) phenomenon. The deformation of the crystal structures under isotropic pressures and anisotropic stresses is then evaluated and analyzed. The organic acids considered display the negative linear compressibility (NLC) phenomenon in several narrow pressure ranges. The presence of large NLC effects in these materials is mainly related to the onset of pressure induced phase transitions or sudden structural rearrangements. The lactic acid exhibits a large NLC effect under the effect of isotropic pressures due to the proximity of a pressure induced phase transition occurring at a pressure of $P \sim 1.0 \mathrm{GPa}$. The maleic acid shows NLC under isotropic pressures of the order of $P \sim 1.1 \mathrm{GPa}$ but no phase transition is observed. Under anisotropic stresses directed along the minimum Poisson's ratio direction, maleic acid also shows a large NLC effect at small external pressures of $P \sim 0.1 \mathrm{GPa}$. Succinic acid displays small NLC effects in several pressure ranges under isotropic pressures but large NLC values under anisotropic stresses directed along the minimum NPR direction because it undergoes a pressure induced phase transition near $P \sim 1.5 \mathrm{GPa}$. Finally, the citric acid shows small NLC values for negative isotropic pressures near $-0.5 \mathrm{GPa}$ and a large NLC effect under low anisotropic stresses ( $P \sim 0.1 \mathrm{GPa}$ ) which is accompanied by the breaking of one intramolecular hydrogen bond present in this material at zero pressure.
\end{abstract}

Instituto de Estructura de la Materia (IEM-CSIC), C/Serrano, 113 - 28006 Madrid, Spain. E-mail: francisco.colmenero@iem.cfmac.csic.es

$\dagger$ Electronic supplementary information (ESI) available: (a) Material data and calculation parameters; (b) atom labelling convention employed; (c) interatomic distances and angles at zero pressure; (d) unit-cell volumes and lattice parameters under isotropic pressures; (d) interatomic distances and angles in Phase II of lactic acid; (e) interatomic distances and angles of succinic and citric acids under several anisotropic stresses; (f) animated sequences of the crystal structures of lactic, maleic, succinic and citric acids under the effect of increasing pressures; $(\mathrm{g}$ ) computed positions of the atoms in the unit cell of lactic acid under an isotropic pressure of 1.056 GPa (CIF file): CCDC 1945991; (h) computed positions of the atoms in the unit cell of succinic acid under an anisotropic stress with associated pressure of $1.757 \mathrm{GPa}$ (CIF file): CCDC 1945995; (i) computed positions of the atoms in the unit cell of citric acid under an anisotropic stress with associated pressure of 0.168 GPa (CIF file): CCDC 1945994. CCDC 1945991, 1945994 and 1945995. For ESI and crystallographic data in CIF or other electronic format see DOI: 10.1039/d0ma00019a

\section{Introduction}

The investigation of the behavior of solid materials under pressure is highly relevant in many scientific research fields such as geoscience, ${ }^{1-16}$ planetary science and astrophysics, ${ }^{17-28}$ condensed matter physics ${ }^{29-41}$ and materials science. ${ }^{42-78}$ The study of carbon, hydrocarbon, and general organic materials under pressure has played a remarkably important role in these fields and also in biochemistry, biophysics and organic chemistry and physics. ${ }^{2,15,16,18,19,27,28,51,53-55,57-59,67-118}$ Significant progress has been achieved in the last decades in the field of high pressure crystallography and crystal engineering of organic materials. ${ }^{19,35,87,88,96,97,102-104,116-118}$ The earlier studies of matter under pressure were an immediate consequence of 
the fact that most part of the matter in the Earth, solar system and extra-solar solid bodies are subjected to extreme conditions as very high pressures. In geosciences, the influence of pressure is fundamental for understanding the formation and transformation of rocks and minerals. Two fascinating findings at the end of nineteenth century strongly stimulated the research of materials under pressure in materials science and condensed matter physics. The first is the discovery of materials displaying anomalous mechanical behaviors and negative mechanical phenomena such as the negative Poisson's ratio ${ }^{42,44,45}$ (NPR) and negative linear compressibility ${ }^{52,61,62}$ (NLC) effects. These materials, showing anomalous variations of their dimensions as a result of the application of pressure, have found an immense range of potential applications as the development of ultrasensitive pressure detectors, robust shock-absorbing composites, pressure-driven actuators, optical telecommunication cables, artificial muscles, next generation body armor and devices for biomedical applications. ${ }^{45,48,50,53,55,60,70}$ The second is the discovery that compression turns many nonsuperconductor (and even non-conductor) materials into superconductors. ${ }^{32-34,36,37,40}$ One of the most important underlying reasons for the wide dissemination of high pressure research is the possibility of exploiting the changes in the chemical nature and structure of solid materials induced by pressure. The pressure induced phase transitions and structural transformations may be advantageously used, for example, in high-pressure synthesis, mechanochemistry and nanotechnology. ${ }^{35,119-133}$ Mechanically responsible organic crystals showing macroscopic motion as a response to pressure or deformation are very interesting due to their potential applications in nanotechnology as organic actuators. ${ }^{98,130-133}$

The mechanical response of molecular crystals, polymers and organic materials related to living organism physiology is of direct and enormous interest for the human being. The interest in the research of the effect of high pressure on living systems was originated by the discovery of piezophile organisms in the deep marine environments. ${ }^{134-139}$ The corresponding studies involved not only the investigation of the pressure adaptation mechanisms of these organisms but also the possible role of high pressure in the origin of life. ${ }^{140-142}$ In the research of organic materials under pressure, the main purpose is generally the study of the modification of the molecular structure and properties of the material under study associated to changes in the noncovalent interactions present in the system, although the production and analysis of drastic structural changes and the detection of phase transitions is also extremely interesting. The effect of pressure in the structure and function of many organic compounds $^{82-115,143-146}$ including low molecular-weight biomolecules such as peptides, lipids and saccharides and macromolecules such as proteins, nucleic acids and polysaccharides has been investigated at length, as well as the pressure induced modifications of the interactions among many of them (for example the interactions of proteins and lipids in biological membranes ${ }^{143-145,147-153}$ ). The mechanical effects of pressure on compounds of biological interest have been utilized in a plethora of applications in biomedicine and biotechnology. ${ }^{7,100,143-146}$
Very successful applications of the use of high pressure have been achieved in the pharmaceutical ${ }^{103,104,154-157}$ and food industries $^{89,95,106,158-167}$ for the manufacturing, decontamination, sterilization, disinfection, sanitization, conservation and low volume storage of chemical products and foods.

Despite of the large amount of effort devoted to the study of the effects of pressure in organic materials, it is surprising to find that detailed studies involving the determination of the mechanical properties together with the study of the mechanical stability and behavior under pressure of a good series of important prototypical organic materials have not been published, saving the cases of the recent studies concerning the cyclic oxocarbon acids ${ }^{70,73}$ and oxalic acid. ${ }^{71,72}$ The main purpose of this work is to provide such study for four very important organic acids. These organic acids are one monocarboxylic acid (L-(+)-lactic acid), two dicarboxylic acids (maleic and succinic acids) and one tricarboxylic acid (citric acid). Although the mechanical behavior of many polymers based on these compounds and related systems has been studied, the mechanical properties of these materials are completely unknown. These materials have crucial biological roles, are important reagents in synthetic organic chemistry, have a great number of medical and technological applications and are widely used in the food and pharmaceutical industries. In this work, first-principles solid-state methods based in Density Functional Theory (DFT) employing large plane wave basis sets and pseudopotentials will be employed. In the computations, the representative volume element of the materials considered is the unit cell. Periodic boundary conditions are applied in the calculations. ${ }^{168,169}$ Thus, the organic acids studied in this paper are modelized as infinite and space unconstrained systems. Theoretical methods of different degree of complexity, ranging from empirical force field approaches to fully featured quantum theory based methods as those used in this work have been employed in the study of the mechanical properties of solid materials. ${ }^{5,8,28,70-78,170-203}$ The first works concerning the computer modelling of materials displaying negative Poisson's rations (known as auxetic ${ }^{46}$ ) were the pioneering papers of Wojciechowski. $^{204}$ The utilization of large-scale calculations employing state of the art first principles computational modelling techniques for the description of solid-state materials has produced very reliable results and, therefore, this methodology is sufficiently advanced today to predict their mechanical properties in good agreement with experimental measurements. In the first-principles treatment of organic molecular crystals, it is imperative to describe accurately the non-bonding interactions among the atoms forming part of the system ${ }^{205-210}$ including the dense hydrogen bond network present in the crystal structure of the majority of these materials. In this paper appropriate dispersion corrected energy-density functionals were employed.

In this paper, special care is given to the study of the compressibilities of the considered organic acids. In fact, one of the main reasons for performing this study was to extend the previous studies on the mechanical properties of the oxalic $\mathrm{c}^{71,72}$ and cyclic oxocarbon acids. ${ }^{70,73}$ It was found that these compounds in the solid state exhibit the NPR and NLC phenomena 
and undergo pressure induced phase transitions for relatively small external pressures. The extremely anomalous mechanical behavior found in these works, raises the question of whether this behavior is a peculiarity of these materials or is a part a more general trend associated to the organic acids. The compressibility is a fundamental material property which measures the variation of the dimensions of a given material with respect to pressure. The isotropic negative linear compressibility (INLC) $)^{52,62,70,72,76}$ phenomenon is an important elastic anomaly in which one dimension of a given material increases upon hydrostatic compression. The anisotropic linear compressibility phenomenon (ANLC), ${ }^{70,71,75-78}$ however, involves the increase of the dimensions of a given material under the effect of a compressive stress applied along a certain direction. The INLC effect is quantified by means of compressibility associated to a given dimension $\ell, k_{\ell}=1 / \ell \cdot(\partial \ell / \partial P)_{P}$, where $P$ is the external pressure. Conversely, the ANLC phenomenon is measured in terms of the volumetric compressibility along a certain direction, i.e., the directional derivative of the volume with respect to the pressure applied in that direction, $k_{\mathrm{V}}^{\mathrm{m}}=1 / V \cdot\left(\partial V / \partial P_{\mathrm{m}}\right)_{P}$. In this case, the pressure is defined in terms of the trace of the stress tensor as $P=-1 / 3 \cdot\left(\sum \sigma_{i i}\right)$. Since the total volume cannot increase under isotropic compression for thermodynamically and mechanically stable space unconstrained solid materials, ${ }^{43,45,49}$ the isotropic volumetric compressibility, $k_{\mathrm{V}}=1 / V \cdot(\partial V / \partial P)_{P}$, must be strictly positive. The positivity of the isotropic volumetric compressibility does not hold for constrained systems ${ }^{43}$ and in the vicinity of material instabilities as phase transitions ${ }^{45}$ and appropriate counterexamples have been encountered. ${ }^{211}$ However, in the case of anisotropic stresses there is not such limitation and the anisotropic volumetric compressibility $K_{\mathrm{V}}^{\mathrm{m}}$ can be negative.

This article is organized as follows. The first-principles solidstate methods employed in this work and the precise calculation parameters used are described in Appendix A of the ESI. $\dagger$ The main results obtained for the lactic, maleic, succinic and citric acids are presented and discussed in four separate Subsections of Section 2. The results obtained for citric acid monohydrate are reported in Section 2.5. In each Subsection, the results obtained for the crystal structure of the considered material, its elastic tensor, mechanical stability and mechanical properties are given. The presence of anomalous negative mechanical phenomena and pressure induced phase transitions in these materials and the deformation of the crystal structures under pressure are also studied. Finally, Section 4 contains the main conclusions of this article.

\section{Results and discussion}

\subsection{L-(+)-Lactic acid}

The lactic acid, or 2-hydroxypropanoic acid, is a natural monocarboxylic acid which was first isolated from sour milk in 1780 by the Swedish chemist Carl Wilhelm Scheele. ${ }^{212}$ Berzelius discovered that lactate salts are produced in the muscles during exertion. Wislicenus in 1873 established its molecular structure. ${ }^{212}$
The participation of Lactobacillus bacteria in the production of lactic acid in fermentation was discovered in 1856, by Louis Pasteur. $^{213}$ The lactic acid is chiral. The enantiomer studied in this paper is the levogyrous one, $\mathrm{L}-(+)$-lactic acid. It is a product of anaerobic metabolism of sugars in the majority of living organisms and plays a fundamental role as an energy source for neurons in the brain of several mammalian species, including the human one. ${ }^{214-216}$ Aside of other biological functions, L-lactic acid is the primary endogenous agonist of hydroxycarboxylic acid receptor 1 (HCA1). ${ }^{217}$ Lactic acid can be produced by fermentation of carbohydrates or synthetically for example from acetaldehyde. ${ }^{212,218,219}$ Lactic acid is employed in food processing as an additive which is a mild acidulant, as a decontaminant and as a food preservative, and in the pharmaceutical and cosmetic industry. It is also used as a synthetic intermediate in many organic synthesis industries and in various biochemical industries. Lactic acid is an important building block for the production of biodegradable polymers as poly(lactic acid) (PLA) which are among the most frequently used in medical sutures and devices, bioimplants and scaffolds in tissue engineering. ${ }^{220-225}$ While the mechanical properties of PLA films and many related materials have been studied, ${ }^{226-239}$ the mechanical properties of solid lactic acid are unknown.

2.1.1 Crystal structure. The computed crystal structure of $\mathrm{L}-(+)$-lactic acid, $\mathrm{COOH}-\mathrm{CH}(\mathrm{OH})-\mathrm{CH}_{3}$, is displayed in Fig. $1 \mathrm{~A}$. A picture of a $2 \times 2 \times 2$ supercell is shown in Fig. 2A. Fig. 2 shows the crystal structures of the materials considered in this paper in a larger scale than Fig. 1. The unit-cell of $\mathrm{L}_{-}(+)$-lactic acid is orthorhombic (see Table S1, ESI $\dagger$ ). The computed unit-cell parameters, volume and density are given in Table 1. The calculated unit cell parameters obtained using the dispersion corrected Perdew-Burke-Ernzerhof (PBE) energy-density functional are in good agreement with the experimental values. $^{240,241}$ The computed unit cell volume is only $2.4 \%$ smaller than the experimental value reported by Schouten et al. ${ }^{240}$ Since the first principles result corresponds to zero temperature, the thermal expansion effect should reduce the difference with respect to the experimental value, corresponding to room temperature, significantly. As can be seen in the first row of the table, the introduction of dispersion corrections is mandatory for the description of molecular crystals, since the uncorrected PBE functional overestimates the experimental unit-cell volume by nearly $16 \%$.

A set of interatomic distances and angles in the crystal structure of lactic acid are given in Tables S2 and S3 of the ESI, $\dagger$ compared with the corresponding experimental results. ${ }^{240}$ The labelling convention used to denote the different atoms in the crystal structure of lactic acid is shown in Fig. S1 of the ESI. $\dagger$ The computed data agrees satisfactorily with the experimental results, despite of the fact that the both set of structural data correspond to different temperatures. The differences in the $\mathrm{C}-\mathrm{C}$ and $\mathrm{C}-\mathrm{O}$ distances are smaller than $0.01 \AA$, except for the $\mathrm{C}-\mathrm{O}$ double bonds for which the differences are of the order of $0.02 \AA$. The fact that for the computed $\mathrm{C}-\mathrm{H}, \mathrm{O}-\mathrm{H}$ and $\mathrm{H} \cdots \mathrm{O}$ distances, involving hydrogen atoms, there are larger discrepancies with respect to the corresponding experimental values was expected because the 

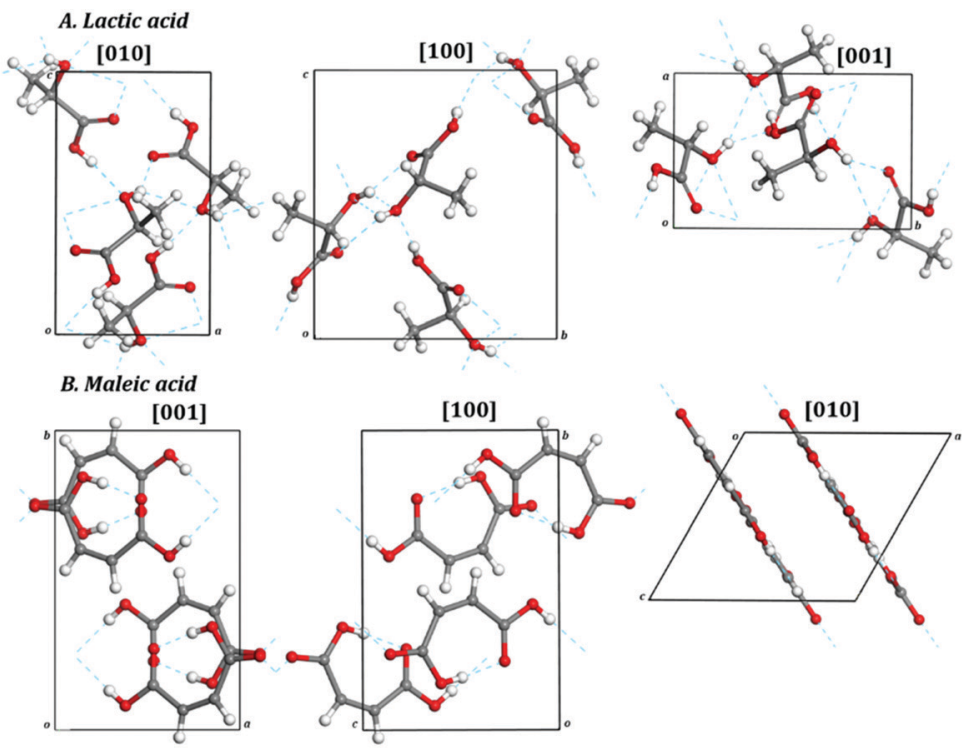

\section{Succinic acid}

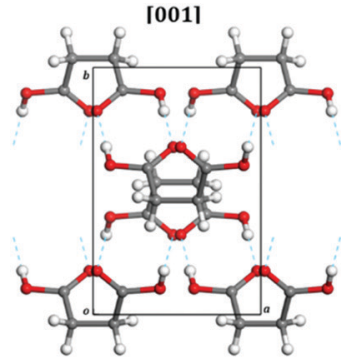

D. Citric acid

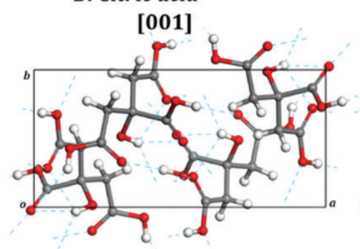

E. Citric acid monohydrate [001]
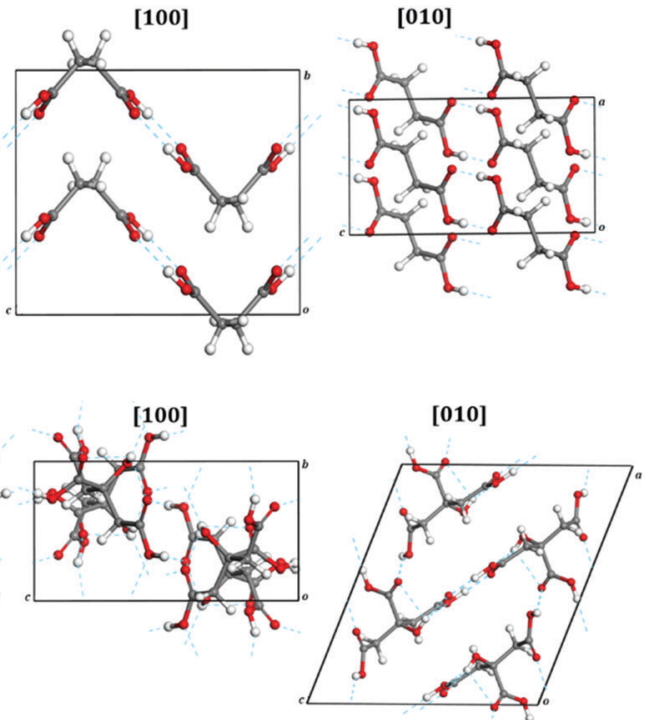

[010]

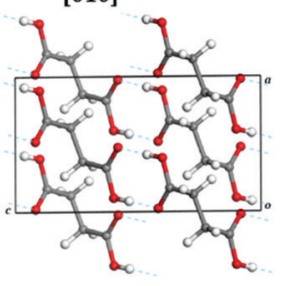

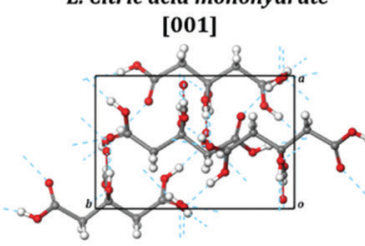

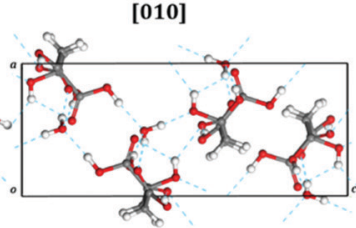

[010]

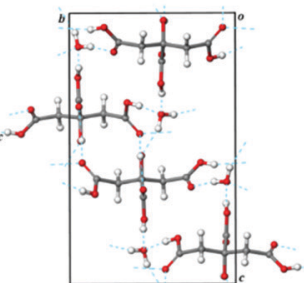

Fig. 1 Computed crystal structures of (A) L-(+)-lactic acid; (B) maleic acid; (C) succinic acid; (D) citric acid; (E) citric acid monohydrate. In all the cases, views of the unit cell from the [001], [010] and [100] crystallographic directions are given. Color code: O - red; C - gray; $\mathrm{H}-$ white.

experimental structure was determined by refinement from X-ray diffraction data. In general, the experimental hydrogen locations are very unprecise due to the small scattering factor of hydrogen.

As can be observed in Fig. S1 (see also Tables S2 and S3) of the ESI, $\dagger$ there are three non-equivalent hydrogen bonds in lactic acid: $\mathrm{O} 1-\mathrm{H} 1 \cdots \mathrm{O} 3^{\prime \prime \prime}, \mathrm{O} 3-\mathrm{H} 3 \cdots \mathrm{O} 2{ }^{\prime}$ and $\mathrm{O} 3-\mathrm{H} 3 \cdots \mathrm{O}^{\prime}$. In the first one, the donor oxygen atom (O1) is from the $\mathrm{OH}$ bond in the carboxylic functional group and the acceptor oxygen atom $\left(\mathrm{O}^{\prime \prime \prime}\right)$ is from the $\mathrm{OH}$ alcoholic group of a different molecule. In the second and third hydrogen bonds, the donor oxygen atom (O3) is from the alcoholic $\mathrm{OH}$ group and the acceptor oxygen atoms are one $\left(\mathrm{O}_{2}^{\prime}\right)$ from a $\mathrm{C}=\mathrm{O}$ bond and the other $\left(\mathrm{O}^{\prime}\right)$ from a carboxylic $\mathrm{OH}$ group both being located in different molecules. 
A. Lactic acid

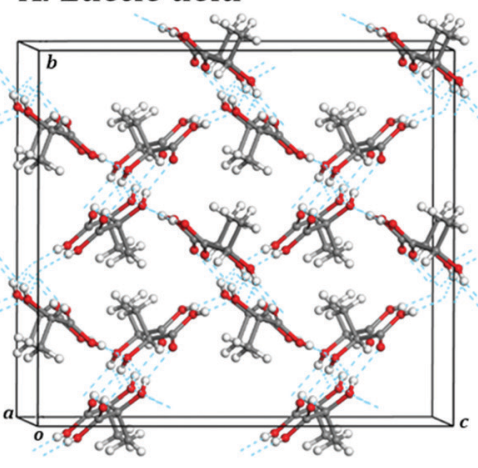

B. Maleic acid

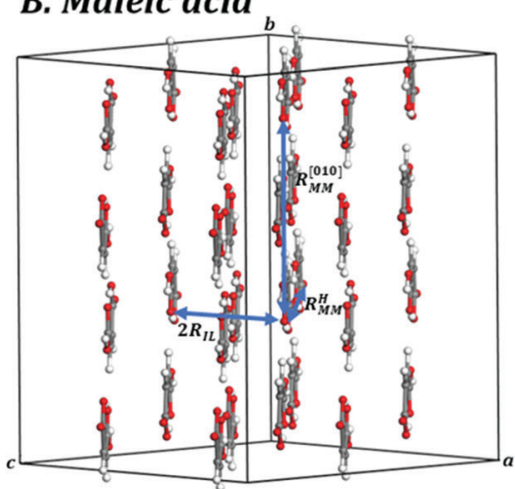

\section{Succinic acid}

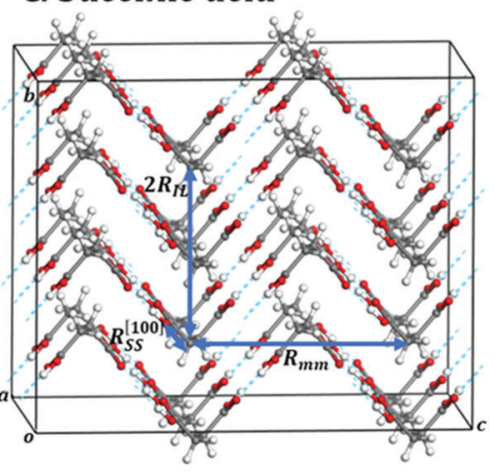

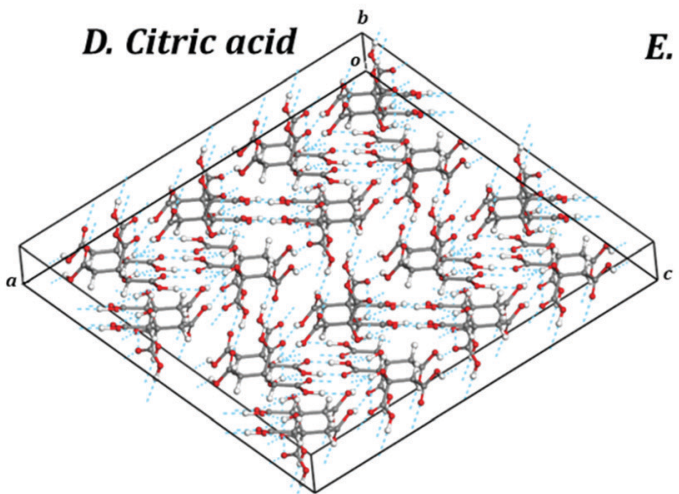

E. Citric acid monohydrate

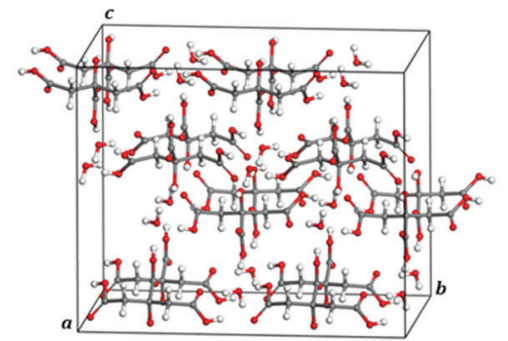

Fig. 2 Views of $2 \times 2 \times 2$ supercells of (A) L-(+)-lactic acid; (B) maleic acid; (C) succinic acid; (D) citric acid; (E) citric acid monohydrate. Color code: O red; C - gray; H - white.

Table 1 Computed lattice parameters of the selected organic acids. The theoretical results correspond to zero temperature and the experimental ones to room temperature

\begin{tabular}{|c|c|c|c|c|c|c|c|c|}
\hline Parameter & $a(\AA)$ & $b(\AA)$ & $c(\AA)$ & $\alpha(\mathrm{deg})$ & $\beta(\mathrm{deg})$ & $\gamma(\mathrm{deg})$ & Vol. $\left(\AA^{3}\right)$ & Dens. $\left(\mathrm{g} \mathrm{cm}^{-3}\right)$ \\
\hline \multicolumn{9}{|c|}{ L-(+)-Lactic $\operatorname{acid}^{240,241}$} \\
\hline PBE & 6.0568 & 8.5894 & 9.6078 & 90.0 & 90.0 & 90.0 & 499.8396 & 1.197 \\
\hline $\mathrm{PBE}+$ disp. & 5.4858 & 8.2410 & 9.3290 & 90.0 & 90.0 & 90.0 & 421.7510 & 1.418 \\
\hline Exp. $^{240}$ & $5.4896(3)$ & $8.4221(3)$ & $9.3453(5)$ & 90.0 & 90.0 & 90.0 & 432.0702 & 1.385 \\
\hline \multicolumn{9}{|c|}{ Maleic acid ${ }^{242-245}$} \\
\hline PBE & 8.0760 & 10.5595 & 8.6302 & 90.0 & 126.78 & 90.0 & 589.4946 & 1.308 \\
\hline $\mathrm{PBE}+$ disp. & 6.8630 & 10.1247 & 7.3947 & 90.0 & 117.52 & 90.0 & 455.6945 & 1.692 \\
\hline Exp. $^{245}$ & $7.1511(8)$ & $10.1107(11)$ & $7.6405(10)$ & 90.0 & 119.405(8) & 90.0 & 481.2594 & 1.602 \\
\hline \multicolumn{9}{|c|}{ Succinic acid $^{246-251}$} \\
\hline PBE & 6.3299 & 8.8155 & 11.0661 & 90.0 & 97.35 & 90.0 & 612.4274 & 1.281 \\
\hline $\mathrm{PBE}+$ disp. & 5.6594 & 8.1169 & 10.3944 & 90.0 & 89.62 & 90.0 & 477.4754 & 1.643 \\
\hline Exp. $^{251}$ & $5.7015(5)$ & $8.4154(8)$ & $10.3538(8)$ & 90.0 & $90.374(3)$ & 90.0 & 496.7689 & 1.579 \\
\hline \multicolumn{9}{|c|}{ Citric acid $^{252-254}$} \\
\hline PBE & 13.1200 & 5.9182 & 11.76015 & 90.0 & 109.32 & 90.0 & 861.7019 & 1.481 \\
\hline PBE + disp. & 12.8179 & 5.5423 & 11.3389 & 90.0 & 112.13 & 90.0 & 746.1776 & 1.710 \\
\hline Exp. $^{254}$ & $12.817(16)$ & $5.628(7)$ & $11.465(15)$ & 90.0 & $111.22(10)$ & 90.0 & 770.9433 & 1.655 \\
\hline \multicolumn{9}{|c|}{ Citric acid monohydrate ${ }^{255,256}$} \\
\hline PBE & 6.5500 & 9.4838 & 15.5143 & 90.0 & 90.0 & 90.0 & 963.7298 & 1.448 \\
\hline PBE + disp. & 6.1856 & 9.2915 & 14.9972 & 90.0 & 90.0 & 90.0 & 861.9491 & 1.619 \\
\hline Exp. $^{256}$ & $6.2343(10)$ & $9.2882(14)$ & $15.246(2)$ & 90.0 & 90.0 & 90.0 & 882.8261 & 1.581 \\
\hline
\end{tabular}

The X-ray powder diffraction pattern of lactic acid was determined from the computed and experimental ${ }^{240}$ crystal structures. The resulting patterns are given in Fig. $3 \mathrm{~A}$ and as can be seen, they are in satisfactory agreement as expected from the consistence between the computed and experimental crystal structures. 
A. Lactic acid

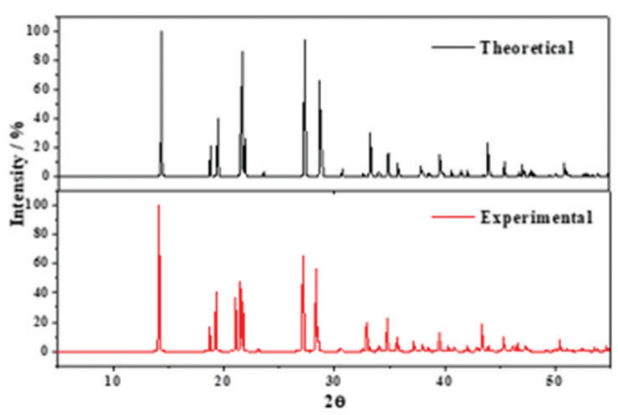

C. Succinic acid

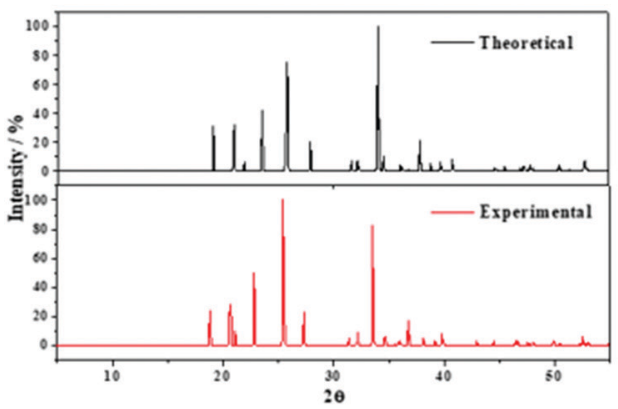

B. Maleic acid

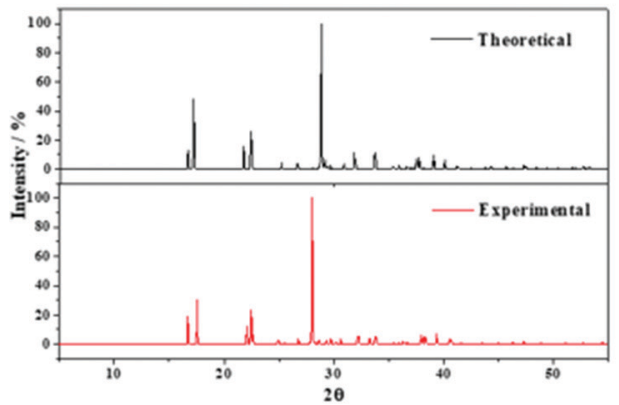

D. Citric acid

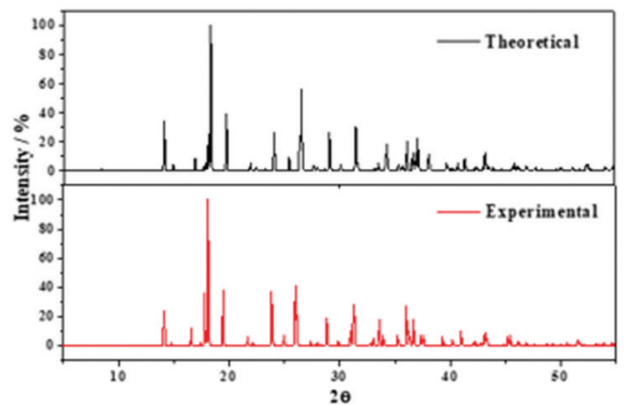

E. Citric acid monohydrate

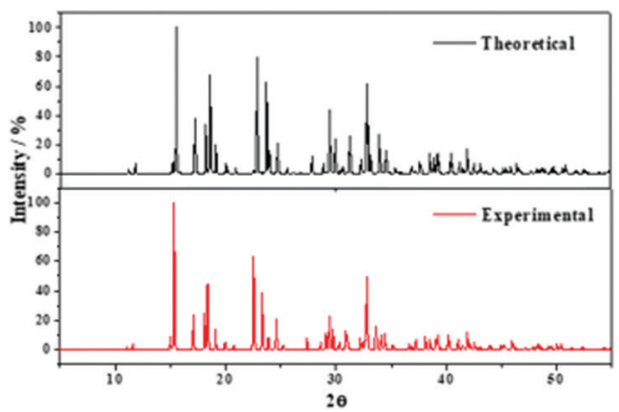

Fig. 3 X-ray powder diffraction patterns of the selected organic acids obtained from the computed and experimental structures using with CuK $\alpha$ radiation $(\lambda=1.540598 \AA)$.

2.1.2 Elasticity tensor, mechanical stability and mechanical properties. The elasticity tensor of $\mathrm{L}-(+)$-lactic acid was computed at the optimized equilibrium structure. The elements of the matrix representation of the elastic tensor of the lactic acid are reported in Table 2. Since the crystal structure of lactic acid is orthorhombic $^{240}$ (see Table S1 of the ESI $\dagger$ ), there are only nine non-vanishing independent matrix elements in its elasticity matrix. ${ }^{257,258}$ A given crystal structure is mechanically stable, if an only if, the Born mechanical stability conditions are satisfied. ${ }^{259,260}$ The generic Born mechanical stability condition can be expressed mathematically in terms of an algebraic condition on the eigenvalues of the matrix representation of the elastic tensor: the elastic matrix must be positive definite, that is, all its eigenvalues must be greater than zero. ${ }^{260}$ Therefore, the elastic matrix of L-(+)-lactic acid was diagonalized numerically. Since all its eigenvalues were positive, $\mathrm{L}-(+)$-lactic is mechanically stable. For orthorhombic space symmetry, a closed set of necessary and sufficient mechanical stability conditions is also known ${ }^{258,260}$ and are given in Appendix B. The satisfaction of these conditions implies the satisfaction of the generic Born mechanical stability condition.

The mechanical properties of polycrystalline aggregates of $\mathrm{L}-(+)$-lactic were determined in terms of the elasticity matrix using the Voigt, ${ }^{261}$ Reuss $^{262}$ and Hill $^{263}$ approximations. As in many previous works, ${ }^{70,71,74,76,77,264}$ the best agreement between the calculated bulk modulus with the single crystal bulk modulus computed from the 4th Birch-Murnaghan equation of state (BM-EOS, see Appendix A in the ESI $\dagger$ ) was obtained with the Reuss scheme. The computed mechanical properties in the Reuss approximation together with the bulk modulus and its first two derivatives with respect to pressure extracted from the BM-EOS are reported in Table 3. The calculated bulk modulus, $B=9.82 \pm 0.15 \mathrm{GPa}$, is quite small, a feature common for most organic acid crystals. ${ }^{70,71}$ Lactic acid in the solid state is a brittle material because the computed ductility index, $D=1.48$, is smaller than $1.75 .^{266,267}$ The calculated Vickers 
Table 2 Computed elastic constants of the selected organic acids. The Voigt convention is employed for the indices of the matrix elements of the elasticity tensor (a pair of Cartesian indices are contracted into a single integer: $1 \leq i \leq 6: x x \rightarrow 1, y y \rightarrow 2, z z \rightarrow 3, y z \rightarrow 4, x z \rightarrow 5, x y \rightarrow 6)$. All the values are given in GPa

\begin{tabular}{llllll}
\hline & $C_{i j}$ & & & & \\
\cline { 2 - 6 }$i j$ & $\begin{array}{l}\text { Lactic } \\
\text { acid }\end{array}$ & $\begin{array}{l}\text { Maleic } \\
\text { acid }\end{array}$ & $\begin{array}{l}\text { Succinic } \\
\text { acid }\end{array}$ & $\begin{array}{l}\text { Citric } \\
\text { acid }\end{array}$ & $\begin{array}{l}\text { Citric acid } \\
\text { monohydrate }\end{array}$ \\
\hline 11 & 13.95 & 38.31 & 23.27 & 21.08 & 22.12 \\
22 & 18.45 & 35.21 & 19.36 & 30.82 & 52.03 \\
33 & 16.47 & 13.74 & 21.43 & 25.27 & 31.65 \\
44 & 8.45 & 7.10 & 13.04 & 13.31 & 4.25 \\
55 & 9.14 & 20.82 & 13.89 & 10.67 & 11.48 \\
66 & 15.48 & 11.76 & 6.45 & 13.87 & 7.38 \\
12 & 7.59 & 9.29 & 10.70 & 6.44 & 6.17 \\
13 & 5.19 & 19.56 & 12.88 & 7.64 & 7.70 \\
15 & 0.0 & 22.28 & 2.42 & 3.45 & 0.0 \\
23 & 9.03 & 4.99 & 14.40 & 12.56 & 4.72 \\
25 & 0.0 & 6.47 & 6.26 & -4.68 & 0.0 \\
35 & 0.0 & 7.57 & 8.88 & -3.40 & 0.0 \\
46 & 0.0 & 6.89 & 0.62 & 8.07 & 0.0 \\
\hline
\end{tabular}

hardness is, $H=0.84$ is small and, therefore, lactic acid is a weak material. ${ }^{268}$ The universal anisotropy index,${ }^{269} A^{\mathrm{U}}=1.38$, is quite significant.

2.1.3 Dependence of the mechanical properties of lactic acid on the orientation of the applied strain. Negative Poisson's ratios. Due to large mechanical anisotropy of the lactic acid, indicated by the value of the universal anisotropy index, its mechanical properties must have a notable directional dependence. The large dependence of bulk, Young and shear moduli and Poisson's ratio of lactic acid on the direction of the applied strain is displayed in Fig. 4. Since the shear modulus and Poisson's ratio depend on two directions, the direction of the applied strain, or longitudinal direction, and the transverse direction, Fig. 4C and D provide representations of surfaces of maximum $G$ and $\nu$, respectively. These surfaces are composed with the maximum values of these properties for the given direction of the longitudinal strain and all possible transverse directions. ${ }^{269}$ Fig. $4 \mathrm{D}$ also shows the surface of minimum Poisson's ratio. Since there exists a strong symmetry-independent correlation between large values of the mechanical anisotropy and
A
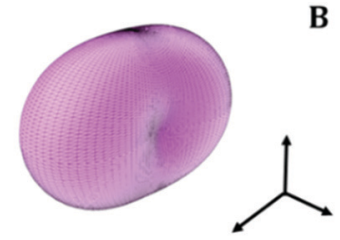

C
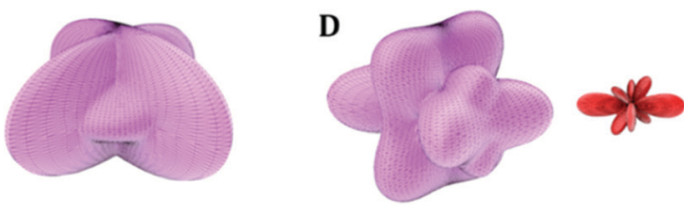

Fig. 4 Elastic properties of lactic acid as a function of the orientation of the applied strain: (A) compressibility; (B) Young modulus; (C) maximum shear modulus; (D) surfaces of minimum (red) and maximum (violet) Poisson's ratio. The maximum values of the compressibility, Young modulus, shear modulus and Poisson's ratio are 49.3 TPa ${ }^{-1}, 23.74 \mathrm{GPa}, 15.48 \mathrm{GPa}$ and 0.59 , respectively.

large values of the difference of the minimum and maximum values of the Poisson's ratio when all the possible directions of the applied strain are taken into account, ${ }^{269,270}$ the lactic acid is likely to display the negative Poisson's ratio phenomenon. Its surface of minimum Poisson's ratio (see Fig. 4D) is negative for all the directions of the applied strain. The minimum value of the Poisson's ratio (see Table 4) is $\nu_{\min }=-0.27$, the longitudinal direction of minimum Poisson's ratio being $U_{\min }^{\mathrm{L}}=(-0.70,-0.71$, 0.00). As it will be shown in the next section, lactic acid not only displays the NPR phenomenon but also significant negative linear compressibilities.

2.1.4 Deformation of the crystal structure of lactic acid as a function of the external isotropic pressure. Isotropic NLC. The deformation of the crystal structure of lactic acid under hydrostatic pressure was studied by optimizing its structure under the effect of twenty one different values of the pressure. The computed unit-cell volume and lattice parameters are given in Table S4 of the ESI $\dagger$ and displayed in Fig. 5. As can be observed, lactic acid displays INLC for applied pressures in the narrow range $P=1.01-1.03 \mathrm{GPa}$, due to a sudden pressure induced phase transition occurring at about $1.03 \mathrm{GPa}$, which leads to a large increase of the $b$ lattice parameter (from 8.10 to $8.64 \AA$ ).

Table 3 Computed mechanical properties of the selected organic acids derived from the calculated elastic constants in the Reuss approximation at zero temperature. The computed bulk modulus and its first two pressure derivatives derived from the BM-EOS are also given

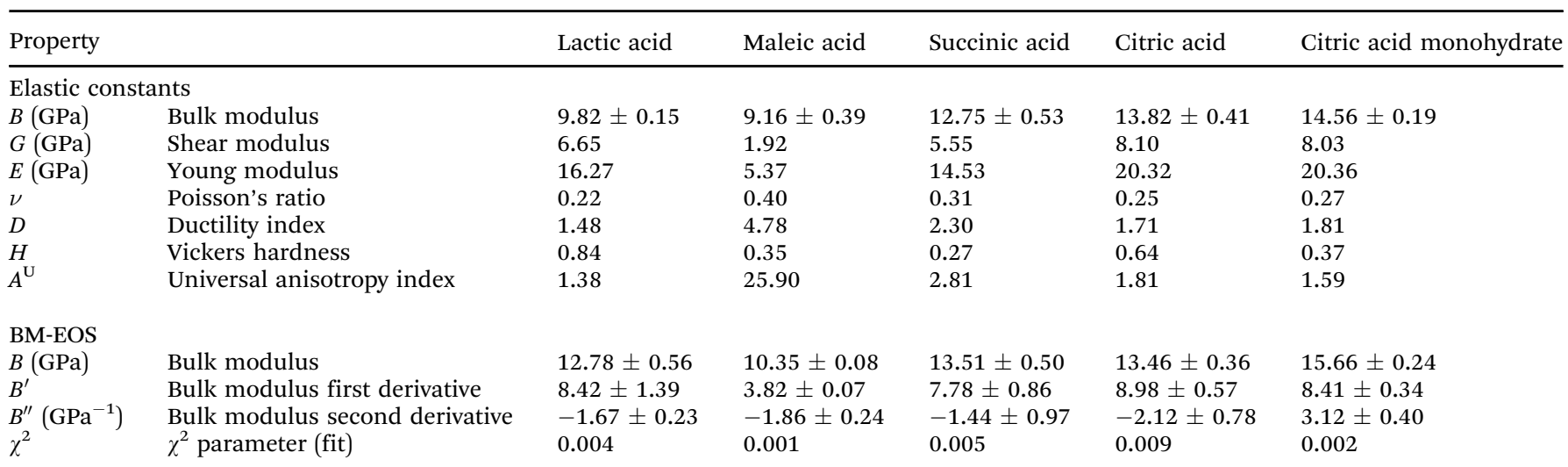


Table 4 Minimum and maximum Poisson's ratios for the selected organic acids. The directions for the associated longitudinal and transverse directions are also given

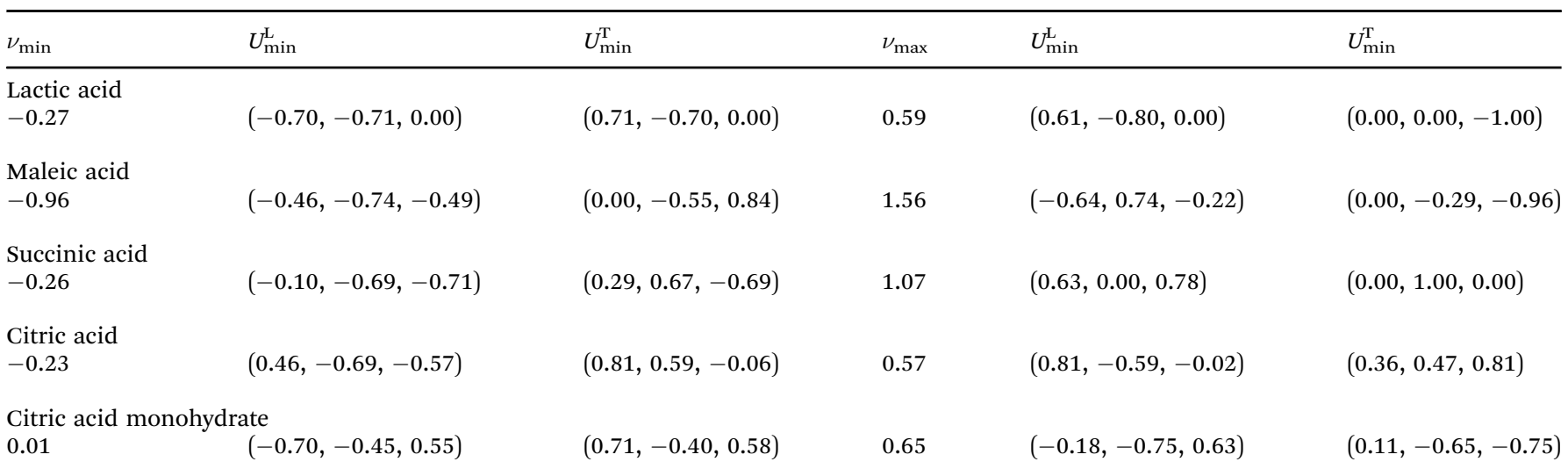
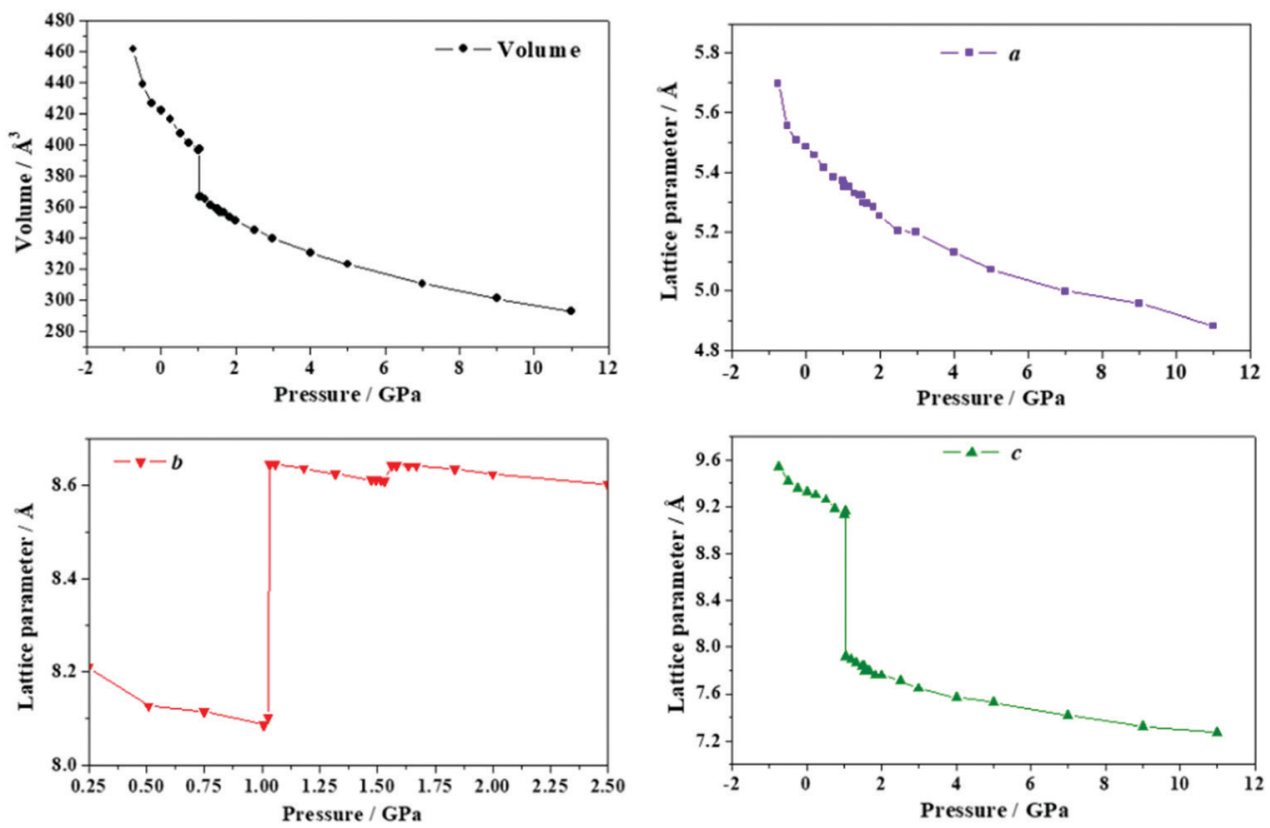

Fig. 5 Unit cell volume and lattice parameters of lactic acid under the effect of different external isotropic pressures. Note that the variation of the $b$ lattice parameter is displayed in an smaller pressure range from 0.25 to $2.5 \mathrm{GPa}$ to show its behavior in this pressure range in more detail.

The compressibility at $P=1.03 \mathrm{GPa}$ is negative and very large, $k_{\mathrm{b}}=-1 / b \cdot(\partial b / \partial P)_{P} \sim-8680.5 \mathrm{TPa}^{-1}$. The $c$ lattice parameter decreases to a larger extent (from 9.16 to $7.91 \AA$ ) and the total unit cell volume decreases. This drastic structural change does not alter the space symmetry of the crystal structure. As can be seen, the volume even increases slightly by about $0.5 \AA^{3}$ before the transition, between pressures $P=1.01$ to $1.03 \mathrm{GPa}$. As it is well known, under the effect of isotropic pressures, a negative volumetric compressibility is possible near a phase transition because the crystal structure becomes unstable before the transition. The crystal structures before and after the phase transition are shown in Fig. 6. The crystal structures are completely different. The new crystal structure at the pressure of $P=1.056 \mathrm{GPa}$ (referred to as Phase II in what follows) is given as ESI $\dagger$ in a file of CIF type. The modification of the crystal structure of lactic acid under increasing external isotropic pressure is displayed as an animated sequence of crystal structures given in the Animation S1 in the ESI. $\dagger$

The $b$ lattice parameter increases again in the pressure range from $P=1.53$ to $1.56 \mathrm{GPa}$. In this case, the increase is much smaller (from 8.60 to $8.64 \AA$ ). The estimated compressibility at $P=1.55 \mathrm{GPa}$ is $k_{\mathrm{b}} \sim-162.9 \mathrm{TPa}^{-1}$. The $c$ and $a$ lattice parameters decrease from 7.83 to $7.79 \AA$ and from 5.32 to $5.30 \AA$, respectively, leading to a decrease of the total volume from 358.98 to $356.69 \AA^{3}$. Tables S5 and S6 of the ESI $\uparrow$ show that the interatomic distances and angles within the lactic molecule units are not altered significantly in this pressure range and that the main bonding change involved is the elongation of the $\mathrm{O} 3-\mathrm{H} 3 \cdots \mathrm{O} 2^{\prime}$ hydrogen bond. However, the change in the $\mathrm{H} 3 \cdots \mathrm{O} 22^{\prime}$ distance $(0.004 \AA)$ is very small in comparison with the variation in the $b$ lattice parameter, $0.04 \AA$. The $b$ lattice parameter is equal to the distance between two successive lactic molecules 

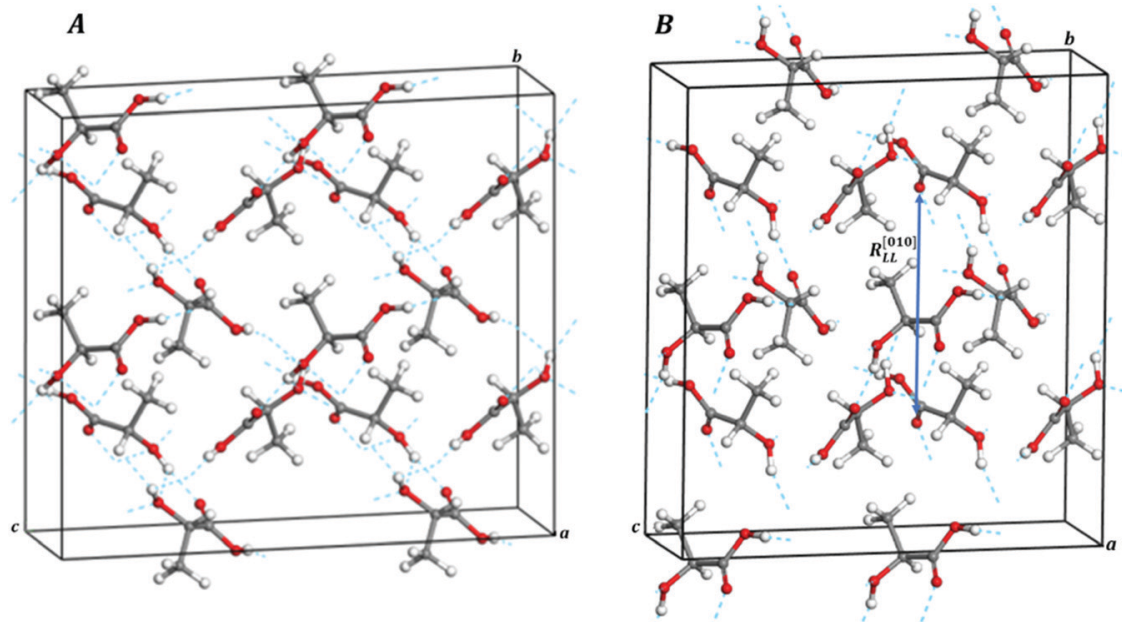

Fig. 6 Computed crystal structures of L-(+)-lactic acid under the effect of isotropic pressures: (A) $P=1.026 \mathrm{GPa}$ and (B) $P=1.056 \mathrm{GPa}(1 \times 2 \times 2$ supercells).

along the $[010]$ crystallographic direction $\left(R_{\mathrm{LL}}^{[010]}\right.$, see Fig. $\left.6 \mathrm{~B}\right)$. The reason for the increase of the $b$ lattice parameter under pressure is, therefore, the enlargement of the non-bonding distances along [010] direction leading to the increase of $R_{\mathrm{LL}}^{[010]}$ in the Phase II of solid lactic acid, which is only partially due to the elongation of the $\mathrm{O} 3-\mathrm{H} 3 \cdots \mathrm{O} 2$ ' hydrogen bond.

2.1.5 Deformation of the crystal structure of lactic acid as a function of the external anisotropic stress. Anisotropic NLC. The crystal structure of lactic acid was optimized under the effect of eight different external stresses applied in the direction of minimum Poisson's ratio with associated pressures in the range from -0.23 to $1.88 \mathrm{GPa}$. The computed unit-cell volumes and lattice parameters are reported in Table S7 of the ESI $\dagger$ and shown in Fig. 7. Lactic acid does not show any sign of ANLC in this pressure range.

\subsection{Maleic acid}

Maleic acid, or cis-butenedioic acid, is an organic dicarboxylic acid. It is the cis-isomer of butenedioic acid, whereas fumaric acid is the trans-isomer. Maleic acid is habitually derived from the hydrolysis of maleic anhydride which, in turn, is produced synthetically by oxidation of benzene or butane. ${ }^{271}$ Maleic acid has an exceptionally high ability to form salts with various amino acids (amino acid maleates). ${ }^{178,245}$ More than 20 salts of this acid with different amino acids have been documented. ${ }^{245}$ Maleic acid is widely employed in synthetic organic chemistry. For example, it is used industrially for the production of glyoxylic acid by ozonolysis. ${ }^{271}$ Succinic acid may be produced from maleic acid by hydrogenation. However, its main use is as precursor of fumaric acid. The isomerization may be produced in several ways and must be catalyzed, for example by several chemical reagents, such as mineral acids and thiourea, because the reaction of interconversion, involving a rotation around a double $\mathrm{C}-\mathrm{C}$ bond, is not spontaneous. ${ }^{271}$ Maleic acid and polymers based in it, as the polymaleic acid (PMA) and terpolymer of maleic acid (TPMA), are employed in textile industry because are able to establish an esterification reaction with cotton and, at moderate temperatures and in the presence of appropriate

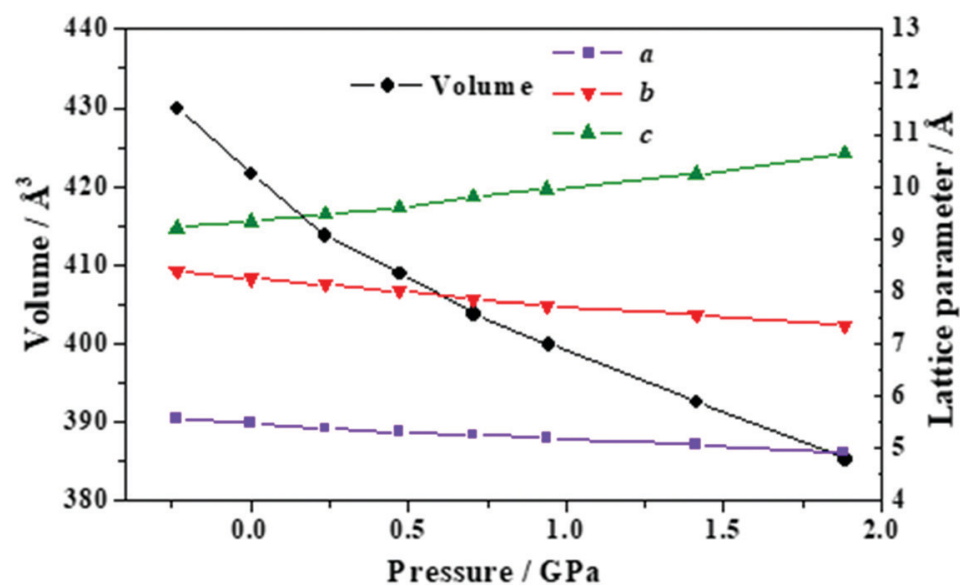

Fig. 7 Unit cell volume and lattice parameters of lactic acid under the effect of different external stresses applied in the direction of the minimum Poisson's ratio. 
catalyzers, can crosslink cotton fibers, leading to a larger durability and improved fabric strength and wash resistance. ${ }^{272,273}$ While the mechanical properties of polymers formed with maleic acid, materials treated or coated with maleic acid, or related materials have been studied ${ }^{178,245,274,275}$ the mechanic properties of crystalline maleic acid have not been reported.

2.2.1 Crystal structure. The computed crystal structure of maleic acid, cis- $\mathrm{COOH}-\mathrm{CH}=\mathrm{CH}-\mathrm{COOH}$, is shown in Fig. $1 \mathrm{~B}$ and a picture of a $2 \times 2 \times 2$ supercell of maleic acid is displayed in Fig. 2B. As can be observed in the view from [010] crystallographic direction included in Fig. 1B and in Fig. 2B, the crystal structure of maleic acid is composed of layers formed with hydrogen-bonded maleic acid molecules. Table 1 provides the computed and experimental unit-cell parameters, volume and density. The results are in reasonable agreement with experiment, ${ }^{242-245}$ the computed unit cell volume being 5.3\% smaller than the experimental value given by Rychkov et al. ${ }^{245}$ As in the case of lactic acid, the main source for this difference must be the fact that the computed crystal structure corresponds to zero temperature and the experimental one to room temperature. The difference could be reduced to a large extent if an experimental determination of the crystal structure at low temperature could be carried out. In fact, volume thermal expansion effects larger than 5\% were observed for example for the closely related crystal structure of oxalic acid dihydrate for which low temperature crystal data are available. ${ }^{71}$ The effect of dispersion interactions in the structure of maleic acid is enormous. As shown in Table 1, the uncorrected PBE functional overestimates the experimental unit-cell volume by nearly $23 \%$.

The interatomic distances and angles in the computed and

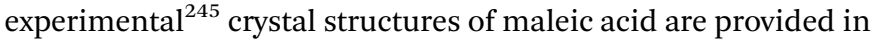
Tables S8 and S9 of the ESI. $\dagger$ The atom labelling convention employed in these tables is given in Fig. S2 of the ESI. $\dagger$ The calculated distances and angles agree well with the experimental data. The differences in the $\mathrm{C}-\mathrm{C}$ and $\mathrm{C}-\mathrm{O}$ distances are smaller than $0.01 \AA$, except for the $\mathrm{C}-\mathrm{C}$ and $\mathrm{C}-\mathrm{O}$ double bonds for which the differences are within $0.02-0.03 \AA$. There are two nonequivalent hydrogen bonds in the structure of maleic acid, $\mathrm{O} 1-\mathrm{H} 1 \cdots \mathrm{O} 3$ and $\mathrm{O} 4-\mathrm{H} 4 \cdots \mathrm{O} 22^{\prime \prime}$ (Fig. S2, ESI $\dagger$ ). The first one is intramolecular, the donor oxygen atom (O1) being from the $\mathrm{OH}$ fragment in one of the two carboxylic functional groups and the acceptor oxygen atom (O3) belonging to the $\mathrm{C}=\mathrm{O}$ bond of the other carboxylic group. In the second hydrogen bond the donor oxygen atom $(\mathrm{O} 4)$ is from the $\mathrm{OH}$ fragment in the second carboxylic group and the acceptor one $\left(\mathrm{O}_{2}^{\prime \prime}\right)$ is from a $\mathrm{C}=\mathrm{O}$ bond in a carboxylic group of other maleic acid molecule.

The X-ray powder diffraction patterns of maleic acid determined from the computed and experimental ${ }^{245}$ crystal structures are shown in Fig. 3B. The agreement between both patterns is very good, providing additional support to the computed crystal structure.

2.2.2 Elasticity tensor, mechanical stability and mechanical properties. The matrix elements of the computed elasticity tensor of maleic acid are given in Table 2. There are only thirteen non-vanishing independent matrix elements in the elasticity matrix $^{257,258}$ of maleic acid because its crystal structure has monoclinic space symmetry ${ }^{245}$ (Table S1 of the ESI $\dagger$ ). In order to study the mechanical stability of the crystal structure of maleic acid, its elasticity matrix was diagonalized numerically. As it occurred with lactic acid, all eigenvalues were positive and, therefore, maleic acid is mechanically stable. ${ }^{259,260}$

The mechanical properties of polycrystalline maleic acid were obtained using the Voigt, ${ }^{261}$ Reuss $^{262}$ and Hill ${ }^{263}$ approximations. As for lactic acid, the Reuss approximation was chosen as the best because it provided the best agreement between the calculated bulk modulus with the single crystal bulk modulus computed from the 4th Birch-Murnaghan EOS. The mechanical properties obtained with this approximation together with the bulk modulus and its first two derivatives with respect to pressure are provided in Table 3 . The calculated bulk modulus, $B=9.16 \pm 0.39 \mathrm{GPa}$, agrees well with the value of $B$ extracted from the BM-EOS, $B=10.35 \pm 0.08 \mathrm{GPa}$. Crystalline maleic acid is ductile because the calculated ductility index, $D=4.8$, is greater than $1.75^{265,266}$ and is very weak because the computed Vickers hardness, $H=0.35$, is very small. ${ }^{267}$ Maleic acid is very anisotropic mechanically because the associated universal anisotropy index, ${ }^{268} A^{\mathrm{U}}=25.90$, is extremely large.

2.2.3 Dependence of the mechanical properties of maleic acid on the orientation of the applied strain. Negative Poisson's ratios. Fig. 8 displays tridimensional representations of the bulk, Young and shear moduli and Poisson's ratio of maleic acid as a function of orientation of the applied strain. The surface of minimum Poison's ratio, given in Fig. 8D, shows that maleic acid is a NPR material with a very significant value of the lowest Poisson's ratio of -0.96 (see Table 4).

2.2.4 Deformation of the crystal structure of maleic acid as a function of the external isotropic pressure. Isotropic NLC. The crystal structure of maleic acid was optimized under the effect of twenty eight different hydrostatic pressures. The computed unit-cell volumes and lattice parameters are reported in Table S10 of the ESI $\dagger$ and displayed in Fig. 9. Maleic acid displays INLC for applied pressures in the narrow pressure range from
A

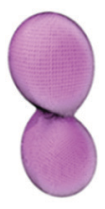

C

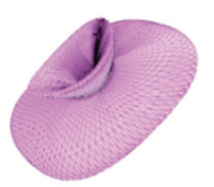

B

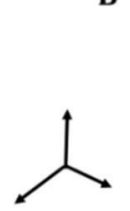

D

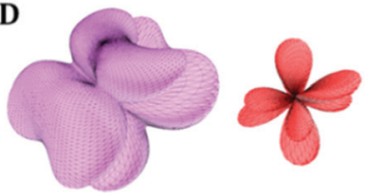

Fig. 8 Elastic properties of maleic acid as a function of the orientation of the applied strain: (A) compressibility; (B) Young modulus; (C) maximum shear modulus; (D) surfaces of minimum (red) and maximum (violet) Poisson's ratio. The maximum values of the compressibility, Young modulus, shear modulus and Poisson's ratio are $101.36 \mathrm{TPa}^{-1}, 72.89 \mathrm{GPa}, 18.13 \mathrm{GPa}$ and 1.56 , respectively. 

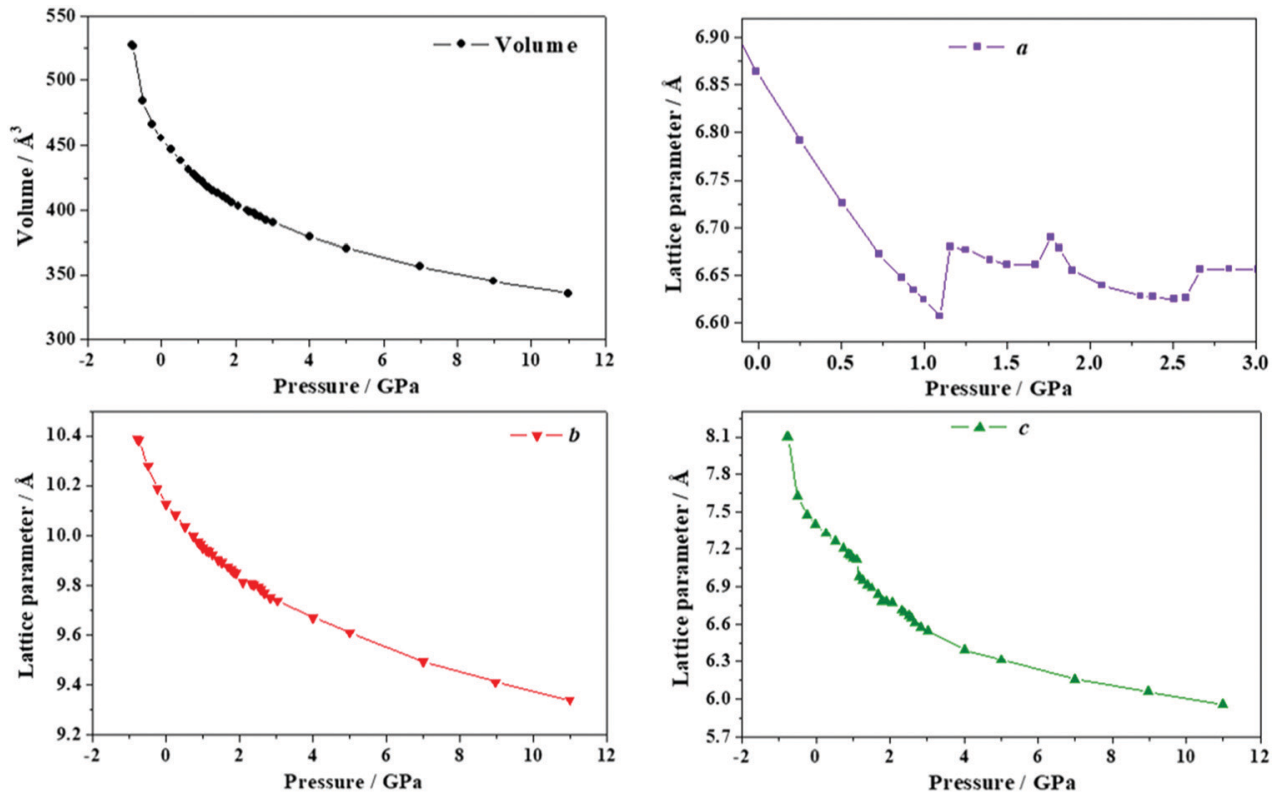

Fig. 9 Unit cell volume and lattice parameters of maleic acid under the effect of different external isotropic pressures.

$P=1.09$ to $P=1.15 \mathrm{GPa}$. The $a$ lattice parameter increases from 6.60 to $6.68 \AA$ A. An estimate of the compressibility at $P=1.13 \mathrm{GPa}$ gives a negative value of $k_{\mathrm{a}}=-1 / a \cdot(\partial a / \partial P)_{P} \sim-177.2 \mathrm{TPa}^{-1}$. The $c$ lattice parameter decreases to a larger extent (from 7.11 to $6.98 \AA$ ) and the total unit cell volume decreases. In this case the bond structure topology is not altered as the pressure increases and no phase transition occurs.

The $a$ lattice parameter increases again in the pressure range from $P=1.67$ to $1.77 \mathrm{GPa}$. Its value increases from 6.66 to $6.69 \AA$ and the $c$ lattice parameter decreases from 6.84 to $6.79 \AA$. In this case, the estimated compressibility at $P=1.73 \mathrm{GPa}$ is $k_{\mathrm{a}} \sim$ $-51.8 \mathrm{TPa}^{-1}$. Finally, from $P=2.58$ to $2.84 \mathrm{GPa}$, the parameter a increases from 6.63 to $6.66 \AA$ (and the $c$ lattice parameter decreases from 6.65 to $6.57 \AA$ ). The estimated compressibility at $P=1.61 \mathrm{GPa}$ is $k_{\mathrm{b}} \sim-38.2 \mathrm{TPa}^{-1}$.

The variation of the unit cell structure of maleic acid under increasing external isotropic pressures is displayed in the Animation S2 of the ESI. $\dagger$ As can be seen in the Animation, the maleic acid structural sheets rotate relative to the reference system and the changes are not easily visualizable. However, the variations of the lattice parameters under pressure may be understood from Fig. 2B. The $a$ lattice parameter is identical to twice the interlayer space $\left(R_{\mathrm{IL}}\right)$ between two sheets in the crystal structure of maleic acid. The $b$ lattice parameter is equal to the distance between two maleic acid molecules belonging to a given sheet along the [010] direction $\left(R_{\mathrm{MM}}^{[010]}\right)$. Finally, the $c$ lattice parameter is equal to the distance between two maleic acid molecules belonging to a given sheet along the perpendicular (horizontal in Fig. 2B) direction $\left(R_{\mathrm{MM}}^{\mathrm{H}}\right)$. It follows from Table S10 $(\mathrm{ESI} \dagger)$ that the INLC in maleic acid arises from the increase of the interlayer space, or equivalently the $a$ lattice parameter, for the three pressure ranges 1.09 to $1.15 \mathrm{GPa}, 1.67$ to $1.77 \mathrm{GPa}$ and 2.58 to $2.84 \mathrm{GPa}$. The maleic acid molecule intra-sheet distances decrease consistently under increasing isotropic pressure.
2.2.5 Deformation of the crystal structure of maleic acid as a function of the external anisotropic stress. Anisotropic NLC. The structure of maleic acid was optimized under the effect of twelve different external stresses applied in the direction of minimum Poisson's ratio in the range of pressure from -0.1 to $0.1 \mathrm{GPa}$. The unit-cell volumes and lattice parameters obtained are given in Table S11 of the ESI $\dagger$ and shown in Fig. 10. Maleic acid displays ANLC for applied pressures in the pressure range $P=0.039$ to $P=0.059 \mathrm{GPa}$. In this case the volume first decreases reach a minimum and then increases. The compressibility at $P=0.043 \mathrm{GPa}$ is $k_{\mathrm{V}}=-1 / V \cdot(\partial V / \partial P)_{P} \sim-1183.3 \mathrm{TPa}^{-1}$. There are not topological changes in the structure as the pressure increases and therefore no phase transition occurs.

The change in the crystal structure of maleic acid under the effect of increasing pressures associated to the anisotropic stresses directed along the minimum Poisson's ratio direction is shown in the Animation S3 of the ESI. $\dagger$ As in the isotropic case, the maleic acid layers rotate relative to the reference system. However, while the rotation in the isotropic case was counterclockwise relative to the $b$ axis, the rotation is clockwise in the present case. The changes in the crystal structure are also opposite to those found for the isotropic case. Now, the interlayer space decreases and the increase in volume is due to the increase of the intrasheet distances between the maleic acid molecule distances. In particular, the distance between two maleic acid molecules belonging to a given sheet along the direction perpendicular to [010] crystallographic direction (referred to as $R_{\mathrm{MM}}^{\mathrm{H}}$ in the previous section) increases from 7.45 to $7.98 \AA$ while the increase in $R_{\mathrm{MM}}^{[010]}$ is insignificantly small.

\subsection{Succinic acid}

Succinic acid is a dicarboxylic acid ${ }^{276}$ whose IUPAC name is 1,4-butanedioic acid. Succinic acid has multiple biological roles 

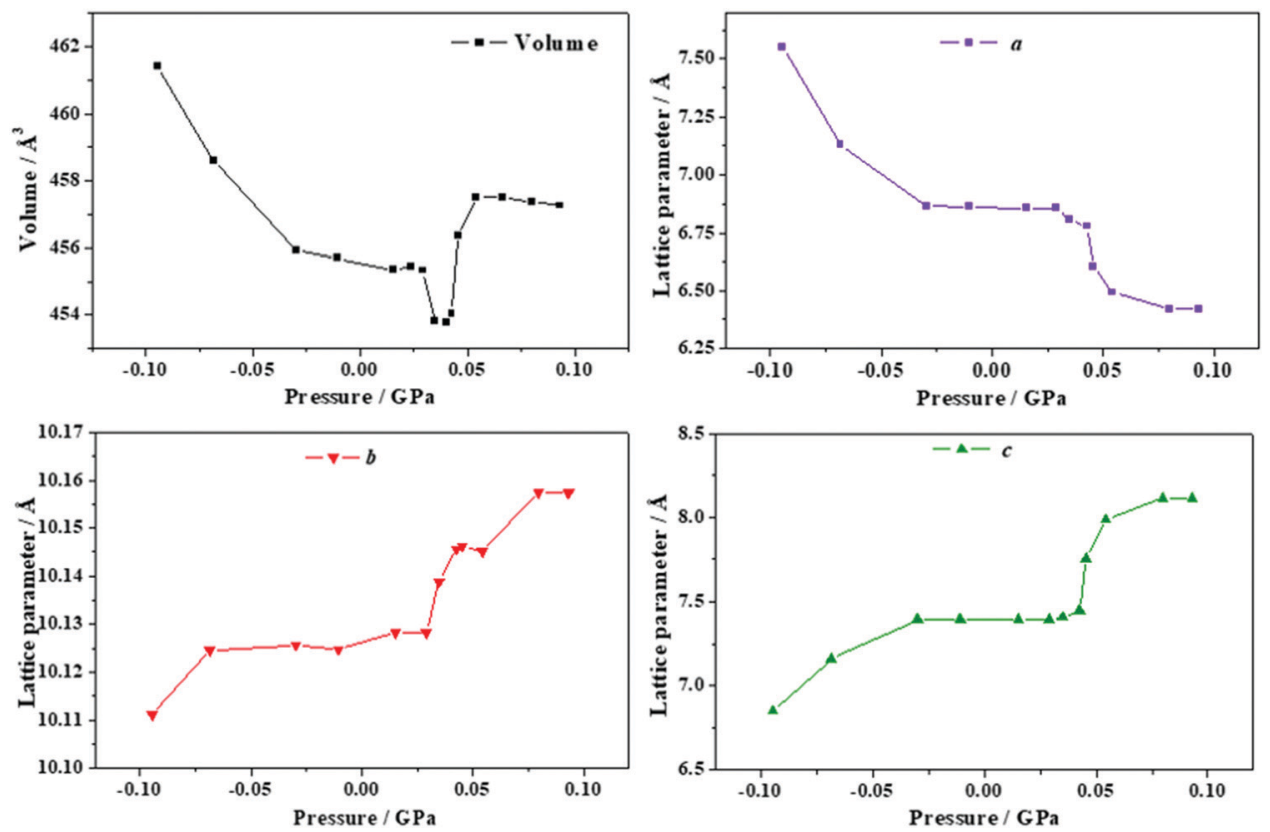

Fig. 10 Unit cell volume and lattice parameters of maleic acid under the effect of different stresses applied in the direction of the minimum Poisson's ratio.

in living organisms where it takes the form of succinate anion. Succinate has a very important primary biological function as a metabolic intermediate which converts into fumarate by the enzyme succinate dehydrogenase (SDH) in the electron transport chain involved in the process of generation of adenosine triphosphate (ATP). ${ }^{277,278}$ All metabolic processes which are connected with the tricarboxylic acid cycle (TCA) cycle, including the metabolism of carbohydrates, amino acids, fatty acids, cholesterol, and hemoproteins, depends on the temporary formation of succinate. Succinate also acts as a signaling molecule reflecting the cellular metabolic state. The excess of succinate or fumarate drives the direct or reverse activity of SDH (direct or reverse electron transport) which leads to oxidation or generation of succinate. ${ }^{277,278}$ Succinate is also a product of the glyoxylate cycle and a re-entry point for the gamma-aminobutyric acid shunt into the TCA cycle. ${ }^{279,280}$ The biological function of succinic acid is believed to be extremely important and to extend to epigenetics, tumorigenesis, signal transduction, endo- and paracrine modulation and inflammation. ${ }^{277-291}$ The action of some bacteria as Actinobacillus succinogenes and Anaerobiospirillum succiniciproducens may be exploited to produce succinate in living organisms ${ }^{292}$ because, under anaerobic conditions, induce the reverse activity of SDH. Succinic acid may be obtained from several synthetic routes ${ }^{276}$ as the partial hydrogenation of maleic acid but, is mostly produced from biomass via fermentation. Using genetically modified microorganisms, such as Escherichia coli or Saccharomyces cerevisiae, a high-yielding, commercial production of succinic acid from fermentation of glucose has been achieved. ${ }^{293,294}$ Succinic acid is widely utilized as a safe food additive and as an excipient in pharmaceutical industry. ${ }^{294-296}$ Succinic acid or succinate salts may be employed to synthesize a large series of organic compounds as 1,4-butanediol, maleic anhydride, succinimide, 2-pyrrolidinone and tetrahydrofuran. ${ }^{276}$ In the framework of crystal engineering, it has been crystallized with many other molecules in order to develop cocrystals and salts having desirable physicochemical properties. ${ }^{251,296-299}$ Succinic acid is employed as a precursor of polyesters, as a component of some resins, and to develop biodegradable polymers of interest in tissue engineering. ${ }^{295,300}$ The characteristics and mechanical properties of many interesting polymers and materials based on, or related to, succinic acid have long been investigated. ${ }^{301-317}$

2.3.1 Crystal structure. The optimized crystal structure of succinic acid, $\mathrm{COOH}-\mathrm{CH}-\mathrm{CH}-\mathrm{COOH}$, is plotted in Fig. 1C. A picture of a $2 \times 2 \times 2$ supercell is shown in Fig. 2C. As can be seen in the view from [010] crystallographic direction contained in Fig. 1C, or even better in Fig. 2C, the succinic acid structure is composed of zigzag folded layers formed with hydrogen-bonded succinic acid molecules. The computed and experimental unit-cell parameters, volume and density of succinic acid are compared in Table 1 . The computational results agree satisfactorily with the experimental results. ${ }^{246-251}$ The experimental volume reported by Lucaioli et al. ${ }^{251}$ is underestimated by $3.9 \%$. The effect of dispersion interactions in the structure of succinic acid is, as in the case of maleic acid, huge. The uncorrected PBE functional overestimates the experimental unit-cell volume by nearly $23 \%$ (see Table 1 ). As mentioned in Sections 2.1.1 and 2.2.2, the major reason for the differences between the present dispersion corrected results and the experiment data may be the different temperatures associated to both sets of data (zero and room temperatures, respectively).

Tables S12 and S13 of the ESI $\dagger$ give a comparison of the interatomic distances and angles in the computed and experimental ${ }^{251}$ crystal structures of succinic acid. The atom 
labelling convention used for succinic acid is shown in Fig. S3 of the ESI. $\dagger$ The computed $\mathrm{C}-\mathrm{C}$ and $\mathrm{C}-\mathrm{O}$ bond distances differ from experiment by less than $0.01 \AA$, except for the $\mathrm{C}-\mathrm{O}$ double bond in which the difference is about $0.02 \AA$. For crystalline succinic acid there is only one non-equivalent hydrogen bond, $\mathrm{O} 1-\mathrm{H} 1 \cdots \mathrm{O} 2{ }^{\prime}$ (Fig. S3, ESI $\dagger$ ). In the crystal structure of succinic acid, the hydrogen bonding is dual, i.e., each pair of adjacent succinic acid molecules are linked by a pair of symmetry equivalent hydrogen bonds. One hydrogen bond links the oxygen atom of an hydroxyl fragment of a carboxylic group of the first molecule with the oxygen atom in the $\mathrm{C}=\mathrm{O}$ bond of a carboxylic group in the second molecule (O1-H1 ․ O2 $\left.2^{\prime}\right)$ and the other hydrogen bond relates the oxygen atom of the hydroxyl fragment of the carboxylic group on the second molecule with the oxygen atom in the $\mathrm{C}=\mathrm{O}$ bond of the carboxylic group in the first molecule $\left(\mathrm{O} 1^{\prime}-\mathrm{H} 1^{\prime} \cdots \mathrm{O} 2^{\prime}\right)$.

The X-ray powder diffraction patterns of succinic acid obtained in terms of the optimized and experimental ${ }^{251}$ structures are shown in Fig. 3C and as can be seen they are in good agreement.

2.3.2 Elasticity tensor, mechanical stability and mechanical properties. The calculated stiffness matrix elements of succinic acid are given in Table 2 . Since the crystal structure of this acid is, as that of maleic acid, monoclinic (Table S1 of the ESI $\dagger$ ), there are only thirteen non-vanishing independent matrix elements in its elasticity matrix. ${ }^{257,258}$ Since all eigenvalues of the elasticity matrix of succinic acid are positive, it is mechanically stable. ${ }^{259,260}$ The mechanical properties of polycrystalline succinic acid obtained from the elasticity constants using the Reuss $^{262}$ approximation and the single crystal bulk modulus and its first two derivatives with respect to pressure obtained from the BM-EOS are reported in Table 3. The agreement between the bulk modulus obtained from the elastic constants, $B=12.75 \pm 0.53 \mathrm{GPa}$, and that extracted from the BM-EOS, $B=13.51 \pm 0.50 \mathrm{GPa}$, is very good. The calculated ductility and hardness indices are $D=2.30$ and $H=0.27$. Consequently, crystalline succinic acid is ductile and very weak. ${ }^{265-267} \mathrm{~T}$ he universal anisotropy index ${ }^{268}$ of succinic acid is very large, $A^{\mathrm{U}}=2.81$.

2.3.3 Dependence of the mechanical properties of succinic acid on the orientation of the applied strain. Negative Poisson's ratios. Tridimensional representations of the mechanical properties of succinic acid as a function of the direction of the applied strain are presented in Fig. 11. From Fig. 11D (see also Table 4), it follows that succinic acid displays the NPR phenomenon, the lowest value of the Poisson's ratio being $\nu_{\min }=-0.26$.

2.3.4 Deformation of the crystal structure of succinic acid as a function of the external isotropic pressure. Isotropic NLC. The unit-cell volumes and lattice parameters associated to the optimized crystal structures of succinic acid under the effect of twenty eight different hydrostatic pressures are reported in Table S14 of the ESI $\dagger$ and displayed in Fig. 12. Succinic acid appears to display INLC for four different small pressure regions between 0.0 and $2.5 \mathrm{GPa}$. The first region is observed for applied pressures in the pressure range from 0.58 to
A

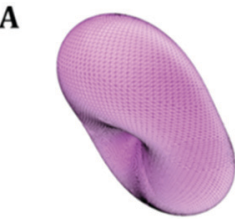

C

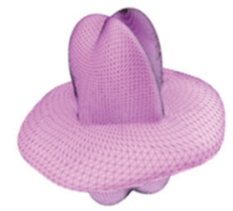

B

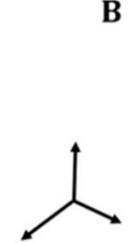

D

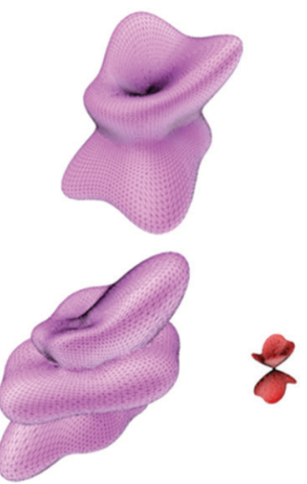

Fig. 11 Elastic properties of succinic acid as a function of the orientation of the applied strain: (A) compressibility; (B) Young modulus; (C) maximum shear modulus; (D) surfaces of minimum (red) and maximum (violet) Poisson's ratio. The maximum values of the compressibility, Young modulus, shear modulus and Poisson's ratio are 43.88 TPa ${ }^{-1}, 31.03 \mathrm{GPa}, 13.09 \mathrm{GPa}$ and 1.07, respectively

$0.82 \mathrm{GPa}$, The a lattice parameter increases from 5.599 to $5.607 \AA$. The compressibility at $P=0.71 \mathrm{GPa}$ become $k_{\mathrm{a}}=-1 / a \cdot(\partial a / \partial P)_{P} \sim-9.1 \mathrm{TPa}^{-1}$. In the second pressure region, from 1.28 to $1.37 \mathrm{GPa}$, the $a$ lattice parameter increases from 5.572 to $5.576 \AA$ (at $P=1.33 \mathrm{GPa}, k_{\mathrm{a}}$ becomes $-12.8 \mathrm{TPa}^{-1}$ ). From 1.93 to $2.06 \mathrm{GPa}$, the $a$ lattice parameter augments from 5.538 to $5.542 \AA\left(k_{\mathrm{a}}=-8.3 \mathrm{TPa}^{-1}\right.$ at $\left.P=2.00 \mathrm{GPa}\right)$. Finally, from 2.17 to $2.22 \mathrm{GPa}$, the $a$ lattice parameter increases from 5.531 to $5.534 \AA$ (at $P=2.18 \mathrm{GPa}, k_{\mathrm{a}} \sim-13.7 \mathrm{TPa}^{-1}$ ). The $b$ lattice parameter also increases slightly within two narrow pressure regions. The increments are also small (0.006 $\AA$ in both cases).

The variation of the unit cell structure of succinic acid under increasing external isotropic pressure is displayed in the Animation S4 of the ESI. $\dagger$ The interpretation of the variations of the lattice parameters under pressure may be achieved in a simple way from Fig. 2D. The $c$ lattice parameter is identical to the distance between two successive minima in a given folded sheet $\left(R_{\mathrm{mm}}\right)$. According to Table S14 (ESI $\dagger$ ), this distance decreases uniformly under pressure and therefore the folds become narrower as pressure increases or, equivalently, the folding angle decreases. The $a$ lattice parameter is equal to the distance between two succinic acid molecules in a given sheet along [100] direction $\left(R_{\mathrm{SS}}^{[100]}\right)$. Thus, the INLC in succinic acid is related to the increase of this intrasheet distance in the four pressure intervals mentioned in the previous paragraph. The $b$ lattice parameter is twice the space between two consecutive folded sheets or interlayer space $\left(R_{\mathrm{IL}}\right)$. According Table S14 (ESI $\dagger$ ), the interlayer space also decreases when the pressure increases except, as was mentioned in the previous paragraph, in two small pressure regions.

2.3.5 Deformation of the crystal structure of succinic acid as a function of the external anisotropic stress. Anisotropic NLC. The unit cell volumes and lattice parameters for the crystal structures of succinic acid optimized under the effect of twenty six different external stresses applied in the direction of minimum Poisson's ratio in the range of pressure from -0.1 to $0.1 \mathrm{GPa}$ are presented in Table S15 (ESI $\dagger$ ) and displayed in Fig. 13. 

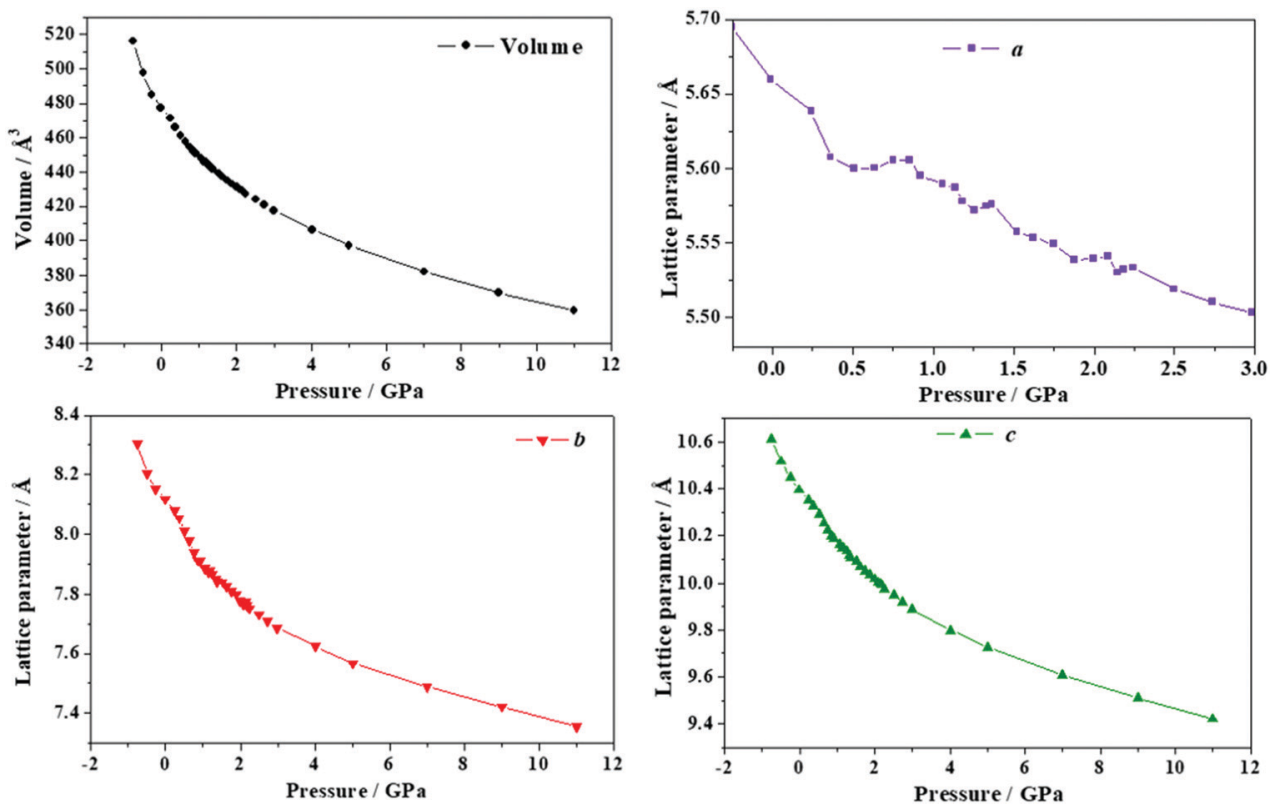

Fig. 12 Unit cell volume and lattice parameters of succinic acid under the effect of different external isotropic pressures.
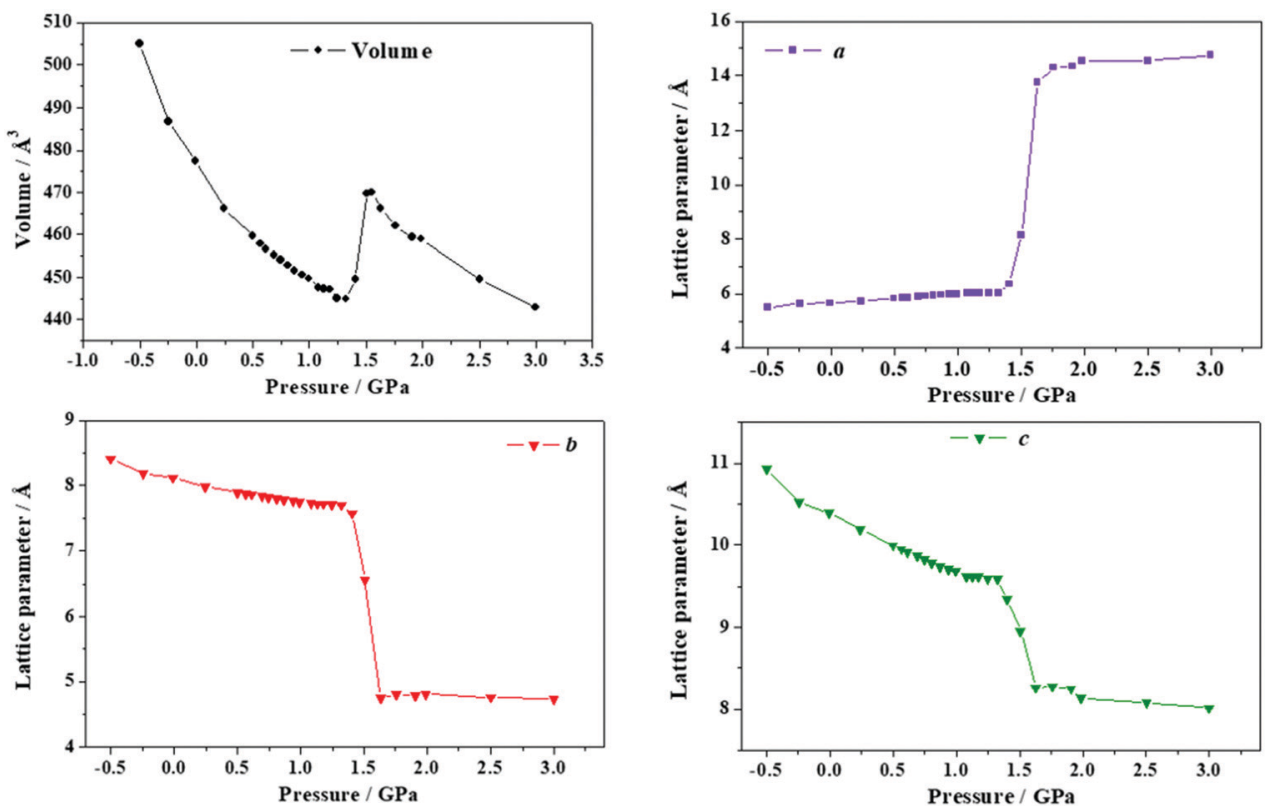

Fig. 13 Unit cell volume and lattice parameters of succinic acid under the effect of different stresses applied in the direction of the minimum Poisson's ratio.

The variation of the crystal structure under increasing pressures is shown in the Animation S5 of the ESI. $\dagger$ Succinic acid displays ANLC for applied external stresses directed along the minimum Poisson's ratio direction in the pressure range from 1.30 to $1.53 \mathrm{GPa}$, due to a sudden pressure induced phase transition occurring at about $P=1.3 \mathrm{GPa}$, which leads to a large increase of the unit cell volume (from 444.73 to $469.83 \AA$ ). The volume compressibility at $P=1.47 \mathrm{GPa}$ is negative and very large in absolute value, $k_{\mathrm{V}}=-1 / V \cdot(\partial V / \partial P)_{P} \sim-505.0 \mathrm{TPa}^{-1}$. The crystal structures before, within and after the phase transition are shown in Fig. 14. The crystal structures are completely different. The new crystal structure at the pressure of $P=1.757 \mathrm{GPa}$ is given as $\mathrm{ESI}^{\dagger}+$ in a file of CIF type. The most important interatomic distances and angles in succinic acid at the pressures $P=1.404$ and $P=1.757 \mathrm{GPa}$ are given in Tables S16 and S17 of the ESI, $\dagger$ respectively. While the internal geometry of succinic acid molecules is almost unchanged, the relative disposition of the molecules is different. The intermolecular hydrogen bond length $\mathrm{H} 1 \cdots \mathrm{O} 2^{\prime}$ increases by $0.02 \AA$ and the $\mathrm{O} 1-\mathrm{H} 1 \cdots \mathrm{O} 2^{\prime}$ angle decreases by nearly 3 degrees. 

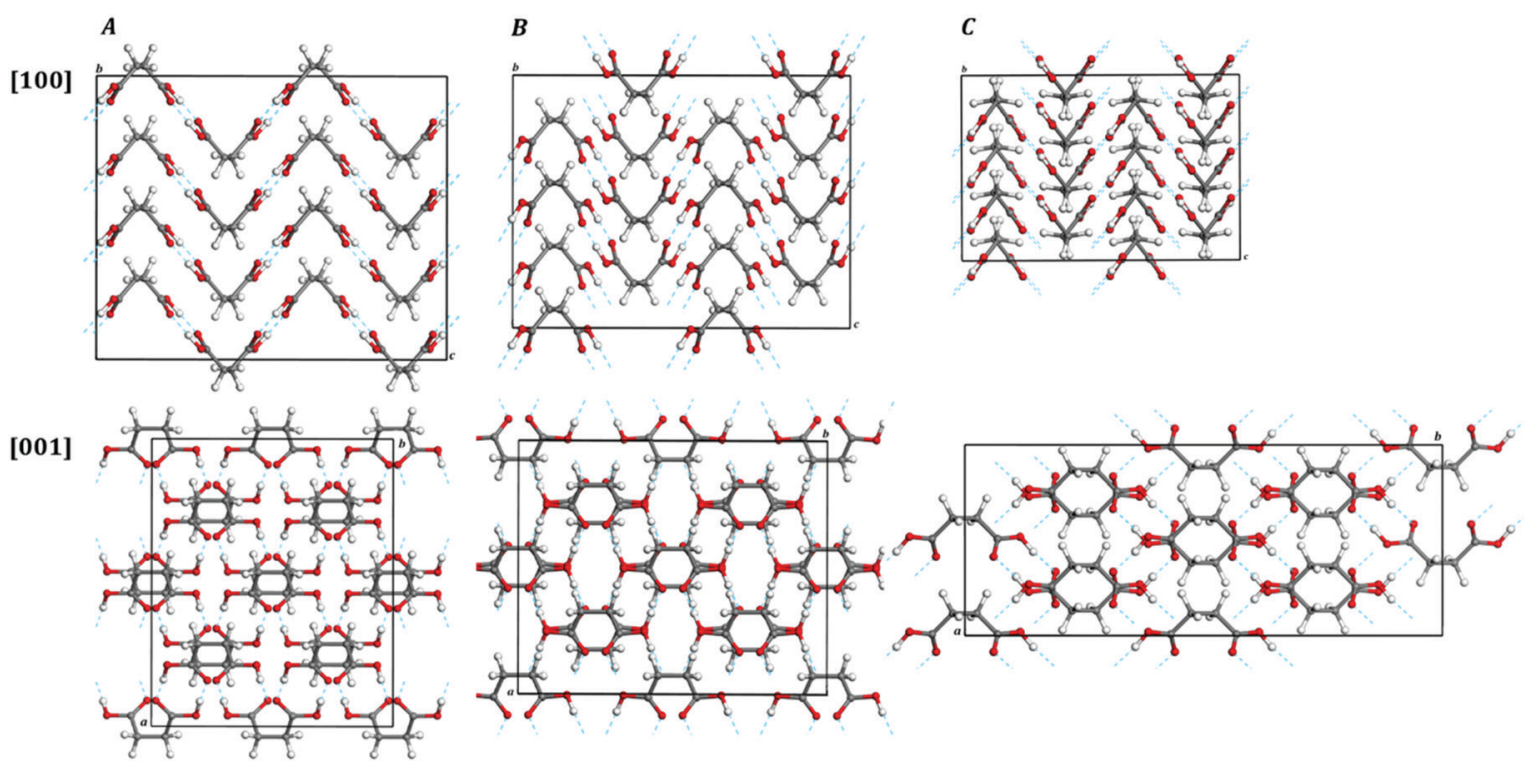

Fig. 14 Computed crystal structures of succinic acid under the effect of pressures directed along the minimum Poisson's ratio: (A) $P=1.321 \mathrm{GPa}$; (B) $P=1.404 \mathrm{GPa}$ and (C) $P=1.757 \mathrm{GPa}$.

\subsection{Anhydrous citric acid}

Citric acid, or 2-hydroxypropane-1,2,3-tricarboxylic acid, is a weak organic acid. ${ }^{318}$ His name is due to the fact that it occurs naturally in citrus fruits. It was isolated for the first time from lemon juice in 1784 by the chemist Carl Wilhelm Scheele. ${ }^{319}$ It can exist either in anhydrous form or as a monohydrate, the last being converted to the first at about $78{ }^{\circ} \mathrm{C}$. Citric acid is present in biologic organisms as the citrate ion and as the mono-hydrogen citrate ion. The citric acid can form diverse citrate salts and may also be esterified at one or more of the carboxylic acid functional groups with different alcohols, to form a variety of mono-, di- and tri-esters. The citrate ion forms chelate complexes with many cations, the alkali metal ones included. ${ }^{318}$

The citric acid is a fundamental intermediate in the tricarboxylic acid cycle ${ }^{279,320}$ occurring in the metabolism of all aerobic organisms. In this cycle, citrate synthase catalyzes the condensation of oxaloacetate with acetyl coenzyme A (CoA) to form citrate. Then, aconitase catalyses the conversion from citrate to aconitic acid. The series of reactions involved in the TCA to release energy through the oxidation of acetyl-CoA derived from carbohydrates, lipids and proteins, produces nearly two-thirds of the energy derived from food. Citrate can also be transported from the mitochondria into the cytoplasm and transform into acetyl-CoA for fatty acid synthesis. Citrate is a modulator of the conversion regulating allosterically the enzyme acetyl-CoA carboxylase. Large concentrations of citrate in the cytoplasm indicate the presence of enough biosynthetic precursor molecules and inhibits phosphofructokinase and glycolysis. ${ }^{279}$ Citrate is an essential component of bones, helping to regulate the size of apatite crystals. ${ }^{321}$ The microbial production of citric acid by several species of fungi as Aspergillus niger from sucrose or glucose is well known from the beginning of nineteenth century and has been exploited widely. ${ }^{318,322}$
However, citric acid is nowadays also produced synthetically from aconitic or isocitrate salts under high pressure conditions using a reverse nonenzymatic TCA cycle reaction. ${ }^{323}$ Citric acid is massively produced and used, for instance, as an acidifying, flavoring, cleaning or chelating agent. ${ }^{318,324}$ It is also used for the development of different materials as biodegradable polymers whose properties including the mechanical ones have been investigated. ${ }^{325-341}$

2.4.1 Crystal structure. The optimized crystal structure of anhydrous citric acid, $\mathrm{COOH}-\mathrm{CH}_{2}-\mathrm{C}(\mathrm{OH})(\mathrm{COOH})-\mathrm{CH}_{2}-\mathrm{COOH}$, is drawn in Fig. 1D and a picture of a $2 \times 2 \times 2$ supercell is shown in Fig. 2D. The computed unit-cell parameters, volume and density of anhydrous citric acid are given in Table 1 . The theoretical results reproduce satisfactorily the experimental data. $^{252-254}$ The computed unit-cell volume is smaller than the experimental volume measured by Rammohan et al. ${ }^{254}$ by $3.2 \%$. The uncorrected PBE functional overestimates strongly the experimental unit-cell volume by nearly $12 \%$ (see Table 1).

Tables S18 and S19 of the ESI $\dagger$ give a comparison of the interatomic distances and angles in the computed and experimental $^{254}$ crystal structures of citric acid. The atom labelling convention employed ion these tables is displayed in Fig. S4 of the ESI. $\dagger$ The differences of the computed $\mathrm{C}-\mathrm{C}$ and $\mathrm{C}-\mathrm{O}$ bond distances with respect to the experimental ones are smaller than $0.01 \AA$, except for the $\mathrm{C}-\mathrm{O}$ double bonds for which the differences are about $0.02 \AA$.

For crystalline citric acid there are six non-equivalent hydrogen bonds (see Tables S18, S19 and Fig. S4 of the ESI $\dagger$ ). The hydrogen bonds $\mathrm{O} 1-\mathrm{H} 5 \cdots \mathrm{O} 2^{\prime}$, O3-H6 $\cdots \mathrm{O}^{\prime}$ and $\mathrm{O} 5-\mathrm{H} 7 \cdots \mathrm{O} 4^{\prime}$ link the oxygen atoms of the hydroxyl fragments of the three carboxylic groups with the oxygen atom in the $\mathrm{C}=\mathrm{O}$ bonds of carboxylic groups in three different citric acid molecules. The remaining three hydrogen bonds are $\mathrm{O} 7-\mathrm{H} 8 \cdots \mathrm{O} 2, \mathrm{O} 7-\mathrm{H} 8 \cdots \mathrm{O} 1^{\prime}$ and $\mathrm{O} 7-\mathrm{H} 8 \cdots \mathrm{O} 6$ and link the oxygen atom in the $\mathrm{OH}$ alcoholic 


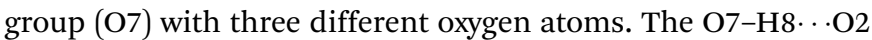
and $\mathrm{O} 7-\mathrm{H} 8 \cdots \mathrm{O} 6$ hydrogen bonds are intramolecular, the acceptor $\mathrm{O} 2$ and $\mathrm{O} 6$ oxygen atoms belonging to the $\mathrm{C}=\mathrm{O}$ bond of carboxylic groups in the same citric acid molecule. The $\mathrm{O} 7-\mathrm{H} 8 \cdot \mathrm{O}^{\prime}$ ' hydrogen bond is intermolecular and the acceptor oxygen atom belongs to the $\mathrm{OH}$ fragment of a carboxylic group of a different molecule.

Fig. 3D shows that the agreement between the X-ray powder diffraction patterns of citric acid obtained from the optimized and experimental ${ }^{254}$ structures is very good.

2.4.2 Elasticity tensor, mechanical stability and mechanical properties. The matrix elements of the elasticity matrix of citric acid computed at the optimized crystal structure are given in Table 2. Since the space symmetry of its crystal structure is monoclinic (Table S1 of the ESI $\dagger$ ), there are only 13 nonvanishing independent matrix elements in its stiffness matrix. $^{257,258}$ After diagonalizing the elasticity matrix, all the eigenvalues were found to be positive, and, therefore, this acid is mechanically stable. ${ }^{259,260}$ The elastic properties of polycrystalline citric acid determined in terms of the matrix elements of the elasticity tensor employing the Reuss ${ }^{262}$ approximation are provided in Table 3 together with the bulk modulus and its first two pressure derivatives obtained from the BM-EOS. The value of the bulk modulus obtained from the elastic constants is, $B=13.82 \pm 0.41 \mathrm{GPa}$, which agrees well with that extracted from the BM-EOS, $B=13.46 \pm 0.36 \mathrm{GPa}$. From the data given in Table 3, it follows that citric acid is a brittle and weak material ${ }^{265-267}$ because the ductility and hardness indices are $D=1.71$ and $H=0.64$, respectively. The calculated value of the universal anisotropy index ${ }^{268}$ is rather large, $A^{\mathrm{U}}=1.81$.

2.4.3 Dependence of the mechanical properties of anhydrous citric acid on the orientation of the applied strain. Negative Poisson's ratios. Images of the spatial representations of the bulk, Young and shear moduli and Poisson's ratio of anhydrous citric acid as a function of orientation of the applied strain are plotted in Fig. 15. The surface of minimum Poison's ratio, showed in Fig. 15D, reveals that citric acid exhibits the
A
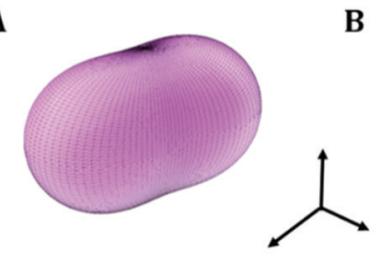

C

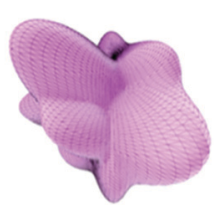

B

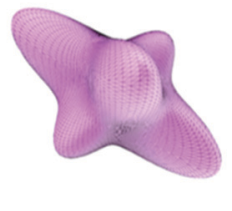

D

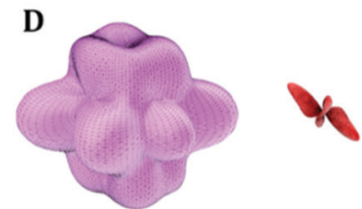

Fig. 15 Elastic properties of citric acid as a function of the orientation of the applied strain: (A) compressibility; (B) Young modulus; (C) maximum shear modulus; (D) surfaces of minimum (red) and maximum (violet) Poisson's ratio. The maximum values of the compressibility, Young modulus, shear modulus and Poisson's ratio are $34.17 \mathrm{TPa}^{-1}, 40.90 \mathrm{GPa}$, 21.66 GPa and 0.57, respectively.
NPR phenomenon, the value of the smallest Poisson's being -0.23 (Table 4).

2.4.4 Deformation of the crystal structure of anhydrous citric acid as a function of the external isotropic pressure. Isotropic NLC. Table S20 of the ESI $\dagger$ contains the unit-cell volumes and parameters of the optimized crystal structures of anhydrous citric acid under eighteen different hydrostatic pressures in the range from -1.0 to $2.5 \mathrm{GPa}$. The results are also displayed in Fig. 16. Citric acid does not display INLC for applied positive pressures although the behavior of the unit cell volume and lattice parameters is very irregular between -0.25 and $0.25 \mathrm{GPa}$. However, a small increase of the $a$ lattice parameter is observed for negative pressures between -0.54 to $-0.34 \mathrm{GPa}$. The compressibility in this pressure interval is negative but its absolute value is relatively small. The minimum compressibility is found at $P=-0.46 \mathrm{GPa}, k_{\mathrm{a}}=-1 / a \cdot(\partial a / \partial P)_{P} \sim$ $-15.5 \mathrm{TPa}^{-1}$. The occurrence of negative mechanical properties under tension (negative pressure) has been observed in several previous works. The presence of negative Poisson's ratios for two-dimensional systems at negative pressures was found by Boal et al. $^{342}$ in 1993, by Wojciechowski ${ }^{343}$ in 1995 for any dimensionality and rediscovered by Rechtsman et al. ${ }^{344}$ in 2008. Likewise, it has been recently found that oxalic acid dihydrate ${ }^{72}$ displays the phenomenon of negative area compressibility under tension and that silver oxalate exhibits very large negative linear compressibilities for negative pressures. ${ }^{76}$ The variation of the unit cell structure of citric acid under increasing external isotropic pressures is shown in the Animation S6 of the ESI. $\dagger$

2.4.5 Deformation of the crystal structure of anhydrous citric acid as a function of external anisotropic stresses. Anisotropic NLC. The unit cell volumes and lattice parameters obtained for anhydrous citric acid under the effect of twelve different external stresses applied in the direction of minimum Poisson's ratio in the range of pressure from -0.27 to $0.80 \mathrm{GPa}$ are reported in Table S21 of the ESI $\dagger$ and displayed in Fig. 17. Citric acid displays ANLC for applied external stresses directed along the minimum Poisson's ratio direction in the pressure range from 0.10 to $0.16 \mathrm{GPa}$. The unit cell volume increases from 740.25 to $750.21 \AA$ and the volume compressibility at $P=0.13 \mathrm{GPa}$ is negative and very large in absolute value, $k_{\mathrm{V}}=-1 / V \cdot(\partial V / \partial P)_{P} \sim-405.1 \mathrm{TPa}^{-1}$. The crystal structures before and after the phase transition are shown in Fig. 18. As can be observed, one of the intramolecular hydrogen bonds (O7-H8 - O 2) disappears under the effect of pressure. The new crystal structure at the pressure of $P=0.168 \mathrm{GPa}$ is given as ESI $\dagger$ in a file of CIF type.

The interatomic distances and angles at $P=0.1163 \mathrm{GPa}$ and $P=0.1613 \mathrm{GPa}$ are given in Tables S22 and S23 of the ESI. $\dagger$ These tables show that the citric acid molecule geometry remains almost the same. The intramolecular hydrogen bond lengths $\mathrm{O} 7 \cdots \mathrm{O} 2$ and $\mathrm{H} 8 \cdots \mathrm{O} 2$ in the hydrogen bond O7-H8 $\cdots$ O 2 increase by 0.08 and $0.12 \AA$, respectively, and the $\mathrm{O} 7-\mathrm{H} 8 \cdots \mathrm{O} 2$ angle decreases by nearly $2.3 \mathrm{deg}$. Thus, the intramolecular hydrogen bond become larger as the pressure increases and finally disappears. However, as in the case of the lactic acid, the increase of the hydrogen bond lengths is very 

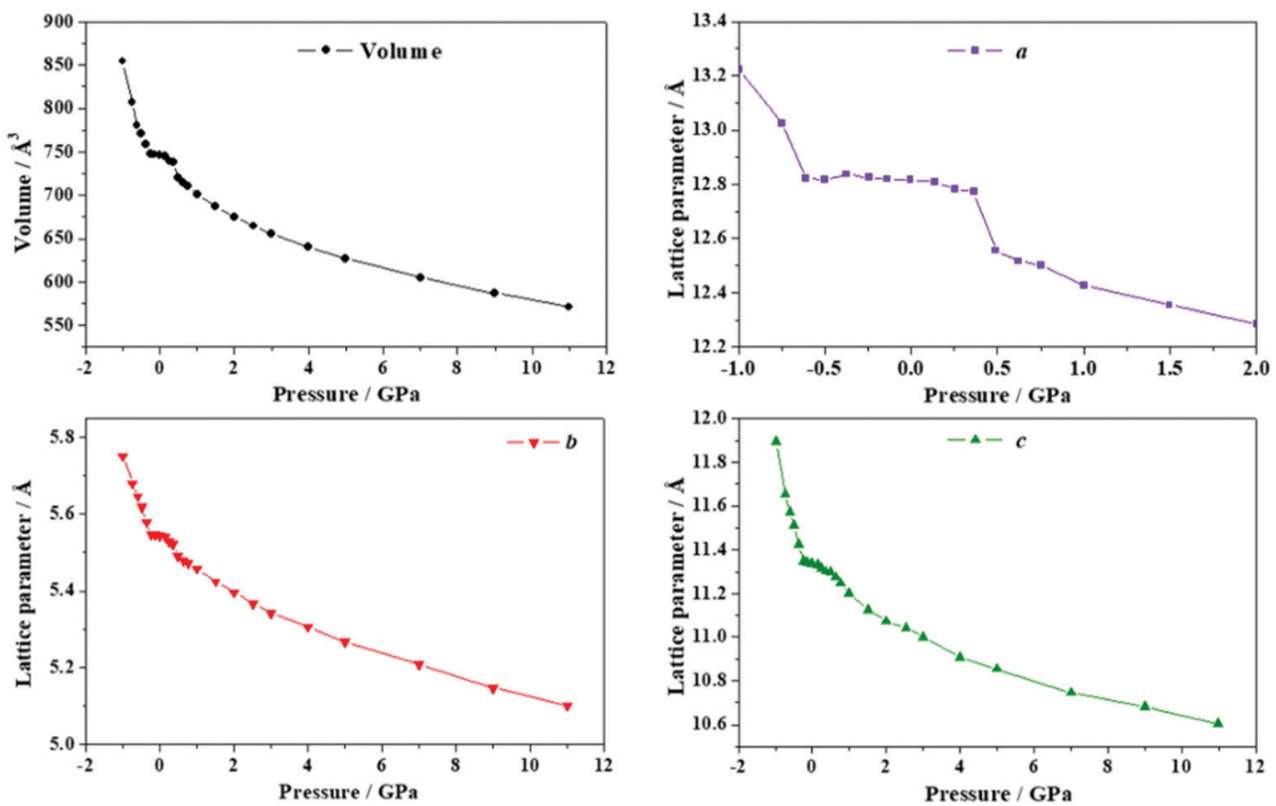

Fig. 16 Unit cell volume and lattice parameters of anhydrous citric acid under the effect of different external isotropic pressures.
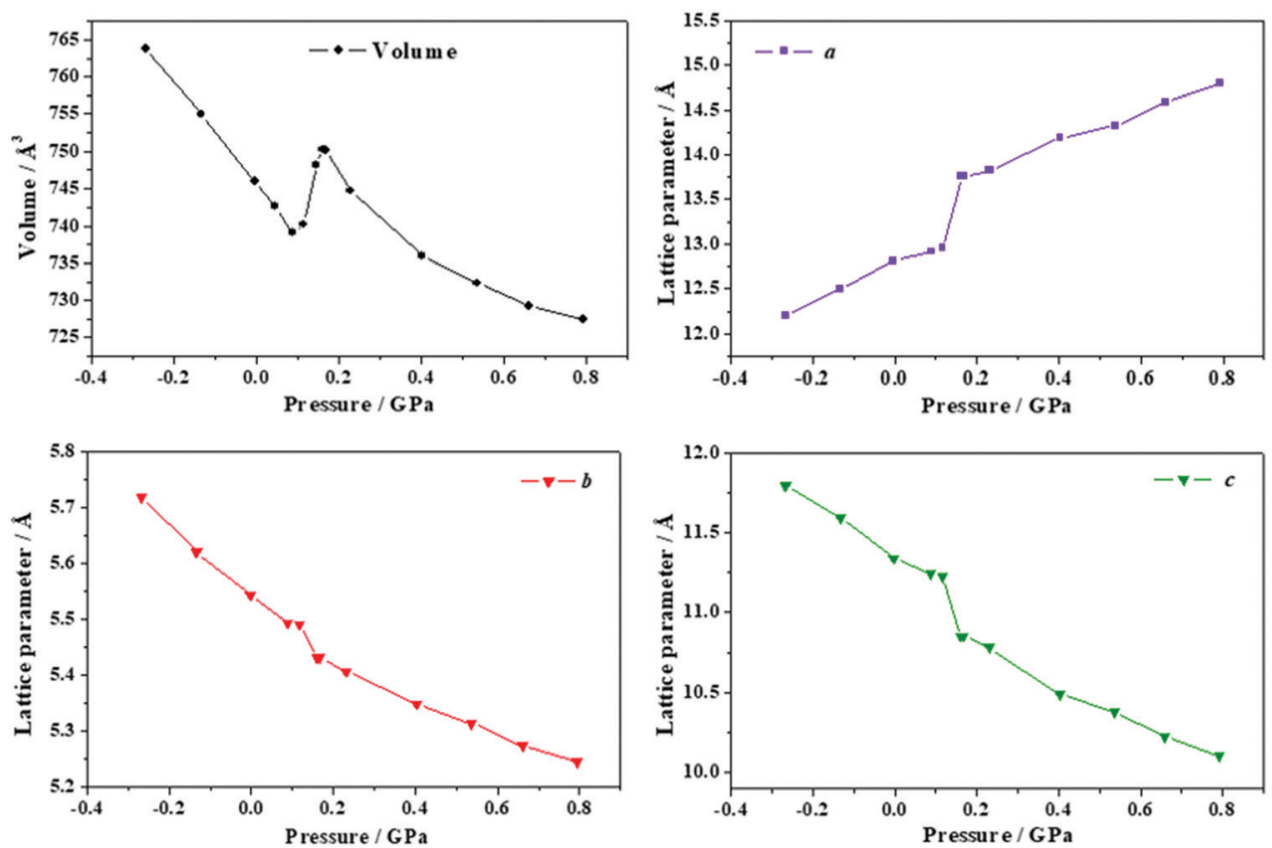

Fig. 17 Unit cell volume and lattice parameters of anhydrous citric acid under the effect of different stresses applied in the direction of the minimum Poisson's ratio.

small in comparison with the variation of the lattice parameters and cannot be considered the reason for the large volume increase. Particularly, the $a$ lattice parameter increases by $0.80 \AA$ in passing from 0.10 to $0.16 \mathrm{GPa}$. The $a$ lattice is identical to the distance between the two citric acid molecules along the [100] crystallographic direction and, therefore, the increase of the unit cell volume under pressure results from the enlargement of the non-bonding distances along $[010]$ which are not compensated by the decrease of the $b$ and $c$ lattice parameters.
Animation S7 of the ESI $\dagger$ displays the variation of the unit cell structure of citric acid under increasing external stresses applied in the direction of minimum Poisson's ratio.

\subsection{Citric acid monohydrate}

2.5.1 Crystal structure. The optimized crystal structure of citric acid monohydrate, $\mathrm{C}_{6} \mathrm{H}_{8} \mathrm{O}_{7} \cdot \mathrm{H}_{2} \mathrm{O}$, is displayed in Fig. $1 \mathrm{E}$ and a picture of a $2 \times 2 \times 2$ supercell is shown in Fig. 2E. The computed unit-cell parameters, volume and density are 
$\boldsymbol{A}$

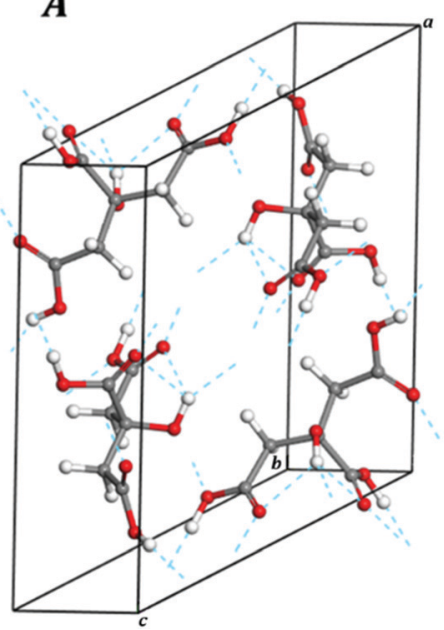

$\boldsymbol{B}$

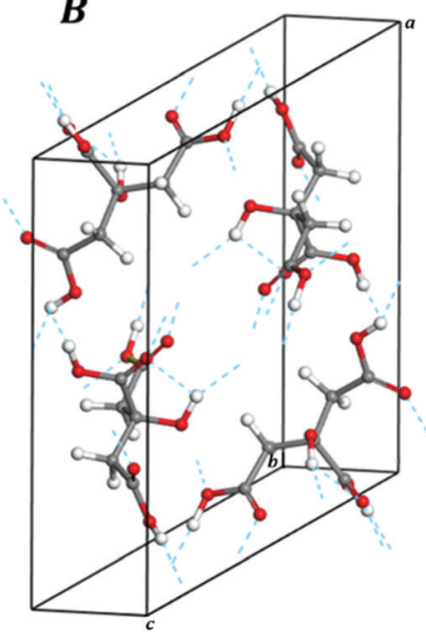

Fig. 18 Computed crystal structures of anhydrous citric acid under the effect of external stresses applied along the direction of minimum Poisson's ratio: (A) $P=0.089 \mathrm{GPa}$ and (B) $P=0.168 \mathrm{GPa}$.

provided in Table 1 compared with the corresponding experimental information. ${ }^{255,256}$ The computed unit-cell volume is smaller than the experimental one reported by King et al. ${ }^{256}$ by $2.4 \%$. For comparison, the uncorrected PBE functional overestimates the experimental unit-cell volume by $9.2 \%$ (see Table 1). The calculated and experimental ${ }^{256}$ interatomic distances and angles are given in Tables S24 and S25 of the ESI. $\dagger$ The atom labelling convention utilized for citric acid monohydrate is shown in Fig. S5 of the ESI. $\dagger$ The differences between the computed $\mathrm{C}-\mathrm{C}$ and $\mathrm{C}-\mathrm{O}$ bond distances and the experimental ones are smaller than $0.01 \AA$, except for the $\mathrm{C}-\mathrm{O}$ double bonds for which the variations are about $0.02 \AA$.

There are seven non-equivalent hydrogen bonds (see Tables S24 and S25 and Fig. S5 of the ESI $\dagger$ ) in the crystal structure of citric acid monohydrate. The hydrogen bonds

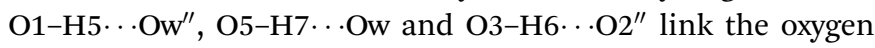
atoms of the hydroxyl fragments of the three carboxylic groups with the oxygen atoms of two water molecules ( $\mathrm{Ow}^{\prime \prime}$ and $\left.\mathrm{Ow}\right)$ and the oxygen atom from a $\mathrm{C}=\mathrm{O}$ bond of a carboxylic group in another citric acid molecule $\left(\mathrm{O}^{\prime \prime}\right)$. Two additional hydrogen bonds $\left(\mathrm{O} 7-\mathrm{H} 8 \cdots \mathrm{O} 2^{\prime}\right.$ and $\left.\mathrm{O} 7-\mathrm{H} 8 \cdots \mathrm{O} 6\right)$ link the oxygen atom in the $\mathrm{OH}$ alcoholic functional group $(\mathrm{O} 7)$ with two oxygen atoms from the $\mathrm{C}=\mathrm{O}$ bonds of two carboxylic groups, the first from a different citric acid molecule $\left(\mathrm{O}^{\prime}\right)$ and the second from the same one (O6). Thus, the second of these hydrogen bonds is intramolecular. The last two hydrogen bonds (Ow-Hw1 …7 and $\mathrm{Ow}-\mathrm{Hw} 2 \cdots \mathrm{O} 4)$ originate in the oxygen atom of a water molecule $(\mathrm{Ow})$ and end in the oxygen atom of the alcoholic group $(\mathrm{O} 7)$ and in the oxygen atom of the $\mathrm{C}=\mathrm{O}$ bond of a carboxylic group (O4).

The X-ray powder diffraction patterns of citric acid monohydrate obtained from the optimized and experimental ${ }^{256}$ structures are highly consistent (see Fig. 3E).

2.5.2 Elasticity tensor, mechanical stability and mechanical properties. The computed elasticity matrix of citric acid monohydrate has only nine non vanishing independent elements due to the space symmetry of its crystal structure ${ }^{257,258}$ (orthorhombic, see Table S1 of the ESI $\dagger$ ) and is given in Table 2. The numerical diagonalization of the elasticity matrix leads to a set of eigenvalues which are all positive. Thus, citric acid monohydrate is mechanically stable. ${ }^{259,260}$ The mechanical properties of polycrystalline citric acid monohydrate obtained from the elements of the elasticity matrix using the Reuss ${ }^{262}$ scheme are reported in Table 3 together with the bulk modulus and its first two pressure derivatives obtained from the BM-EOS. The value of the bulk modulus obtained from the elastic constants and from the BM-EOS are, $14.56 \pm 0.19 \mathrm{GPa}$ and $15.66 \pm 0.24 \mathrm{GPa}$, respectively. The ductility and hardness indices of citric acid monohydrate are $D=1.81$ and $H=0.37$. Therefore, it is a ductile and weak material. ${ }^{265-267}$ The calculated value of the universal anisotropy index ${ }^{268} A^{\mathrm{U}}=1.59$, is quite large but smaller than that of anhydrous citric acid.
A

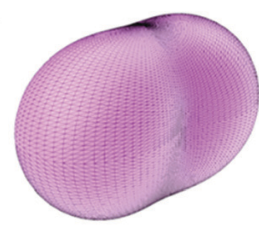

C

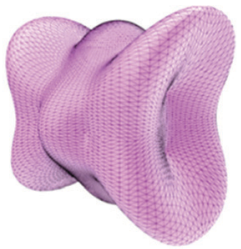

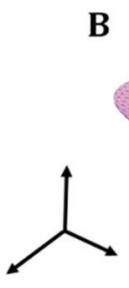

B

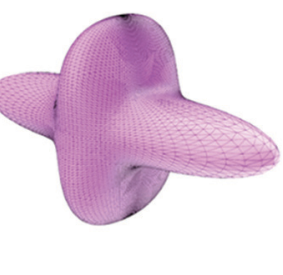

D

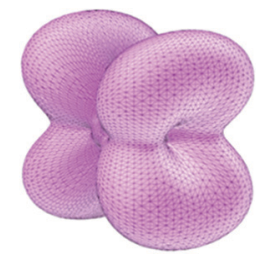

Fig. 19 Elastic properties of citric acid monohydrate as a function of the orientation of the applied strain: (A) compressibility; (B) Young modulus; (C) maximum shear modulus; (D) surfaces of minimum (red) and maximum (violet) Poisson's ratio. The maximum values of the compressibility, Young modulus, shear modulus and Poisson's ratio are $34.09 \mathrm{TPa}^{-1}, 50.03 \mathrm{GPa}$, $17.18 \mathrm{GPa}$ and 0.65 , respectively. In this case the surface of minimum Poisson's ratio is not shown. All the values of $\nu$ on this surface are positive. 


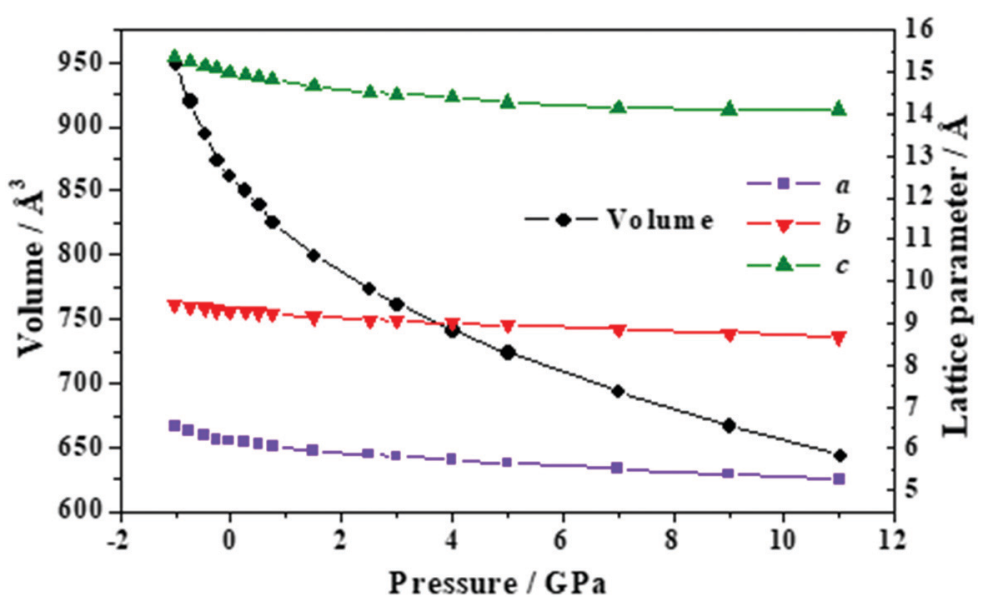

Fig. 20 Unit cell volume and lattice parameters of citric acid monohydrate under the effect of different external isotropic pressures.

2.5.3 Dependence of the mechanical properties of citric acid monohydrate on the orientation of the applied strain. Fig. 19 displays the 3D representations of the bulk, Young and shear moduli and Poisson's ratio of citric acid monohydrate as a function of orientation of the applied strain. As can be seen, its mechanical properties have a large directional dependence, as expected from the value obtained of the universal anisotropy index. However, unlike all the other materials considered in this work, citric acid monohydrate does not exhibit negative values of the Poisson's ratio. The surface of minimum Poisson's ratio is positive for all possible orientations. The minimum value of the Poisson's ratio is close to zero, +0.01 (Table 4).

2.5.4 Deformation of the crystal structure of citric acid monohydrate as a function of the external isotropic pressures and anisotropic stresses. The crystal structure of citric acid monohydrate was optimized under the effect of a large series of isotropic pressures and anisotropic stresses. However, no mechanical anomalies in the computed data were found. For example, Fig. 20 shows that the unit-cell volume and lattice parameters of citric acid monohydrate (the numerical values are given in Table S26, ESI $\dagger$ ) decrease invariably under the effect of increasing isotropic pressures within the range of pressure going from -1.0 to $11.0 \mathrm{GPa}$.

\section{Conclusions}

The crystal structures and mechanical properties of the L-(+)-lactic, maleic, succinic and anhydrous citric acid and citric acid monohydrated were determined by means of first principles solid-state methods based in density functional theory using large plane wave basis sets and pseudopotential functions. The computed crystal structures were in very good agreement with their experimental counterparts. The calculations were carried out using the PBE energy-density functional supplemented with dispersion corrections to improve the description of the dense network of hydrogen bonds present in the unit cell of these materials. The experimental unit cell volumes of these materials were underestimated by $2.4,5.3,3.9$,
3.2 and $2.4 \%$, respectively. These results may be compared with those obtained using the uncorrected PBE functional which overestimates the experimental data enormously by 15.7, 22.5, $23.3,11.8,9.2 \%$, respectively, due to the inaccurate description of dispersion interactions. The remaining differences with respect to experiment may be attributed mainly to the fact that the experimental structures were determined at room temperature and the first principles results correspond to zero temperature. Low temperature experimental studies of the crystal structures of these materials could reduce to a large extent the differences. For example, very large thermal expansion effects in the crystal structures of related organic materials as oxalic acid have been found. ${ }^{71,345}$ The good agreement of the $\mathrm{X}$-ray powder diffraction patterns of these materials determined from the optimized and experimental crystal structures provided additional support for the computed structures.

The set of organic materials considered includes one mono-, two di- and one tri-carboxylic acids in order to provide diversity and generality to the study of the mechanical behavior of organic acids, thus extending the previous studies of the cyclic oxocarbon acids ${ }^{70,73}$ and oxalic acid. ${ }^{71,72}$ These organic acids have extremely important biological functions and are widely utilized in synthetic organic chemistry, crystal and tissue engineering, polymer technology and in the food and pharmaceutical industries. In the majority of these fields, the research on the effects of pressure is growing very fast. However, the lack of very complete studies for a series of prototypical important systems to be used as models is a significant gap in this research. In fact, the mechanical properties and stability and the behavior of these materials under pressure is almost completely unknown. The elastic tensors of these materials were determined using the finite deformation method and the mechanical stability of their structures was studied. A set of relevant elastic properties was derived in terms of the computed elastic tensors. This set includes the bulk, shear and Young moduli, the Poisson's ratio, the ductility, hardness and anisotropy indices and the bulk modulus pressure derivatives. In the solid state, these organic acids are shown to be stable, weak and very anisotropic materials and, with the exception of 
citric acid monohydrate, all of them exhibit the negative Poisson's ratio (NPR) phenomenon.

Crystalline materials possessing a normal mechanical behavior commonly show decreasing unit cell volumes and lattice parameters under compression and do not present mechanical anomalies. On the other hand, the deltic, squaric, croconic and $\alpha$ - and $\beta$-oxalic acids and oxalic acid dihydrate exhibit a rich set of mechanical anomalies, including the NPR and NLC phenomena, as well as pressure induced phase transitions for relatively small external pressures. ${ }^{70-74}$ This study has demonstrated that the lactic, maleic, succinic and anhydrous citric acids also show negative mechanical phenomena and pressure induced phase transitions. Therefore, it seems that the extremely anomalous mechanical behavior is the norm rather than the exception for the organic acids in the solid state. The mechanical properties of materials belonging to other important organic compound types as alcohols, esters, aldehydes, ketones, amines and amides could be also very interesting and should be investigated in detail.

The NLC effects in these materials are primarily associated to the onset of pressure induced phase transitions or sudden structural rearrangements. L(+)-Lactic acid shows a large NLC effect under isotropic pressures due to the fact that it undergoes a pressure induced phase transition occurring at a pressure of $P \sim 1.0 \mathrm{GPa}$. The maleic acid exhibits NLC under isotropic pressures of the order of $P \sim 1.1 \mathrm{GPa}$ but no phase transition is observed. Under anisotropic stresses directed along the minimum Poisson's ratio direction, maleic acid also shows a large NLC effect at small external pressures of $P \sim 0.1 \mathrm{GPa}$. Succinic acid displays small NLC effects under isotropic pressures but large negative compressibilities under anisotropic stresses directed along minimum NPR direction because it undergoes a pressure induced phase transition near $P \sim 1.5 \mathrm{GPa}$. Finally, the citric acid shows small NLC values for negative isotropic pressures near $-0.5 \mathrm{GPa}$ and a large NLC effect under low anisotropic stresses $(P \sim 0.1 \mathrm{GPa})$ which is accompanied by the breaking of one of the intramolecular hydrogen bonds present in this material at zero pressure.

\section{Conflicts of interest}

There are no conflicts to declare.

\section{Acknowledgements}

The supercomputer time provided by the CTI-CSIC center is greatly acknowledged. The author wants to thank the help of Dr V. Timón and A. M. Fernández and for their help and for revising the manuscript.

\section{Notes and references}

1 (a) R. M. Hazen, Am. Mineral., 1977, 62, 286-295; (b) R. Jeanloz and R. M. Hazen, Nature, 1983, 304, 620-623; (c) R. M. Hazen and L. W. Finger, J. Appl. Phys., 1984, 56, 1838-1840; (d) L. W. Finger, R. M. Hazen and A. M. Hofmeister, Phys.
Chem. Miner., 1986, 13, 215-220; (e) R. J. Angel, R. M. Hazen, T. C. McCormick, C. T. Prewitt and J. R. Smyth, Phys. Chem. Miner., 1988, 15, 313-318; $(f)$ N. Ross and R. M. Hazen, Phys. Chem. Miner., 1990, 17, 228-237; (g) R. Jeanloz and R. M. Hazen, Science, 1993, 261, 923-924; (h) R. M. Hazen, R. T. Downs and L. W. Finger, Science, 1996, 272, 1769-1771; (i) R. M. Hazen and A. Navrotsky, Am. Mineral., 1996, 81, 1021-1035; (j) H. Yang, R. M. Hazen, C. T. Prewitt, L. W. Finger, R. Lu and R. J. Hemley, Am. Mineral., 1998, 83, 288-299.

2 R. M. Hazen, R. T. Downs, A. P. Jones and L. Kah, Carbon Mineralogy and Crystal Chemistry, Rev. Mineral. Geochem., 2013, 75, 7-46.

3 L. G. Liu, Phys. Earth Planet. Int., 1986, 42, 255-262.

4 (a) K. J. Kingma, R. E. Cohen, R. J. Hemley and H. K. Mao, Nature, 1995, 374, 243-245; (b) T. S. Duffy, C.-S. Zha, R. T. Downs, H. K. Mao and R. J. Hemley, Nature, 1995, 378, 170-173; (c) H.-R. Wenk, S. Matthies, R. J. Hemley, H. K. Mao and J. Shu, Nature, 2000, 405, 1044-1047.

5 (a) L. Stixrude, R. E. Cohen and D. J. Singh, Phys. Rev. B: Condens. Matter Mater. Phys., 1994, 50, 6442-6445; (b) R. M. Wentzcovitch and L. Stixrude, Am. Mineral., 1997, 82, 663-671; (c) B. B. Karki and L. Stixrude, J. Geophys. Res., 1999, 104, 13025-13033; (d) L. Stixrude and C. Lithgow-Bertelloni, J. Geophys. Res., 2005, 110, B03204; (e) L. Stixrude, C. Lithgow-Bertelloni, B. Kiefer and P. Fumagalli, Phys. Rev. B: Condens. Matter Mater. Phys., 2007, 75, 024108; (f) P. Fumagalli and L. Stixrude, Earth Plan. Sci. Lett., 2007, 260, 212-226; (g) M. Mookherjee and L. Stixrude, Earth Plan. Sci. Lett., 2009, 279, 11-19; (h) S. Stackhouse, L. Stixrude and B. B. Karki, Earth Plan. Sci. Lett., 2010, 289, 449-456; (i) L. Stixrude, Phys. Rev. Lett., 2012, 108, 055505; (j) N. de Koker, B. B. Karki and L. Stixrude, Earth Plan. Sci. Lett., 2013, 361, 58-63.

6 B. Wunder, R. Wirth and M. Gottschalk, Eur. J. Mineral., 2001, 13, 485-495.

7 M. Osako, A. Yoneda and E. Ito, Phys. Earth Planet. Int., 2010, 183, 229-233.

8 (a) L. Bezacier, B. Reynard, J. D. Bass, J. Wang and D. Mainprice, Tectonophysics, 2010, 494, 201-210; (b) M. Mookherjee and L. Bezacier, Phys. Earth Planet. Int., 2012, 208-209, 50-58.

9 S. Schwartz, S. Guillot, B. Reynard, R. Lafay, B. Debret, C. Nicollet, P. Lanari and A. Line Auzende, Lithos, 2013, 178, 197-210.

10 M. O. Schrenk, W. J. Brazelton and S. Q. Lang, Rev. Mineral. Geochem., 2013, 75, 575-606.

11 F. Deschamps, M. Godard, S. Guillot and K. Hattori, Lithos, 2013, 178, 96-127.

12 B. Li and R. C. Liebermann, Phys. Earth Planet. Int., 2014, 233, 135-153.

13 T. Pippinger, R. Miletich, H. Effenberger, G. Hofer, P. Lotti and M. Merlini, Phys. Chem. Miner., 2014, 41, 737-755.

14 J. A. Padrón-Navarta, A. Tommasi, C. J. Garrido and D. Mainprice, Contrib. Mineral. Petrol., 2015, 169, 35.

15 (a) J. F. Kenney, V. G. Kutcherov, N. A. Bendeliani and V. A. Alekseev, Proc. Natl. Acad. Sci. U. S. A., 2002, 99, 
10976-10981; (b) V. G. Kutcherov, N. A. Bendiliani, V. A. Alekseev and J. F. Kenney, Dokl. Phys. Chem., 2003, 387, 328-330; (c) V. G. Kutcherov, Abiogenic Deep Origin of Hydrocarbons and Oil and Gas Deposits Formation, InTechOpen, London, 2013, DOI: 10.5772/51549.

16 T. Al Darouich, F. Behar and C. Largeau, Org. Geochem., 2006, 37, 1155-1169.

17 Y. A. Dyadin., E. G. Larionov, E. Y. Aladko, A. Y. Manakov, F. V. Zhurko., T. V. Mikina., V. Yu. Komarov and E. V. Grachev, J. Struct. Chem., 1999, 40, 790-795.

18 H. Shimizu, T. Kumazaki, T. Kume and S. Sasaki, J. Phys. Chem. B, 2002, 106, 30-33.

19 W. F. Kuhs, in High-Pressure Crystallography, ed. A. Katrusiak and P. F. McMillan, Kluwer Academic Publishers, Dordrecht, 2004, pp. 475-494.

20 (a) A. Pommier, T. L. Grove and B. Charlier, Earth Plan. Sci. Lett., 2012, 333-334, 272-281; (b) B. Charlier, T. L. Grove and M. T. Zuber, Earth Plan. Sci. Lett., 2013, 363, 50-56.

21 (a) K. Nishida, Y. Kono, H. Terasaki, S. Takahashi, M. Ishii, Y. Shimoyama, Y. Higo, K. Funakoshi, T. Irifune and E. Ohtani, Earth Plan. Sci. Lett., 2013, 362, 182-186; (b) K. Nishida, A. Suzuki, H. Terasaki, Y. Shibazaki, Y. Higo, S. Kuwabara, Y. Shimoyama, M. Sakurai, M. Ushioda, E. Takahashi, T. Kikegawa, D. Wakabayashi and N. Funamori, Phys. Earth Planet. Inter., 2016, 257, 230-239.

22 N. Tsujino, Y. Nishihara, Y. Nakajima, E. Takahashi, K. Funakoshi and Y. Higo, Earth Plan. Sci. Lett., 2013, 375, 244-253.

23 N. L. Chabot, E. A. Wollack, R. L. Klima and M. E. Minitti, Earth Plan. Sci. Lett., 2014, 390, 199-208.

24 Z. Jing, Y. Wang, Y. Konoc, T. Yu, T. Sakamaki, C. Park, M. Rivers, S. R. Sutton and G. Shen, Earth Plan. Sci. Lett., 2014, 396, 78-87.

25 M. Laneuville, M. A. Wieczorek, D. Breuer, J. Aubert, G. Morard and T. Rückriemen, Earth Plan. Sci. Lett., 2014, 400, 251-260.

26 J. A. Cartwright, U. Ott, S. Herrmann and C. B. Agee, Earth Plan. Sci. Lett., 2014, 400, 77-87.

27 L. J. Conway and A. Hermann, Geoscience, 2019, 9, 227.

28 (a) A. R. Oganov, R. J. Hemley, R. M. Hazen and A. P. Jones, Rev. Mineral. Geochem., 2013, 75, 47-77; (b) G. Saleh and A. Oganov, Sci. Rep., 2016, 6, 32486; (c) A. S. Naumova, S. V. Lepeshkin and A. R. Oganov, J. Phys. Chem. C, 2019, 123, 20497-20501.

29 H. G. Drickamer and C. W. Frank, Electronic Transitions and the High Pressure Chemistry and Physics of Solids, Chapman and Hall, London, 1973.

30 (a) R. M. Hazen and L. W. Finger, J. Appl. Phys., 1979, 50, 6826-6828; (b) H. K. Mao, R. M. Hazen and P. M. Bell, J. Appl. Phys., 1981, 52, 4572-4574; (c) H. K. Мao, A. P. Jephcoat, R. J. Hemley, L. W. Finger, C. S. Zha, R. M. Hazen and D. E. Cox, Science, 1988, 239, 1131-1134; (d) R. M. Hazen, D. C. Palmer, L. W. Finger, G. D. Stucky, W. T. A. Harrison and T. E. Gier, J. Phys.: Condens. Matter, 1994, 6, 1333.

31 P. P. Edwards and F. Hensel, Nature, 1997, 388, 621-622.
32 (a) V. V. Struzhkin, R. J. Hemley, H. K. Mao and Y. A. Timofeev, Nature, 1997, 390, 382-384; (b) R. J. Hemley and N. W. Ashcroft, Phys. Today, 1998, 51, 26-32; (c) R. J. Hemley, Science, 1998, 281, 1296-1297; (d) R. J. Hemley, G. W. Crabtree and M. V. Buchanan, Phys. Today, 2009, 62, 32-37.

33 (a) K. Shimizu, K. Suhara, M. Ikumo, M. I. Eremets and K. Amaya, Nature, 1998, 393, 767-768; (b) K. Shimizu, T. Kimura, S. Furomoto, K. Takeda, K. Kontani, Y. Onuki and K. Amaya, Nature, 2001, 412, 316-318; (c) K. Shimizu, H. Ishikawa, D. Takao, T. Yagi and K. Amaya, Nature, 2002, 419, 597-599; (d) K. Shimizu, K. Amaya, N. Suzuki and Y. Ōnuki, Phys. B, 2006, 378-380, 632-635.

34 N. W. Ashcroft, Nature, 2002, 419, 569-571.

35 H. Huppertz, Z. Kristallograph, 2004, 219, 330-338.

36 A. Gauzzi, E. Gilioli, F. Licci, A. Prodi, F. Bolzoni, M. Marezio, S. Massidda, F. Bernardini, A. Continenza and P. G. Radaelli, in High-Pressure Crystallography, ed. A. Katrusiak and P. F. McMillan, Kluwer Academic Publishers, Dordrecht, 2004, pp. 429-446.

37 T. Oda, K. Sugimori, H. Nagao, I. Hamada, S. Kagayama, M. Geshim, H. Nagara, K. Kusakabe and N. Suzuki, J. Phys.: Condens. Matter, 2007, 19, 365211.

38 E. Kim, T. Pang, W. Utsumi, V. L. Solozhenko and Y. Zhao, Phys. Rev. B: Condens. Matter Mater. Phys., 2007, 75, 184115.

39 R. S. Kumar, E. Kim, O. Tschauner, A. L. Cornelius, M. P. Sulic and C. M. Jensen, Phys. Rev. B: Condens. Matter Mater. Phys., 2007, 75, 174110.

40 R. P. Dias, C. S. Yoo, V. V. Struzhkin, M. Kim, T. Muramatsu, T. Matsuoka, Y. Ohishi and S. Sinogeikin, Proc. Natl. Acad. Sci. U. S. A., 2013, 110, 11720-11724.

41 M. K. Schmitt, O. Janka, R. Pöttgen and H. Huppertz, Z. Anorg. Allg. Chem., 2017, 643, 1344-1350.

42 R. S. Lakes, Science, 1987, 235, 1038-1040.

43 R. S. Lakes and K. W. Wojciechowski, Phys. Status Solidi B, 2008, 245, 545-551.

44 G. N. Greaves, A. L. Greer, R. S. Lakes and T. Rouxel, Nat. Mater., 2011, 10, 823-837.

45 R. S. Lakes, Annu. Rev. Mater. Res., 2017, 47, 63-81.

46 K. E. Evans, Endeavour, 1991, 15, 170-174.

47 J. N. Grima, R. Jackson, A. Alderson and K. E. Evans, Adv. Mater., 2000, 12, 1912-1918.

48 K. E. Evans and A. Alderson, Adv. Mater., 2000, 12, 617-628.

49 J. N. Grima and R. Caruana-Gauci, Nat. Mater., 2012, 11, 565-566.

50 (a) J. N. Grima, R. Caruana-Gauci, K. W. Wojciechowski and K. E. Evans, Smart Mater. Struct., 2013, 22, 084015; (b) J. N. Grima, R. Caruana-Gauchi, M. R. Dudek, K. W. Wojciechowski and R. Gatt, Smart Mater. Struct., 2013, 22, 084016; (c) R. Gatt, L. Mizzi, J. I. Azzopardi, K. M. Azzopardi, D. Attard, A. Casha, J. Briffa and J. N. Grima, Sci. Rep., 2015, 5, 8395.

51 E. P. Degabriele, D. Attard, J. N. Grima-Cornish, R. Caruana-Gauci, R. Gatt, K. E. Evans and J. N. Grima, Phys. Status Solidi B, 2019, 256, 1800572. 
52 (a) R. H. Baughman, S. Stafström, S. Cui and S. O. Dantas, Science, 1998, 279, 1522; (b) J. A. Kornblatt, E. B. Sirota, H. E. King, R. H. Baughman and C. Cui, Science, 1998, 281, 143.

53 G. M. Spinks, G. G. Wallace, L. S. Fifield, L. R. Dalton, A. Mazzoldi, D. de Rossi, I. Khayrullin and R. H. Baughman, Adv. Mater., 2002, 14, 1728-1732.

54 (a) L. J. Hall, V. R. Coluci, D. S. Galvao, M. E. Koslov, M. Zhang, S. O. Dantas and R. H. Baughman, Science, 2008, 320, 504-507; (b) V. R. Coluci, L. J. Hall, M. E. Kozlov, M. Zhang, S. O. Dantas, D. S. Galvao and R. H. Baughman, Phys. Rev. B: Condens. Matter Mater. Phys., 2008, 78, 115408.

55 A. E. Aliev, J. Oh, M. E. Kozlov, A. A. Kuznetsov, S. Fang, A. F. Fonseca, R. Ovalle, M. D. Lima, M. H. Haque, Y. N. Gartstein, M. Zhang, A. A. Zakhidov and R. H. Baughman, Science, 2009, 323, 1575-1578.

56 R. H. Baughman and A. F. Fonseca, Nat. Mater., 2015, 15, 7-8.

57 (a) E. F. Oliveira, P. A. S. Autreto, C. F. Woellner and D. S. Galvao, Carbon, 2018, 139, 782-788; (b) E. F. Oliveira, P. A. S. Autreto, C. F. Woellner and D. S. Galvao, Comput. Mater. Sci., 2019, 161, 190-198; (c) S. M. Sajadi, C. F. Woellner, P. Ramesh, S. L. Eichmann, Q. Sun, P. J. Boul, C. J. Thaemlitz, M. M. Rahman, R. H. Baughman, D. S. Galvao, C. S. Tiwary and P. M. Ajayan, Small, 2019, 15, 1904747.

58 J. Mu, M. Jung de Andrade, S. Fang, X. Wang, E. Gao, N. Li, S. H. Kim, H. Wang, C. Hou and Q. Zhang, et al., Science, 2019, 365, 150-155.

59 C. N. Weng, K. T. Wang and T. Chen, Adv. Mater. Res., 2008, 33-37, 807-814.

60 H. Abramovitch, M. Burgard, L. Edery-Azulay, K. E. Evans, M. Hoffmeister, W. Miller, F. Scarpa, C. W. Smith and K. F. Tee, Compos. Sci. Technol., 2010, 70, 1072-1079.

61 (a) A. B. Cairns, A. L. Thompson, M. G. Tucker, J. Haines and A. L. Goodwin, J. Am. Chem. Soc., 2012, 134, 4454-4456; (b) A. B. Cairns, J. Catafesta, C. Levelut, J. Rouquette, A. van der Lee, L. Peter, A. L. Thompson, V. Dmitriev, J. Haines and A. L. Goodwin, Nat. Mater., 2013, 12, 212-216; (c) S. A. Hodgson, L. Adamson, S. L. Hunt, M. J. Cliffe, A. B. Cairns, A. L. Thompson, M. G. Tucker, N. P. Funnella and A. L. Goodwin, Chem. Commun., 2014, 50, 5264-5266.

62 A. B. Cairns and A. L. Goodwin, Phys. Chem. Chem. Phys., 2015, 17, 20449-20465.

63 (a) W. Cai and A. Katrusiak, Nat. Commun., 2014, 5, 4337; (b) W. Cai, A. Gładysiak, M. Anioła, V. J. Smith, L. J. Barbour and A. Katrusiak, J. Am. Chem. Soc., 2015, 137, 9296-9301.

64 L. Chen, W. Liu, W. Zhang, C. Hu and S. Fan, Appl. Phys. Lett., 2009, 94, 253111.

65 J. Qu, M. Kadic and M. Wegener, Extreme Mech. Lett., 2018, 22, 165-171.

66 L. Francesconi, A. Baldi, X. Liang, F. Aymerich and M. Taylor, Extreme Mech. Lett., 2019, 26, 1-7.

67 J. Hou, B. Deng, H. Zhu, Y. Lan, Y. Shi, S. De, L. Liu, P. Chakraborty, F. Gao and Q. Peng, Carbon, 2019, 149, 350-354.
68 (a) L. Xie, T. Sun, C. He, H. An, Q. Qin and Q. Peng, Crystals, 2019, 9, 238; (b) W. Wang, C. He, L. Xie and Q. Peng, Nanomaterials, 2019, 9, 487.

69 Y. Wen, E. Gao, Z. Hu, T. Xu, H. Lu, Z. Xu and C. Li, Nat. Commun., 2019, 10, 2446.

70 F. Colmenero, Mater. Res. Express, 2019, 6, 045610.

71 F. Colmenero, Phys. Chem. Chem. Phys., 2019, 21, 2673-2690.

72 F. Colmenero, Mater. Lett., 2019, 245, 25-28.

73 F. Colmenero, Mater. Res. Express, 2019, 6, 069401.

74 F. Colmenero, Appl. Sci., 2019, 8, 2281-2290.

75 F. Colmenero, J. Cobos and V. Timón, J. Phys.: Condens. Matter, 2019, 31, 175701.

76 F. Colmenero, Adv. Theor. Simul., 2019, 2, 19000402.

77 F. Colmenero and V. Timón, J. Mater. Sci., 2020, 55, 218-236.

78 F. Colmenero, J. Sejkora and J. Plášil, Sci. Rep., 2020, 10, 7510 .

79 F. Meersman, I. Daniel, D. H. Bartlett, R. Winter, R. Hazael and P. F. McMillan, Rev. Mineral. Geochem., 2013, 75, 607-648.

80 (a) E. C. Pattee and G. G. Brown, Ind. Eng. Chem., 1934, 26, 511-515; (b) J. D. Lindsay and G. G. Brown, Ind. Eng. Chem., 1935, 27, 817-820.

81 (a) B. H. Sage and W. N. Lacey, Ind. Eng. Chem., 1934, 26, 1103-1106; (b) B. H. Sage, W. N. Lacey and J. G. Schaafsma, Ind. Eng. Chem., 1934, 26, 214-217; (c) B. H. Sage, Ind. Eng. Chem., Anal. Ed., 1933, 5, 261-263; (d) B. H. Sage, Studies of Thermal and Physical Properties of Hydrocarbons, $\mathrm{PhD}$ thesis, California Institute of Technology, Pasadena, California, 1934.

82 K. Suzuki, Y. Taniguchi and Y. Miyosawa, J. Biochem., 1962, 72, 1087-1091.

83 R. K. Williams and C. Shen, Arch. Biochem. Biophys., 1972, 152, 606-612; U. Sondermann, A. Kutoglu and H. Bässler, J. Phys. Chem., 1985, 89, 1735-1741.

84 (a) R. B. Macgregor, R. M. Clegg and T. M. Jovin, Biochemistry, 1985, 24, 5503-5510; (b) R. B. Macgregor, Biochem. Biophys. Res. Commun., 1990, 170, 775-778; (c) R. B. Macgregor, Biochim. Biophys. Acta, 1992, 1129, 303-308; (d) J. Q. Wu and R. B. Macgregor, Biochemistry, 1993, 32, 12531-12537; (e) J. Q. Wu and R. B. Macgregor, Biopolymers, 1995, 35, 369-376; $(f)$ R. B. Macgregor, Biopolymers, 1996, 38, 321-327; (g) R. B. Macgregor, Biopolymers, 1998, 48, 253-263.

85 (a) D. N. Dubins, A. Lee, R. B. Macgregor and T. V. Chalikian, J. Am. Chem. Soc., 2001, 123, 9254-9259; (b) R. B. Macgregor, Biochim. Biophys. Acta, 2002, 1595, 266-276; (c) G. Rayan and R. B. Macgregor, J. Phys. Chem. B, 2005, 109, 15558-15565; (d) T. V. Chalikian and R. B. Macgregor, Phys. Life Rev., 2007, 4, 91-115; (e) G. Rayan and R. B. Macgregor, Biophys. Chem., 2009, 144, 62-66; $(f)$ G. Rayan, A. D. Tsamaloukas, R. B. Macgregor and H. Heerklotz, J. Phys. Chem. B, 2009, 113, 1738-1742; $(g)$ A. R. Amiri and R. B. Macgregor, Biophys. Chem., 2011, 156, 88-95; (h) G. Rayan and R. B. Macgregor, Biophys. Chem., 2015, 199, 34-38. 
86 R. M. Hazen, H. K. Mao, L. W. Finger and P. M. Bell, Appl. Phys. Lett., 1980, 37, 288-289.

87 C. E. Kundrot and F. M. Richards, J. Appl. Crystallogr., 1986, 19, 208-213.

88 (a) A. Katrusiak, Cryst. Res. Technol., 1991, 26, 523-531; (b) A. Katrusiak and Z. Dauter, Acta Crystallogr., Sect. D: Biol. Crystallogr., 1996, 52, 607-608; (c) A. Katrusiak, Highpressure crystallography, Acta Crystallogr., Sect. A: Found. Crystallogr., 2008, 64, 135-148; (d) W. Cai and A. Katrusiak, CrystEngComm, 2012, 14, 4420-4424; (e) E. Patyk and A. Katrusiak, Acta Crystallogr., Sect. A: Found. Adv., 2015, 71, s369; $(f)$ K. Ostrowska, M. Kropidlowska and A. Katrusiak, Cryst. Growth Des., 2015, 15, 1512-1517.

89 (a) R. M. Siegoczynski, High Press Res., 1994, 13, 89-92; (b) R. Kościesza, A. J. Rostocki, A. Kos, D. B. Tefelski, R. M. Siegoczyński and L. Zych, High Pres. Res., 2007, 27, 51-55; (c) D. B. Tefelski, A. J. Rostocki, A. Kos, R. Kościesza and R. M. Siegoczyński, High Pres. Res., 2007, 27, 57-61; (d) R. Kosciesza, R. M. Siegoczynski, A. J. Rostocki, D. B. Tefelski, A. Kos and W. Ejchart, J. Phys.: Conf. Ser., 2008, 121, 142005; (e) D. B. Tefelski, R. M. Siegoczyński, A. J. Rostocki, A. Kos, R. Kościesza and K. Wieja, J. Phys.: Conf. Ser., 2008, 121, 142004; $(f)$ R. Tarakowski, A. Malanowski, R. Kościesza and R. M. Siegoczyński, J. Food Eng., 2014, 122, $28-32$.

90 (a) C. R. Robinson and S. G. Sligar, Biochemistry, 1994, 33, 3787-3793; (b) C. R. Robinson and S. G. Sligar, Proc. Natl. Acad. Sci. U. S. A., 1995, 92, 3444-3448.

91 H. Kabata, A. Nomura, N. Shimamoto and S. Kunugi, J. Mol. Recognit., 1994, 7, 25-30.

92 (a) L. Erijman and R. M. Clegg, J. Mol. Biol., 1995, 253, 259-265; (b) L. Erijman and R. M. Clegg, Biophys. J., 1998, 75, 453-462.

93 E. A. Rudd, Biochem. Biophys. Res. Commun., 1997, 230, 140-142.

94 (a) J. Barciszewski, J. Jurczak, S. Porowski, T. Specht and V. A. Erdmann, Eur. J. Biochem., 1999, 260, 293-307; (b) M. Giel-Pietraszuk and J. Barciszewski, Int. J. Biol. Macromol., 2005, 37, 109-114; (c) A. Fedoruk-Wyszomirska, E. Wyszko, M. Giel-Pietraszuk, M. Z. Barciszewska and J. Barciszewski, Int. J. Biol. Macromol., 2007, 41, 30-45.

95 P. Tandon, G. Forster, R. Neubert and S. Wartewig, J. Mol. Struct., 2000, 524, 201-215.

96 (a) E. V. Boldyreva, J. Mol. Struct., 2003, 647, 159-179; (b) E. V. Boldyreva, Crystal Eng., 2003, 6, 235-254; (c) E. V. Boldyreva, J. Mol. Struct., 2004, 700, 151-155.

97 (a) E. V. Boldyreva, H. Sowa, H. Ahsbahs, S. V. Goryainov, V. V. Chernyshev, V. P. Dmitriev, Y. V. Seryotkin, E. N. Kolesnik, T. P. Shakhtshneider, S. N. Ivashevskaya and T. N. Drebushchak, J. Phys.: Conf. Ser., 2008, 121, 022023; (b) E. A. Losev, B. A. Zakharov and E. V. Boldyreva, Acta Crystallogr., Sect. A: Found. Adv., 2015, 71, s363; (c) B. A. Zakharov, Z. Gal, D. Cruickshank and E. V. Boldyreva, Acta Crystallogr., Sect. E: Crystallogr. Commun., 2018, 74, 613-619; (d) N. Bouvart, R. M. Palix, S. G. Arkhipov, I. A. Tumanov, A. A. L. Michalchuk and E. V. Boldyreva,
CrystEngComm, 2018, 20, 1797-1803; (e) A. A. Gaydamaka, S. G. Arkhipov, B. A. Zakharov, Y. V. Seryotkin and E. V. Boldyreva, CrystEngComm, 2019, 21, 4484-4492.

98 I. T. Desta, S. A. Chizhik, A. A. Sidelnikov, D. P. Karothu, E. V. Boldyreva and P. Naumov, J. Phys. Chem. A, 2020, 124, 300-310.

99 G. Heimel, P. Puschnig, M. Oehzelt, K. Hummer, B. Koppelhuber-Bitschnau, F. Porsch, C. Ambrosch-Draxl and R. Resel, MRS Proc., 2003, 771, L7.22.

100 S. M. Gruner, in High-Pressure Crystallography, ed. A. Katrusiak and P. F. McMillan, Kluwer Academic Publishers, Dordrecht, 2004, pp. 543-556.

101 B. Palosz, S. Stelmakh, E. Grzanka, S. Gierlotka, R. Pielaszek, U. Bismayer, S. Werner and W. Palosz, J. Phys.: Condens. Matter, 2004, 16, S353-S377.

102 (a) R. Fourme, E. Girard, K. Ascone, M. Mezouar, T. Lin and J. E. Johnson, in High-Pressure Crystallography, ed. A. Katrusiak and P. F. McMillan, Kluwer Academic Publishers, Dordrecht, 2004, pp. 527-542; (b) E. Girard, A. C. Dhaussy, B. Couzinet, J. C. Chervin, M. Mezouar, R. Kahn, I. Ascone and R. Fourme, J. Appl. Crystallogr., 2007, 40, 912-918; (c) R. Fourme, E. Girard, R. Kahn, T. Prangé, A. C. Dhaussy, M. Mezouar and I. Ascone, High Pressure Res., 2010, 30, 100-103; (d) R. Fourme, I. Ascone, M. Mezouar, A. C. Dhaussy, R. Kahn and E. Girard, in High-Pressure Crystallography, ed. E. V. Boldyreva and P. Dera, NATO Science for Peace and Security Series B: Physics and Biophysics, Springer, Dordrecht, 2010; (e) R. Fourme, E. Girard, A. C. Dhaussy, K. Medjoubi, T. Prangé, I. Ascone, M. Mezouarf and R. Khan, J. Synchrotron Radiat., 2011, 18, 31-36.

103 F. P. A. Fabbiani and C. R. Pulham, High-pressure studies of pharmaceutical compounds and energetic materials, Chem. Soc. Rev., 2006, 35, 932-942.

104 (a) F. P. A. Fabbiani, D. R. Allan, W. I. F. David, A. J. Davidson, A. R. Lennie, S. Parsons, C. R. Pulham and J. E. Warren, Cryst. Growth Des., 2007, 7, 1115-1124; (b) F. P. A. Fabbiani, G. Buth, B. Dittrich and H. Sowa, CrystEngComm, 2010, 12, 2541-2550; (c) M. A. Neumann, J. van de Streek, F. P. A. Fabbiani, P. Hidber and O. Grassmann, Nat. Commun., 2015, 6, 7793.

105 C. J. Schaschke, S. Abid and M. J. Heslop, High Press Res., 2007, 27, 33-37.

106 W. L. Liu, Z. R. Zheng, R. B. Zhu, Z. G. Liu, D. P. Xu, H. M. Yu, W. Z. Wu, A. H. Li, Y. Q. Yang and W. H. Su, J. Phys. Chem. A, 2007, 111, 10044-10049.

107 M. Zhou, D. P. Xu, T. C. Liu, P. Zhang, S. Q. Gao, Z. W. Li and G. H. Lu, J. Phys. Chem. B, 2008, 112, 15562-15568.

108 (a) F. Ya, Z. Jing, L. Shuang, G. Fu-Ying and X. Da-Peng, Chin. Phys. Lett., 2011, 28, 110702; (b) F. Ya, Z. Jing and X. Da-Peng, Spectrochim. Acta, Part A, 2014, 129, 143-147.

109 S. Fanetti, M. Citroni, L. Malavasi, G. A. Artioli, P. Postorino and R. Bini, J. Phys. Chem. C, 2013, 117, 5343-5351.

110 Y. Nishida, IEEE Trans. Plasm. Sci., 2014, 42, 3674-3680.

111 Q. Wang, H. Zhang, Y. Zhang, Ca. Liu, Y. Han, Y. Ma and C. Gao, High Pressure Res., 2014, 34, 355-364. 
112 A. A. Pribylov, N. A. Skibitskaya and L. A. Zekel, Russ. Chem. Bull., Int. Ed., 2015, 64, 841-845.

113 C. M. da Silva, J. G. Silva Filhoa, G. S. Pinheiro, R. C. Vilelac, F. E. A. Meloa, J. A. Lima and P. T. C. Freirea, Vibr. Spectrosc., 2017, 92, 162-168.

114 W. Cai, R. Zhang, Y. Yao and S. Deemyad, Phys. Chem. Chem. Phys., 2017, 19, 6216-6223.

115 Q. Wang, D. Sang, S. Guo, X. Wang, W. Wang, B. Zhang, H. Hu, Q. Fan and C. Liu, CrystEngComm, 2019, 21, 4507-4512.

116 R. J. Hemley and P. Dera, Rev. Mineral. Geochem., 2000, 41, 335-419.

117 G. R. Desiraju, J. Am. Chem. Soc., 2013, 135, 9952-9967.

118 C. Hejny and V. S. Minkov, IUCrJ, 2015, 2, 218-229.

119 M. K. Beyer and H. C. Schaumann, Chem. Rev., 2005, 105, 2921-2948.

120 E. Horvath-Bordon, R. Riedel, P. McMillan, P. Kroll, G. Miehe, P. van Aken, A. Zerr, P. Hoppe, O. Shebanova and I. McLaren, et al., Angew. Chem., Int. Ed., 2007, 46, 1476-1480.

121 X. Yue, H. Wang, S. Wang, F. Zhang and R. Zhang, J. Alloys Compd., 2010, 505, 286-290.

122 Z. G. Zhang, S. F. Zhang, H. Wang, J. W. Liu and M. Zhu, J. Alloys Compd., 2010, 505, 717-721.

123 (a) G. Ligios, A. M. Bertetto and F. Delogu, J. Alloys Compd., 2013, 554, 426-431; (b) F. Delogu and L. Takacs, Acta Mater., 2014, 80, 435-444; (c) F. Delogu, Acta Mater., 2014, 66, 388-395.

124 H. Kulla, S. Greiser, S. Benemann, K. Rademann and F. Emmerling, Molecules, 2016, 21, 917.

125 (a) A. A. L. Michalchuk, I. A. Tumanov and E. V. Boldyreva, J. Mater. Sci., 2018, 53, 13380-13389; (b) A. A. L. Michalchuk, I. A. Tumanov and E. V. Boldyreva, CrystEngComm, 2019, 21, 2174-2179.

126 G. Ayoub, B. Karadeniz, A. J. Howarth, O. K. Farha, I. Đilović, L. S. Germann, R. E. Dinnebier, K. Užarević and T. Friščić, Chem. Mater., 2019, 31, 5494-5501.

127 M. Bykov, S. Chariton, H. Fei, T. Fedotenko, G. Aprilis, A. V. Ponomareva, F. Tasnádi, I. A. Abrikosov, B. Merle and P. Feldner, et al., Nat. Commun., 2019, 10, 2994.

128 E. Y. Mora, A. Sarmiento, E. Vera López, V. Drozd, A. Durygin, J. Chen and S. K. Saxena, Processes, 2019, 7, 735.

129 A. San-Miguel, Chem. Soc. Rev., 2006, 35, 876-889.

130 P. Naumov, S. Chizhik, M. K. Panda, N. K. Nath and E. Boldyreva, Chem. Rev., 2015, 115, 12440-12490.

131 J. M. Abendroth, O. S. Bushuyev, P. S. Weiss and C. J. Barrett, ACS Nano, 2015, 9, 7746-7768.

132 M. D. Manrique-Juárez, S. Rat, L. Salmon, G. Molnár, C. M. Quintero, L. Nicu, H. J. Shepherd and A. Bousseksou, Coord. Chem. Rev., 2016, 308, 395-408.

133 O. Sato, Nat. Chem., 2016, 8, 644-656.

134 E. F. Delong and A. A. Yayanos, Science, 1985, 228, 1101-1103.

135 (a) D. H. Bartlett, M. Wright, A. A. Yayanos and M. Silverman, Nature, 1989, 342, 572-574; (b) D. H. Bartlett, Res. Microbiol., 1991, 142, 923-925; (c) E. Chi and D. H. Bartlett, J. Bacteriol.,
1993, 175, 7533-7540; (d) T. J. Welch and D. H. Bartlett, J. Bacteriol., 1996, 178, 5027-5031.

136 G. Bernhardt, R. Jaenicke, H. D. Ludemann, H. Konig and K. O. Stetter, Appl. Environ. Microbiol., 1988, 54, 1258-1261.

137 P. M. Oger and M. Jebbar, Res. Microbiol., 2010, 161, 799-809.

138 M. K. Behan, A. G. Macdonald, G. R. Jones and A. R. Cossins, Biochim. Biophys. Acta, 1992, 1103, 317-323.

139 M. L. Porter, N. W. Roberts and J. C. Partridge, Mol. Phylogen. Evol., 2016, 105, 160-165.

140 R. M. Hazen, N. Boctor, J. Brandes, G. D. Cody, R. J. Hemley, A. Sharma and H. S. Yoder, J. Phys.: Condens. Matter, 2002, 14, 11489-11494.

141 I. Daniel, P. Oger and R. Winter, Chem. Soc. Rev., 2006, 35, 858-875.

142 F. Pradillon and F. Gaill, Rev. Environ. Sci. Biotechnol., 2007, 6, 181-195.

143 V. V. Mozhaev, K. Heremans, J. Frank, P. Masson and C. Balny, Trends Biotechnol., 1994, 12, 493-501.

144 V. V. Mozhaev, K. Heremans, J. Frank, P. Masson and C. Balny, Proteins: Struct., Funct., Genet., 1996, 24, 81-91.

145 N. Rivalain, J. Roquain and G. Demazeau, Biotechnol. Adv., 2010, 28, 659-672.

146 J. L. Silva, A. C. Oliveira, T. C. R. G. Vieira, G. A. P. de Oliveira, M. C. Suarez and D. Foguel, Chem. Rev., 2014, 114, 7239-7267.

147 K. Heremans, Annu. Rev. Biophys. Bioeng., 1982, 11, 1-21.

148 M. Deckmann, R. Haimovitz and M. Shinitzky, Biochim. Biophys. Acta, 1985, 821, 334-340.

149 L. F. Braganza and D. L. Worcester, Biochemistry, 1986, 25, 7484-7488.

150 D. S. Lester, J. Neurochem., 1989, 52, 1950-1953.

151 N. Orr, E. Yavin, M. Shinitzky and D. S. Lester, Anal. Biochem., 1990, 191, 80-85.

152 D. A. Plager and G. L. Nelsestuen, Protein Sci., 1992, 530-539.

153 J. Jonas and A. Jonas, Annu. Rev. Biophys. Biomol. Struct., 1994, 23, 287-318.

154 (a) P. Masson, Ann. Pharm. Fr., 1999, 57, 49-55; (b) P. Masson, C. Tonello and C. Balny, J. Biomed. Biotechnol., 2001, 1, 85-88.

155 (a) Y. Rigaldie and G. Demazeau, Ann. Pharm. Fr., 2004, 62, 116-127; (b) Y. Rigaldie, G. Lemagnen, A. Largeteau, D. Larrouture, M. Abba and C. Durandeau, et al., Eur. J. Parenteral Sci., 2001, 6, 73-77.

156 J. L. Silva, D. Foguel, M. Suarez, A. M. O. Gomes and A. C. Oliveira, J. Phys.: Condens. Matter, 2004, 16, S929-S944.

157 T. Elshaarani, H. Yu, L. Wang, R. S. Ullah, S. Fahad, K. U. Rahman, A. Khan, A. Nazir, M. Usman, R. U. Khan, F. Haq, R. Liang, X. Chen and M. Haroon, J. Mater. Sci., 2019, 54, 10009-10023.

158 D. F. Keenan, N. P. Brunton, R. Gormley, F. Butler, B. K. Tiwari and A. Patras, Innov. Food Sci. Emerg. Technol., 2010, 11, 551-556.

159 (a) G. Ferrari, P. Maresca and R. Ciccaron, J. Food Eng., 2010, 100, 245-253; (b) G. Ferrari, P. Maresca and R. Ciccarone, Proc. Food Sci., 2011, 1, 847-853.

160 V. Briones-Labarca, G. Venegas-Cubillos, S. Ortiz-Portilla, M. Chacana-Ojeda and H. Maureira, Food Chem., 2011, 128, 520-529. 
161 Z. A. Kruk, H. Y. D. L. Rutley, E. J. Lee, Y. J. Kim and C. Jo, Food Control, 2011, 22, 6-12.

162 W. Li, F. Zhang, P. Liu, Y. Bai, L. Gao and Q. Shen, J. Food Eng., 2011, 103, 388-393.

163 F. J. Barba, H. Jäger, N. Meneses, M. J. Esteve, A. Frígola and D. Knorr, Innov. Food Sci. Emerg. Technol., 2012, 14, 18-24.

164 H. Li, K. Zhu, H. Zhou and W. Peng, Food Chem., 2012, 132, 808-814.

165 M. Bashari, M. H. Abdelhai, S. Abbas, A. Eibaid, X. Xu and Z. Jin, Ultrason. Sonochem., 2014, 21, 76-83.

166 Y. Zhang, X. C. Liu, Y. Wang, F. Zhao, Z. Sun and X. Liao, Innov. Food Sci. Emerg. Technol., 2016, 33, 135-144.

167 F. Liu, X. Zhang, L. Zhao, Y. Wang and X. Liao, Innov. Food Sci. Emerg. Technol., 2016, 34, 51-58.

168 T. von Kármán and M. Born, Phys. Z., 1913, 14, 15-19; 1913, 14, 65-71.

169 R. Dovesi, in Quantum Mechanical Ab Initio Calculation of the Properties of Crystalline Materials, ed. C. Pisani, Lecture Notes in Chemistry, Springer, Berlin, vol. 67, 1996, pp. 31-46.

170 (a) T. Oxby, W. F. Perger, J. Zhao, J. M. Winey and Y. M. Gupta, AIP Conf. Proc., 2004, 706, 247-250; (b) J. Zhao, J. M. Winey, Y. M. Gupta and W. F. Perger, AIP Conf. Proc., 2004, 706, 429-432; (c) A. Brillante, R. Della Valle, L. Farina, E. Venuti, C. Cavazzoni, A. P. Emerson and K. Syassen, J. Am. Chem. Soc., 2005, 127, 3038; (d) E. Venuti, R. Della Valle, L. Farina, A. Brillante, M. Masino and A. Girlando, Phys. Rev. B: Condens. Matter Mater. Phys., 2004, 70, 104106.

171 (a) E. V. Boldyreva, H. Ahsbahs, V. V. Chernyshev, S. N. Ivashevskaya and A. R. Oganov, Z. Kristallogr., 2006, 221, 186-197; (b) D. A. Rychkov, J. Stare and E. V. Boldyreva, Phys. Chem. Chem. Phys., 2017, 19, 6671-6676.

172 (a) J. C. Tan, B. Civalleri, L. Chung-Cherng, L. Valenzano, R. Galvelis, C. Po Fei, T. D. Bennett, C. Mellot-Draznieks, C. M. Zicovich-Wilson and A. K. Cheetham, Phys. Rev. Lett., 2012, 108, 095502; (b) M. R. Ryder, B. Civalleri and J. C. Tan, Phys. Chem. Chem. Phys., 2016, 18, 9079-9087.

173 T. P. Rupasinghe, K. M. Hutchins, B. S. Bandaranayake, S. Ghorai, C. Karunatilake, D. K. Bučar, D. C. Swenson, M. A. Arnold, L. R. MacGillivray and A. V. Tivanski, J. Am. Chem. Soc., 2015, 137, 12768-12771.

174 M. J. Turner, S. P. Thomas, M. W. Shi, D. Jayatilaka and M. A. Spackman, Chem. Commun., 2015, 51, 3735-3738.

175 I. Azuri, E. Meirzadeh, D. Ehre, S. R. Cohen, A. M. Rappe, M. Lahav, I. Lubomirsky and L. Kronik, Angew. Chem., Int. Ed., 2015, 127, 13770-13774.

176 M. R. Mohamed, M. K. Mishra, L. M. Al Harbi, M. S. Al Ghamdic and U. Ramamurty, RSC Adv., 2015, 5, 64156-64162.

177 I. A. Fedorov, E. S. Rubtsova, N. S. Khaydukova and Y. N. Zhuravlev, IOP Conf. Ser.: Mater. Sci. Eng., 2015, 81, 012120.

178 Y. V. Matveychuk, E. V. Bartashevich and V. G. Tsirelson, Cryst. Growth Des., 2018, 18, 3366-3375.
179 N. R. Keskar and J. R. Chelikowsky, Nature, 1992, 358, 222-224.

180 (a) J. N. Grima, R. Gatt, A. Alderson and K. E. Evans, Mater. Sci. Eng., A, 2006, 423, 219-224; (b) J. N. Grima, R. Gatt, V. Zammit, J. J. Williams, K. E. Evans, A. Alderson and R. I. Walton, J. Appl. Phys., 2007, 101, 086102.

181 (a) F. X. Coudert, Phys. Chem. Chem. Phys., 2013, 15, 1602-16018; (b) F. X. Coudert, Chem. Mater., 2017, 29, 7833-7839.

182 Y. T. Yao, K. L. Alderson and A. Alderson, Cellulose, 2016, 23, 3429-3448.

183 (a) J. C. Tan, B. Civalleri, A. Erba and E. Albanese, CrystEngComm, 2015, 17, 375-382; (b) M. R. Ryder and J. C. Tan, Dalton Trans., 2016, 45, 4154-4161.

184 H. Sun, S. Mukherjee and C. V. Singh, Phys. Chem. Chem. Phys., 2016, 18, 26736-26742.

185 Y. Du, J. Maassen, W. Wu, Z. Luo, X. Xu and P. D. Ye, Nano Lett., 2016, 16, 6701-6708.

186 W. Li, M. R. Probert, M. Kosa, M. T. D. Bennett, A. Thirumurugan, R. P. Burwood, M. Parinello, J. A. Howard and A. K. Cheetham, J. Am. Chem. Soc., 2012, 134, 11940-11943.

187 Y. Qiao, K. Wang, H. Yuan, K. Yang and B. Zou, J. Phys. Chem. Lett., 2015, 6, 2755-2760.

188 C. S. Coates, J. W. Makepeace, A. G. Seel, M. Baise, B. Slater, A. L. Goodwin and A. L. Synthesis, Dalton Trans., 2018, 47, 7263-7271.

189 A. Marmier, P. S. Ntoahae, P. E. Ngoepe, D. G. Pettifor and S. C. Parker, Phys. Rev. B: Condens. Matter Mater. Phys., 2010, 81, 172102.

190 L. Kang, X. Jiang, S. Luo, P. Gong, W. Li, X. Wu, Y. Li, X. Li, C. Chen and Z. Lin, Sci. Rep., 2016, 5, 13432.

191 J. Dagdelen, J. Montoya, M. De Jong and K. Persson, Nat. Commun., 2017, 8, 323.

192 D. T. Ho, S. D. Park, S. Y. Kwon, K. Park and S. Y. Kim, Nat. Commun., 2014, 5, 3255.

193 D. Wu, S. Wang, S. Zhan, S. J. Yuan, B. Yang and H. Chen, Phys. Chem. Chem. Phys., 2018, 20, 18924-18930.

194 F. Hao, X. Liao, M. Li, H. Xiao and X. Chen, J. Phys.: Condens. Matter, 2018, 30, 315302.

195 H. Wang, Q. Li, Y. Gao, F. Miao, X. Zhou and X. G. Wan, New J. Phys., 2016, 18, 073016.

196 H. Wang, Z. D. Zhang, R. Q. Wu and L. Z. Sun, Acta Mater., 2013, 61, 2919-2925.

197 H. Wang, X. Li, P. Li and J. Yang, Nanoscale, 2017, 9, 850-855. 198 X. F. Wang, T. E. Jones, W. Li and Y. C. Zhou, Phys. Rev. B: Condens. Matter Mater. Phys., 2012, 85, 134108.

199 S. Yalameha and A. Vaez, Ab-initio thermodynamic and elastic properties of $\mathrm{AlNi}$ and AlNi3 intermetallic compounds, Int. J. Mod. Phys. B, 2018, 32, 1850129.

200 H. Hsueh, C. Lee, C. W. Wang and J. Crain, Phys. Rev. B: Condens. Matter Mater. Phys., 2000, 61, 3851-3856.

201 W. Ren, J. Ye, W. Shi, Z. K. Tang, C. T. Chan and P. Sheng, New J. Phys., 2009, 11, 103014.

202 (a) D. V. Korabel'nikov and Y. N. Zhuravlev, Phys. Chem. Chem. Phys., 2016, 18, 33126-33133; (b) D. V. Korabel'nikov 
and Y. N. Zhuravlev, Phys. Solid State, 2016, 58, 1166-1171; (c) D. V. Korabel'nikov and Y. N. Zhuravlev, J. Phys. Chem. A, 2017, 121, 6481-6490.

203 (a) D. T. Ho, C. T. Nguyen, S. Y. Kwon and S. Y. Kim, Phys. Status Solidi B, 2019, 256, 1800122; (b) C. T. Nguyen, D. T. Ho, S. T. Choi, D. M. Chun and S. Y. Kim, Comput. Mater. Sci., 2019, 157, 17-24.

204 (a) K. W. Wojciechowski, Mol. Phys., 1987, 61, 1247-1258; (b) K. W. Wojciechowski, Phys. Lett. A, 1989, 137, 60-64.

205 (a) S. Grimme, J. Comput. Chem., 2006, 27, 1787-1799; (b) S. Grimme, J. Antony, S. Ehrlich and H. Krieg, J. Chem. Phys., 2010, 132, 154104; (c) S. Grimme, Wiley Interdiscip. Rev.: Comput. Mol. Sci., 2011, 1, 211-228; (d) J. G. Brandenburg and S. Grimme, J. Phys. Chem. Lett., 2014, 5, 1785-1789.

206 (a) A. Tkatchenko and M. Scheffler, Phys. Rev. Lett., 2009, 102, 073005; (b) B. Schatschneider, S. Monaco, A. Tkatchenko and A. J. Liang, J. Phys. Chem. A, 2014, 117, 8323-8331.

207 M. Abdulla, K. Refson, R. H. Friend and P. D. Haynes, J. Phys.: Condens. Matter, 2015, 27, 375402.

208 J. Hoja, A. M. Reilly and A. Tkatchenko, Wiley Interdiscip. Rev.: Comput. Mol. Sci., 2017, 7, e1294.

209 P. L. Silvestrelli and A. Ambrosetti, J. Chem. Phys., 2019, 150, 164109.

210 D. Geatches, I. Rosbottom, R. L. M. Robinson, P. Byrne, P. Hasnip, M. I. J. Probert, D. Jochym, A. Maloney and K. J. Roberts, J. Chem. Phys., 2019, 151, 044106.

211 K. W. Wojciechowski, P. Pieranski and J. Malecki, J. Phys. A, 1983, 16, 2197-2203.

212 G. Westhoff and J. N. Starr, in Ullmann's Encyclopedia of Industrial Chemistry, Wiley-VCH, Weinheim, 2014.

213 L. Pasteur, C. R. Chim., 1857, 45, 913-916.

214 M. T. Wyss, R. Jolivet, A. Buck, P. J. Magistretti and B. Weber, J. Neurosci., 2011, 31, 7477-7485.

215 L. B. Gladden, J. Physiol., 2004, 558, 5-30.

216 K. Kasischke, Front. Neuroenerg., 2011, 3, 4.

217 S. Offermanns, S. L. Colletti, T. W. Lovenberg, G. Semple, A. Wise and A. P. Ijzerman, Pharmacol. Rev., 2011, 63, 269-290.

218 H. Benninga, A History of Lactic Acid Making: A Chapter in the History of Biotechnology, Chemists and Chemistry, Springer, Berlin, 1990, vol. 11.

219 I. A. Shuklov, N. V. Dubrovina, K. Kühlein and A. Börner, Adv. Synth. Catal., 2016, 358, 3910-3931.

220 A. Stout, B. Basu and T. J. Webster, Acta Biomater., 2011, 7, 3101-3112.

221 H. Liu and T. J. Webster, Biomaterials, 2007, 28, 354-365.

222 T. W. J. Steele, C. L. Huang, E. Widjaja, F. Y. C. Boey, J. S. C. Loo and S. S. Venkatraman, Acta Biomater., 2011, 7, 1973-1983.

223 S. C. J. Loo, Z. Y. S. Tan and S. L. I. Lin, J. Pharm. Sci., 2010, 99, 3060-3071.

224 H. K. Makadia and J. Siegel, Polymers, 2011, 3, 1377-1397.

225 A. Basu, K. R. Kunduru, S. Doppalapudi, A. J. Domb and W. Khan, Adv. Drug Delivery Rev., 2016, 107, 192-205.
226 J. Chick and Z. Ustunol, J. Food Sci., 1998, 63, 1024-1027.

227 M. E. Broz, D. L. VanderHart and N. R. Washburn, Biomaterials, 2003, 24, 4181-4190.

228 J. F. Zhang and X. Sun, Biomacromolecules, 2004, 54, 1446-1451.

229 F. Carrasco, P. Pages, J. Gamez-Perez, O. O. Santana and M. L. Maspoch, Polym. Degrad. Stab., 2010, 95, 116-125.

230 G. Perego and G. D. Cella, in Poly(lactic acid): Synthesis, Structures, Properties, Processing, and Applications, ed. R. F. Grossman, D. Nwabunma, R. Auras, L. Lim, S. E. Selke and H. Tsuji, Wiley, New York, 2010.

231 S. W. Hwang, S. B. Lee, C. K. Lee, J. Y. Lee, J. K. Shim, S. E. M. Selke, H. Soto-Valdez, L. Matuana, M. Rubino and R. Auras, Polym. Test., 2012, 31, 333-344.

232 V. S. G. Silverajah, N. A. Ibrahim, N. Zainuddin, W. M. Z. W. Yunus and H. A. Hassan, Molecules, 2012, 17, 11729-11747.

233 P. Sennan and J. Pumchusak, Malaysian J. Anal. Sci., 2014, 18, 669-675.

234 S. Farah, D. G. Anderson and R. Langer, Adv. Drug Delivery Rev., 2016, 107, 367-392.

235 J. L. Orellana, D. Wichhart and C. L. Kitchens, J. Nanomater., 2018, 2018, 7124260.

236 M. S. Nasab, M. Tabari and M. H. Azizi, Nanomed. Res. J., 2018, 3, 96-101.

237 Z. Wang, Z. Yao, J. Zhou, M. He, Q. Jiang, A. Li, S. Li, M. Liu, S. Luo and D. Zhang, Int. J. Biol. Macromol., 2019, 29, 878-886.

238 Y. Zhang, L. Cui, H. Xua, X. Feng, B. Wang, B. Pukanszky, Z. Mao and X. Sui, Int. J. Biol. Macromol., 2019, 29, 197-204.

239 K. Lertphirun and K. Srikulkit, Int. J. Polym. Sci., 2019, 2019, 7835172.

240 A. Schouten, J. A. Kanters and J. van Krieken, J. Mol. Struc., 1994, 323, 165-168.

241 A. Borba, A. Gómez-Zavaglia, L. Lapinskic and R. Fausto, Phys. Chem. Chem. Phys., 2004, 6, 2101-2108.

242 M. Shahat, Acta Crystallogr., 1952, 5, 763-768.

243 M. N. G. James and G. J. B. Williams, Acta Crystallogr., Sect. B: Struct. Crystallogr. Cryst. Chem., 1974, 30, 1249-1257.

244 G. M. Day, A. V. Trask, W. D. S. Motherwell and W. Jones, Chem. Commun., 2006, 54-56.

245 D. Rychkov, S. Arkhipov and E. Boldyreva, Acta Crystallogr., Sect. B: Struct. Sci., Cryst. Eng. Mater., 2016, 72, 160-163.

246 G. D. Rieck, Rec. Trav. Chim. Des Pays-Bas, 1944, 63, 170-180.

247 J. D. Morrison and J. M. Robertson, J. Chem. Soc., 1949, 1949, 980-986.

248 J. L. Leviel, G. Auvert and J. M. Savariault, Acta Crystallogr., Sect. B: Struct. Crystallogr. Cryst. Chem., 1981, 37, 2185-2189.

249 I. M. Dodd, S. J. Maginn, M. M. Harding and R. J. Davey, CSD Commun., CCDC 1263474, 1998, https:/www.drug bank.ca/drugs/DB00139.

250 R. S. Gopalan, P. Kumaradhas, G. U. Kulkarni and C. N. R. Rao, J. Mol. Struct., 2000, 521, 97-106.

251 P. Lucaioli, E. Nauha, I. Gimondi, L. S. Price, R. Guo, L. Iuzzolino, I. Singh, M. Salvalaglio, S. L. Price and N. Blagden, CrystEngComm, 2018, 20, 3971-3977. 
252 J. P. Glusker, J. A. Minkin and A. L. Patterson, Acta Crystallogr., Sect. B: Struct. Crystallogr. Cryst. Chem., 1969, 25, 1066-1072.

253 A. V. Churakov, CSD Commun., CCDC 635772, 2007, DOI: 10.5517/ccpbksb.

254 A. Rammohan and J. A. Kaduk, Acta Crystallogr., Sect. B: Struct. Sci., Cryst. Eng. Mater., 2018, 74, 239-252.

255 A. G. Roelofsen and J. A. Kanters, Cryst. Struct. Commun., 1972, 1, 23-26.

256 M. D. King, E. A. Davis, T. M. Smith and T. M. Korter, J. Phys. Chem. A, 2011, 115, 11039-11044.

257 J. F. Nye, The Physical Properties of Crystals: Their Representation by Tensors and Matrices, Oxford University Press, New York, 1985.

258 P. F. Weck, E. Kim and E. C. Buck, RSC Adv., 2015, 5, 79090-79097.

259 M. Born, Math. Proc. Camb. Phil. Soc., 1940, 36, 160-172.

260 F. Mouhat and F. X. Coudert, Phys. Rev. B: Condens. Matter Mater. Phys., 2014, 90, 224104.

261 W. Voigt, Lehrbuch der Kristallphysik, Teubner, Leipzig, 1962.

262 A. Z. Reuss, Angew. Math. Mech., 1929, 9, 49-58.

263 R. Hill, Proc. Phys. Soc. London A, 1952, 65, 349-354.

264 (a) F. Colmenero, L. J. Bonales, J. Cobos and V. Timón, J. Phys. Chem. C, 2017, 121, 5994-6001; (b) F. Colmenero, L. J. Bonales, J. Cobos and V. Timón, J. Solid State Chem., 2017, 253, 249-257; (c) F. Colmenero, J. Cobos and V. Timón, Inorg. Chem., 2018, 57, 4470-4481; (d) F. Colmenero, A. M. Fernández, J. Cobos and V. Timón, RSC Adv., 2018, 8, 24599-24616; (e) F. Colmenero, J. Plášil, J. Cobos, J. Sejkora, V. Timón, J. Čejka and L. J. Bonales, RSC Adv., 2019, 9, 15323-15334; $(f)$ F. Colmenero, J. Plášil and J. Sejkora, Dalton Trans., 2019, 48, 16722-16736; (g) F. Colmenero, J. Plášil, J. Cobos, J. Sejkora, V. Timón, J. Čejka, A. M. Fernández and V. Petř́ícek, RSC Adv., 2019, 9, 40708-40726.

265 S. F. Pugh, Philos. Mag., 1954, 45, 823-843.

266 Y. Bouhadda, S. Djella, M. Bououdina, N. Fenineche and Y. Boudouma, J. Alloys Compd., 2012, 534, 20-24.

267 H. Niu, P. Wei, Y. Sun, C. X. Chen, C. Franchini, D. Li and Y. Li, Appl. Phys. Lett., 2011, 99, 031901.

268 S. I. Ranganathan and M. Ostoja-Starzewski, Phys. Rev. Lett., 2008, 101, 055504.

269 A. Marmier, Z. A. D. Lethbridge, R. I. Walton, C. W. Smith, S. C. Parker and K. E. Evans, Comput. Phys. Commun., 2010, 181, 2102-2115.

270 Z. A. D. Lethbridge, R. I. Walton, A. S. H. Marmier, C. W. Smith and K. E. Evans, Acta Mater., 2010, 58, 6444-6451.

271 K. Lohbeck, H. Haferkorn, W. Fuhrmann and N. Fedtke, Ullmann's Encyclopedia of Industrial Chemistry, Wiley-VCH, Weinheim, 2000.

272 M. Vanneste, Principles of Textile Finishing, Woodhead Publishing Series in Textiles, Cambridge, 2015, pp. 227-256.

273 A. Kumar and R. Choudhury, Functional Finishes for Textiles Improving Comfort, Performance and Protection, Woodhead Publishing Series in Textiles, Amsterdam, 2017; pp. 245-284.
274 N. Safari, V. Esfahanian, M. Kolahdoozan and A. Khosravi, J. Dental Mater. Technol., 2019, 8, 143-148.

275 G. Jiang, J. Feng, M. Zhang, M. S. Zhang and H. Huang, RSC Adv., 2016, 6, 107547-107555.

276 B. Cornils and P. Lappe, Ullmann's Encyclopedia of Industrial Chemistry, Wiley-VCH, Weinheim, 2014.

277 L. Tretter, A. Patocs and C. Chinopoulos, Biochim. Biophys. Acta, 2016, 1857, 1086-1101.

278 R. Haas, D. Cucchi, J. Smith, V. Pucino, C. E. Macdougall and C. Mauro, Trends Biochem. Sci., 2016, 41, 460-471.

279 J. Berg, J. Tymoczko and L. Stryer, Biochemistry, W. H. Freeman, New York, 6th edn, 2006.

280 R. W. Olsen and T. M. DeLorey, in Basic Neurochemistry: Molecular, Cellular and Medical Aspects, ed. G. J. Siegel, B. W. Agranoff and R. W. Albers, Lippincott-Raven, Philadelphia, 6th edn, 1999.

281 A. King, M. A. Selak and E. Gottlieb, Oncogene, 2006, 25, 4675-4682.

282 C. Bardella, P. J. Pollard and I. Tomlinson, Biochim. Biophys. Acta, Bioenerg., 2011, 1807, 1432-1443.

283 S. Drose, Biochim. Biophys. Acta, 2013, 1827, 578-587.

284 M. Yang, T. Soga, P. J. Pollard and J. Patrick, J. Clin. Invest., 2013, 123, 3652-3658.

285 M. Yang and P. J. Pollard, Cancer Cell, 2013, 23, 709-711. 286 G. M. Tannahill, A. M. Curtis, J. Adamik, E. M. PalssonMcDermott, A. F. McGettrick, G. Goel, C. Frezza, N. J. Bernard and B. Kelly, Nature, 2013, 496, 238-242.

287 E. Mills and L. A. J. O'Neill, Trends Cell Biol., 2014, 24, 313-320.

288 E. T. Chouchani, V. R. Pell, E. Gaude, D. Aksentijević, S. Y. Sundier, E. L. Robb, A. Logan, S. M. Nadtochiy, E. N. Ord and A. C. Smith, et al., Nature, 2014, 515, 431-435.

289 V. R. Pell, E. T. Chouchani, C. Frezza, M. P. Murphy and T. Krieg, Cardiovas. Res., 2016, 111, 134-141.

290 J. Gilissen, F. Jouret, B. Pirotte and J. Hanson, Pharmacol. Therap., 2016, 159, 56-65.

291 M. de Castro Fonseca, C. J. Aguiar, J. A. da Rocha Franco, R. Gingold and M. F. Leite, Cell Commun. Signaling, 2016, $14,3$.

292 K. K. Cheng, G. Y. Wang, J. Zeng and J. A. Zhang, BioMed Res. Int., 2013, 2013, 538790.

293 J. M. Otero, D. Cimini, K. R. Patil, S. G. Poulsen, L. Olsson and J. Nielsen, PLoS One, 2013, 8, 541-544.

294 C. Thakker, I. Martínez, K. Y. San and G. N. Bennett, Biotechnol. J., 2017, 7, 213-224.

295 J. G. Zeikus, M. K. Jain and P. Elankovan, Appl. Microbiol. Biotechnol., 1999, 51, 545-552.

296 R. D. B. Walsh, M. W. Bradner, S. Fleischman, L. A. Morales, B. Moulton, N. Rodriguez-Hornedo and M. J. Zaworotko, Chem. Commun., 2003, 186-187.

297 N. Blagden, M. de Matas, P. Gavan and P. York, Adv. Drug Delivery Rev., 2007, 59, 617-630.

298 Q. Yu, L. Dang, S. Black and H. Wei, J. Cryst. Growth, 2012, 340, 209-215.

299 S. Saouane and F. P. A. Fabbiani, Crystals, 2006, 6, 2. 
300 D. G. Barrett and M. N. Yousaf, Molecules, 2019, 14, 4022-4050.

301 J. Mittal, R. B. Mathur, O. P. Bahl and M. Inagaki, Carbon, 1998, 36, 893-897.

302 M. Nagata, H. Goto, W. Sakai and N. Tsutsumi, Polymer, 2000, 41, 4373-4376.

303 S. Abele, C. Gauthier, C. Graillat and A. Guyot, Polymer, 2000, 41, 1147-1155.

304 J. Vega-Baudrit, R. Pereira, K. Nakayama, T. Masuda and A. Cao, Polym. Polym. Compos., 2004, 12, 63-73.

305 P. Jiang, H. Liu, C. Wang, L. Wu, J. Huang and C. Guo, Mater. Lett., 2006, 60, 919-925.

306 N. Elgindy and W. Samy, Int. J. Pharm., 2009, 376, 1-6.

307 M. C. Sweedmana, M. J. Tizzotti, C. Schäfer and R. G. Gilberta, Carbohydr. Polym., 2013, 92, 905-920.

308 S. Tiptipakorn, P. Suwanmala and K. Hemvichian, Adv. Mater. Res., 2013, 747, 253-256.

309 S. L. Li, J. B. Zeng, F. Wu, Y. Yang and Y. Z. Wang, Ind. Eng. Chem. Res., 2014, 53, 1404-1414.

310 K. Zhang and O. Ni, J. Dispersion Sci. Technol., 2015, 36, 556-562.

311 J. Lu, S. Obara, N. Ioannidis, J. Suwardie, C. Gogos and S. Kikuchi, Adv. Polym. Technol., 2016, 37, 154-166.

312 C. Gao, Z. Li, Y. Liu, X. Zhang, J. Wang and Y. Wu, Ind. Eng. Chem. Res., 2017, 56, 3516-3526.

313 X. Hu, T. Su, W. Pan, P. Li and Z. Wang, RSC Adv., 2017, 7, 35496-35503.

314 X. L. Xie, Y. Li, J. Z. Xu, Z. Yan, G. J. Zhong and Z. M. Li, J. Mater. Chem. A, 2018, 6, 13373-13385.

315 S. Qiu, K. Zhang, Z. Su and Z. Qiu, Polym. Test., 2018, 66, 64-69.

316 Z. Zhu, H. He, B. Xue, Z. Zhan, G. Wang and M. Chen, Materials, 2018, 11, 2422.

317 M. Puchalski, G. Szparaga, T. Biela, A. Gutowska, S. Sztajnowski and I. Krucinska, Polymers, 2018, 10, 251.

318 F. H. Verhoff and H. Bauweleers, Ullmann's Encyclopedia of Industrial Chemistry, Wiley-VCH, Weinheim, 2014.

319 C. W. Scheele, New Proc. Roy. Acad. Sci., 1874, 5, 105-109.

320 J. Kay and P. D. Weitzman, Krebs' citric acid cycle: half a century and still turning, Biochemical Society, London, 1987.

321 Y. Y. Hu, A. Rawal and K. Schmidt-Rohr, Proc. Natl. Acad. Sci. U. S. A., 2017, 107, 22425-22429.

322 W. A. Lotfy, K. M. Ghanem and E. R. El-Helow, Biores. Technol., 2007, 98, 3470-3477.
323 M. Berovic and M. Legisa, Biotechnol. Ann. Rev., 2007, 13, 303-343.

324 H. G. Jo, H. J. Yoon, C. H. Lee and K. B. Lee, Ind. Eng. Chem. Res., 2016, 55, 3833-3839.

325 Y. El Ghoul, B. Martel, A. El Achari, C. Campagne, L. Razafimahefa and I. Vroman, Polym. J., 2010, 42, 804-811.

326 J. Yang, A. R. Webb and G. A. Ameer, Adv. Mater., 2004, 16, 511-515.

327 W. Sridach, S. Jonjankiat and T. Wittaya, J. Adhes. Sci. Technol., 2013, 27, 1727-1738.

328 R. T. Tran, Y. Zhang, D. Gyawali and J. Yang, Recent Patents Biomed. Eng., 2009, 2, 216-227.

329 L. V. Thomas and P. D. Nair, Biomatter, 2011, 1, 81-90.

330 H. J. Kim, J. M. Koo, S. H. Kim, S. Y. Hwang and S. S. Im, Polym. Degrad. Stab., 2017, 144, 128-136.

331 A. Narayanan, R. Kartik, E. Sangeetha and R. Dhamodharan, Carbohydr. Polym., 2018, 191, 152-160.

332 X. Ma, R. Jian, P. R. Chang and J. Yu, Biomacromolecules, 2008, 9, 3314-3320.

333 P. Aruna, M. Marie and P. Iyer, Int. J. Curr. Microbiol. Appl. Sci., 2014, 3, 255-261.

334 N. Reddy and Y. Yang, Food Chem., 2010, 118, 702-711.

335 J. M. Halpern, R. Urbanski, A. K. Weinstock, D. F. Iwig, R. T. Mathers and H. von Recum, J. Biomed. Mater. Res., Part A, 2014, 102, 1467-1477.

336 A. Sonseca, O. Sahuquillo, E. J. Foster and E. Gimeneza, RSC Adv., 2015, 5, 55879-55891.

337 L. C. Su, Z. Xie, Y. Zhang, K. Truong Nguyen and J. Yang, Front. Bioeng. Biotechnol., 2014, 2, 23.

338 M. K. Nayunigari, S. K. Gupta, V. Kokkarachedu, K. Kanny and F. Bux, Environ. Technol., 2014, 35, 2903-2909.

339 P. G. Gan, S. T. Sam and A. M. Faiq, IOP Conf. Ser.: Mater. Sci. Eng., 2018, 429, 012042.

340 K. Wilpiszewska, A. K. Antosik and M. Zdanowicz, J. Polym. Environ., 2019, 27, 1379-1387.

341 N. Elgindy and W. Samy, Int. J. Pharm., 2009, 376, 1-6.

342 D. H. Boal, U. Seifert and J. C. Shillcock, Phys. Rev. E: Stat. Phys., Plasmas, Fluids, Relat. Interdiscip. Top., 1993, 48, 4274-4283.

343 K. W. Wojciechowski, Mol. Phys. Rep., 1995, 10, 129-136.

344 M. C. Rechtsman, F. H. Stillinger and S. Torquato, Phys. Rev. Lett., 2008, 101, 085501.

345 Y. Wang, C. Tsai and W. L. Liu, Acta Crystallogr., Sect. B: Struct. Sci., 1985, 41, 131-135. 